

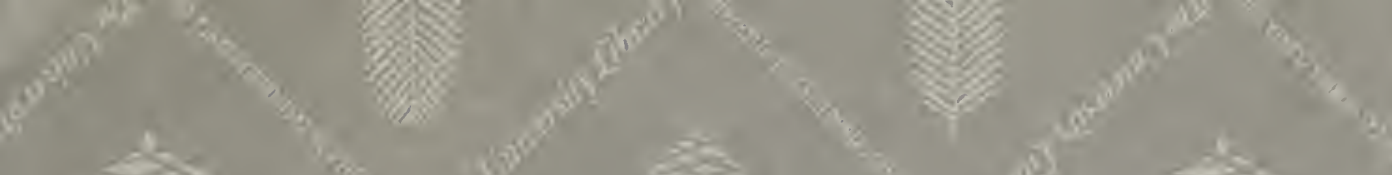

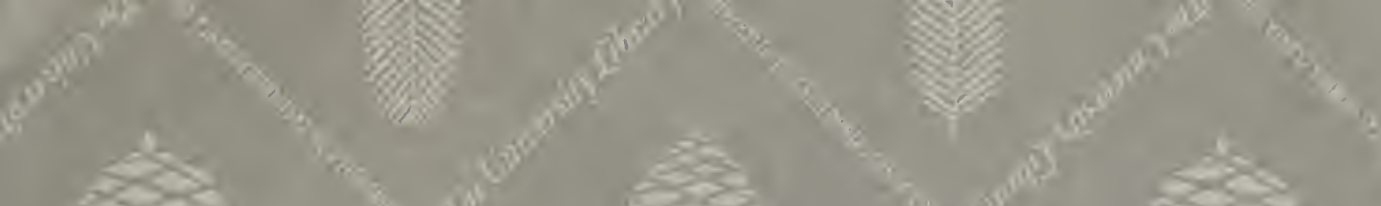
药

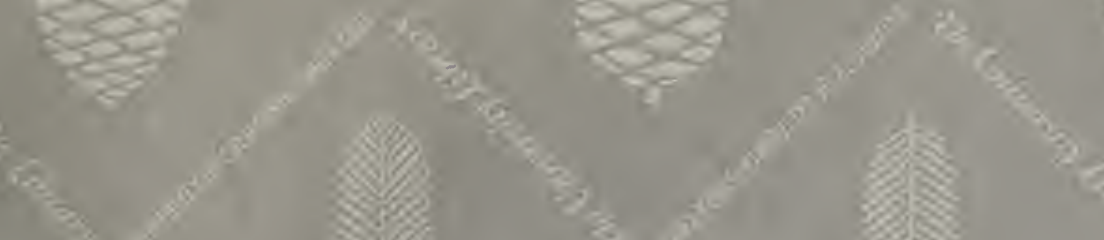

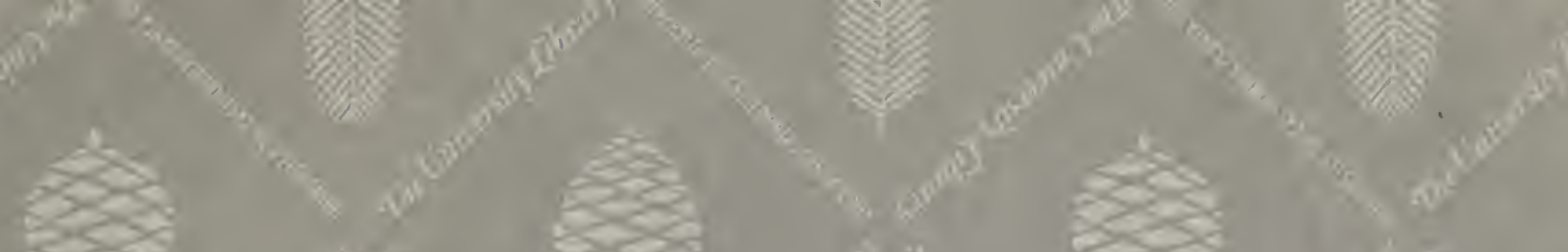

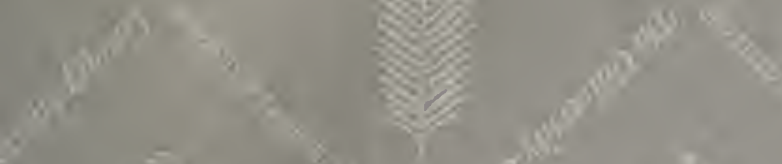

(2) $\quad 40$ $x_{1}$

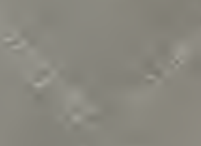

(1)

(1)

(3)

है

\&

$\cos 2$

(3)

(1)

$9^{3}$

(1)

(1) wi

(19)

(1)

$8-6$

\&

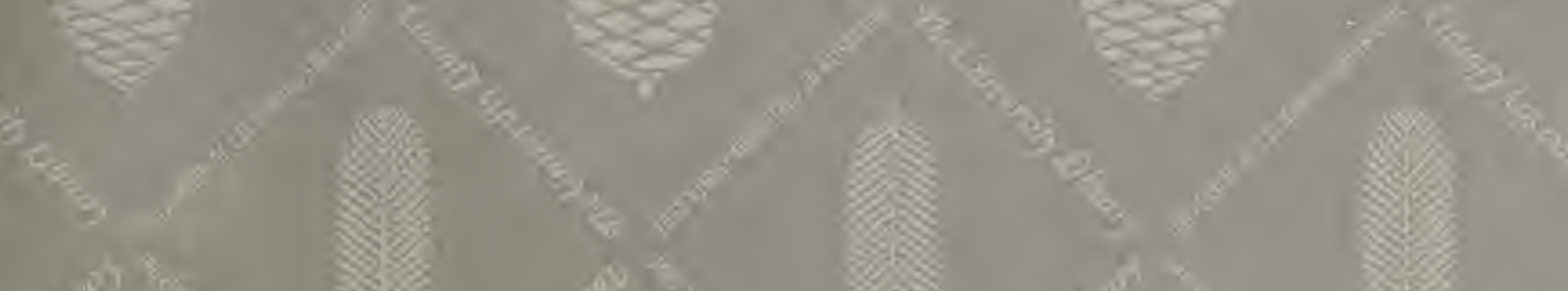


Digitized by the Internet Archive in 2007 with funding from Microsoft Corporation 


\section{THE CORAL SIDERASTREA RADIANS AND ITS POSTLARVAL DEVELOPMENT.}

BY

J. E. DUERDEN.

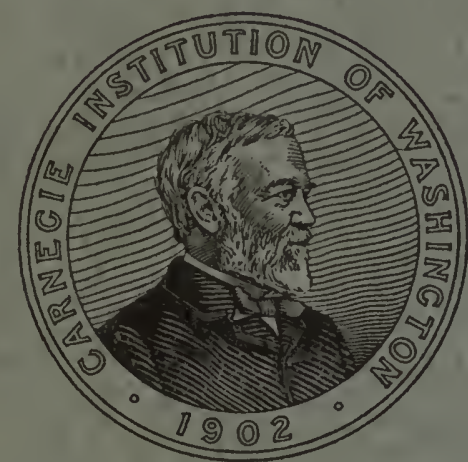

WASHINGTON, U. S. A.

Published by the Carnegie Institution, DECEMBER, 1904. 


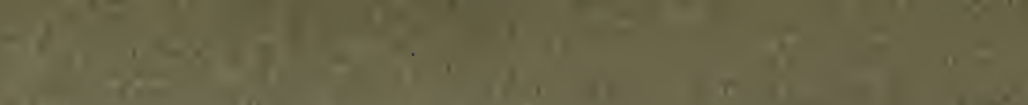

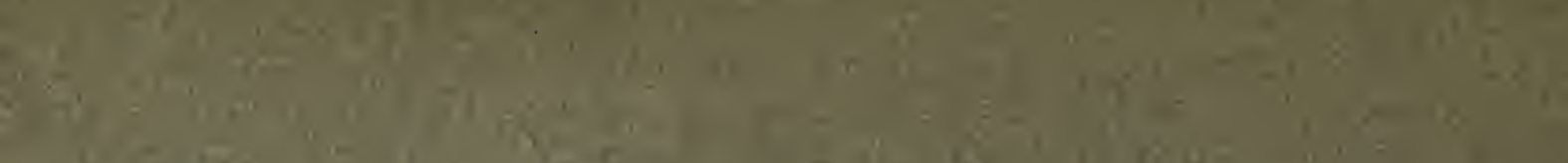
Y)

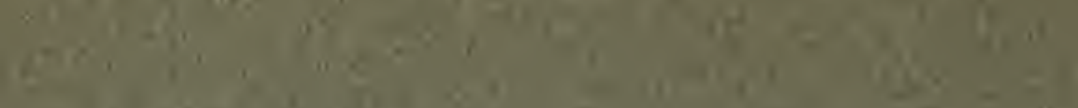

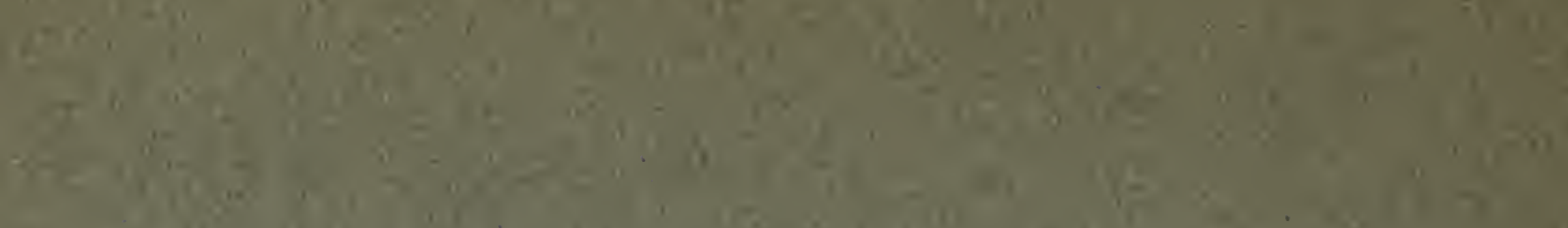
Sh $x$

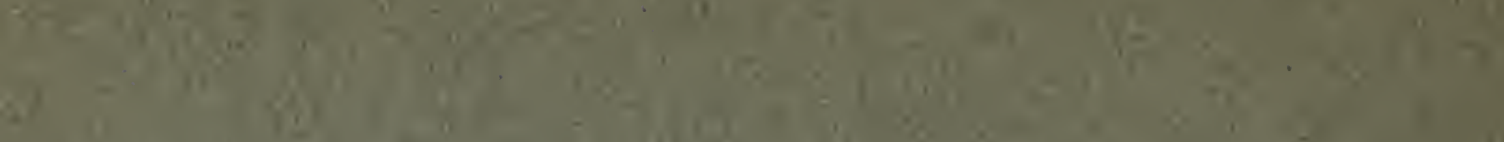

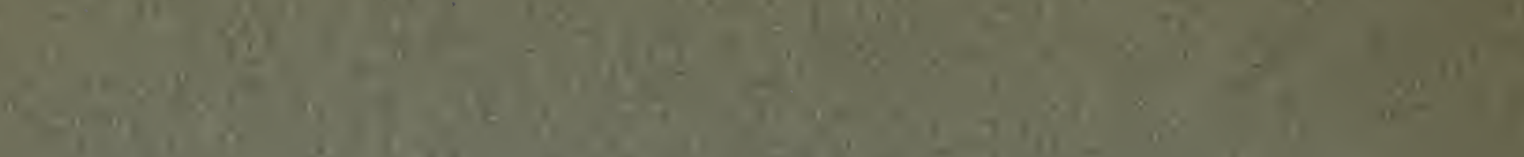

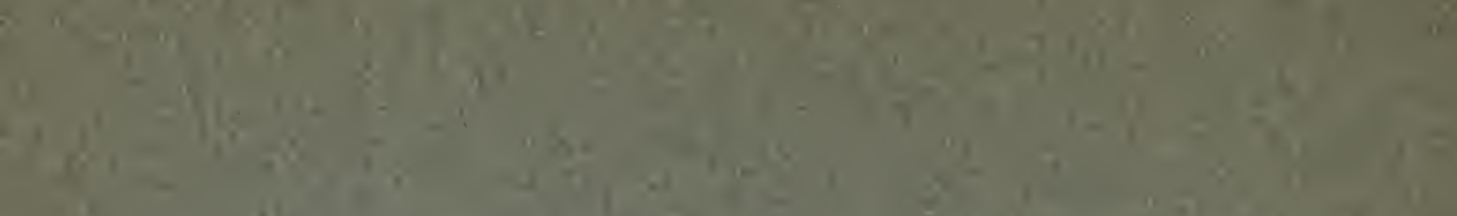

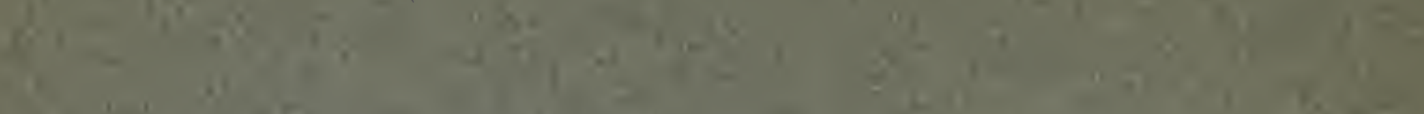

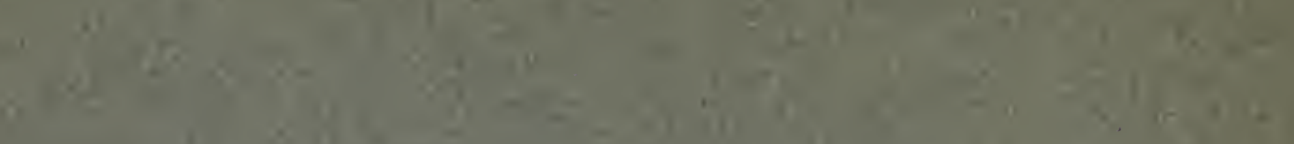

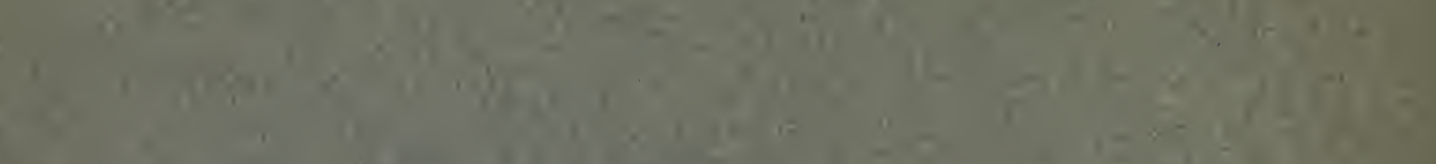

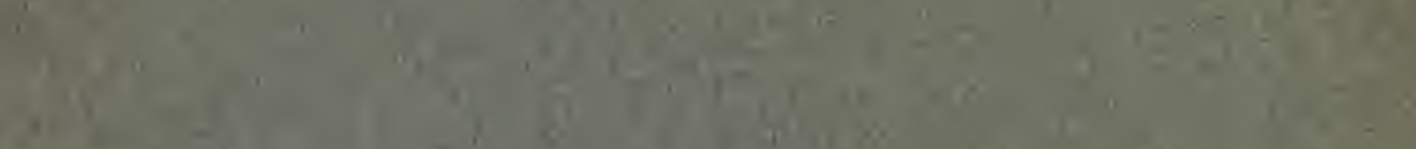

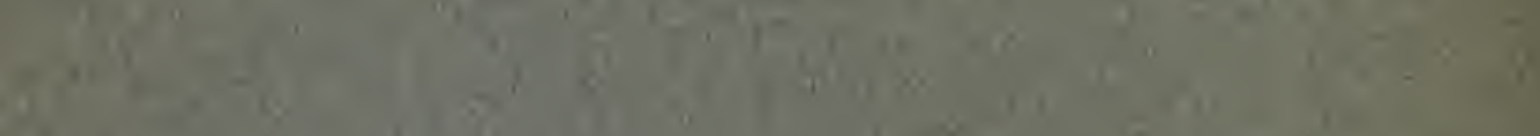

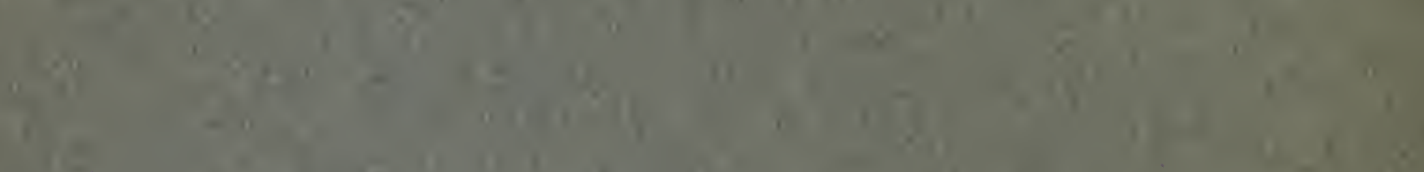

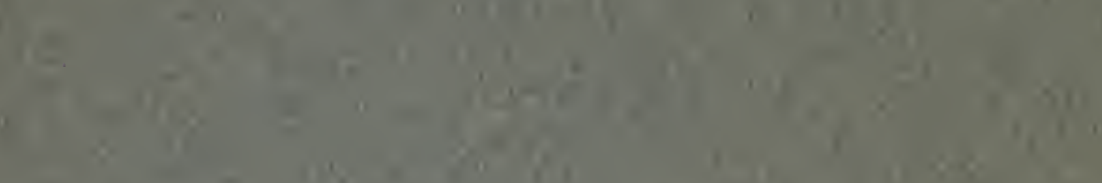

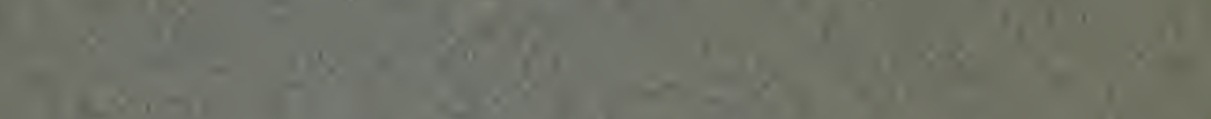

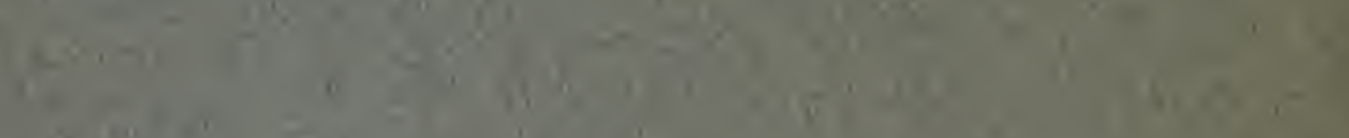

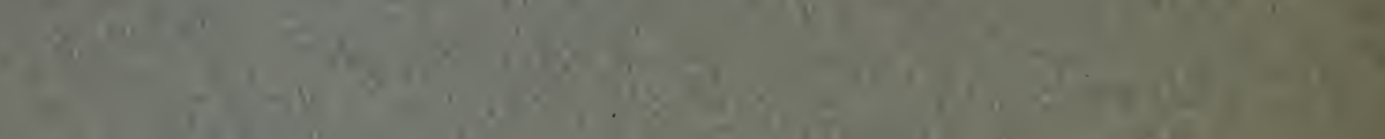

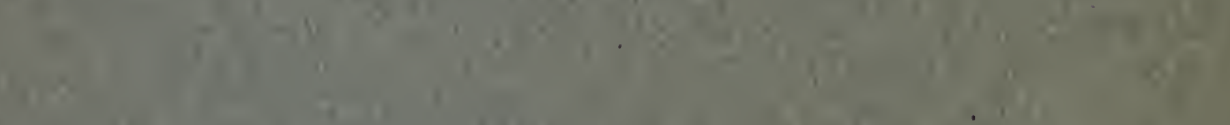

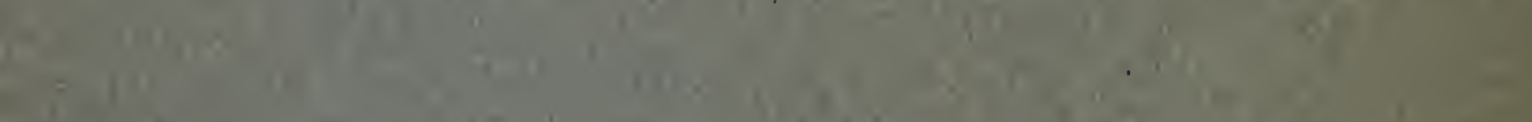

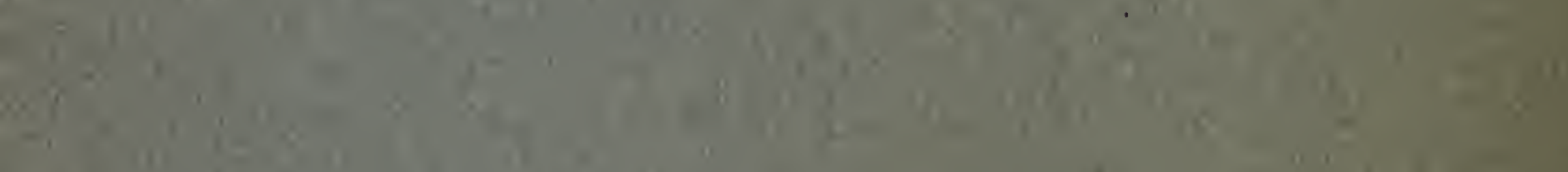

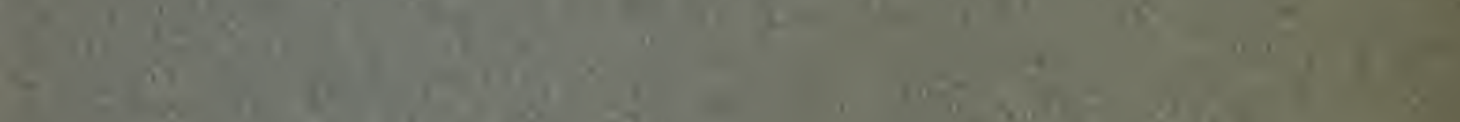
E.t.

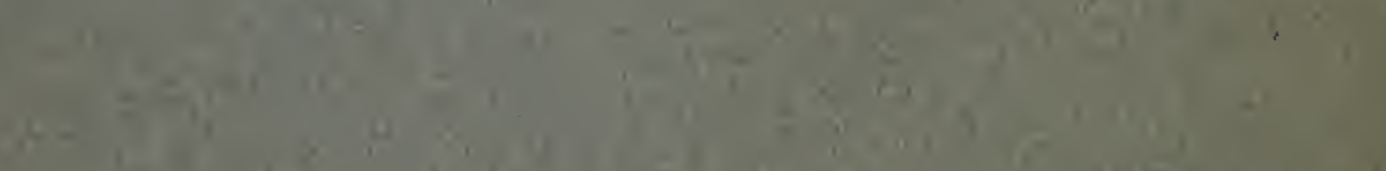

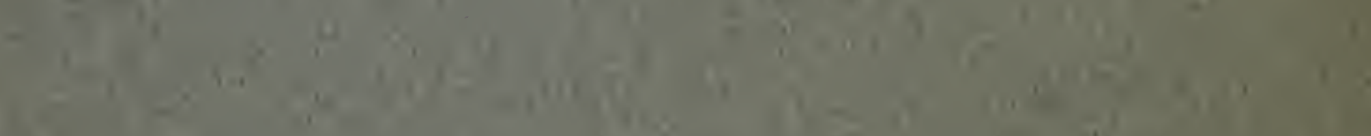

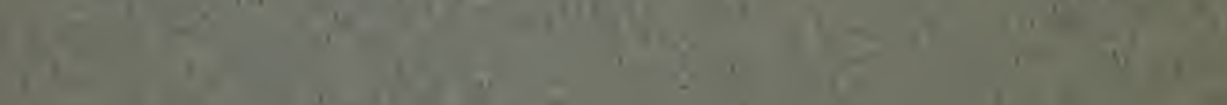

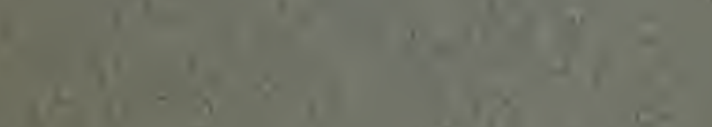

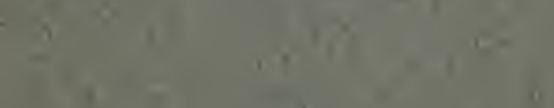

is 14.

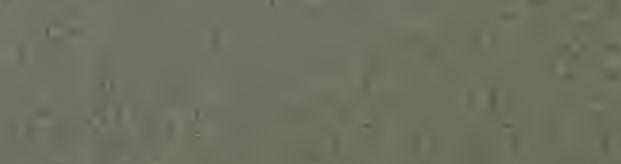

6 (*)

$\underline{s}$

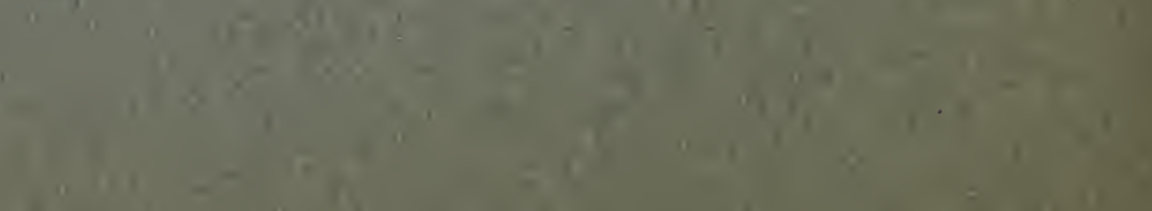

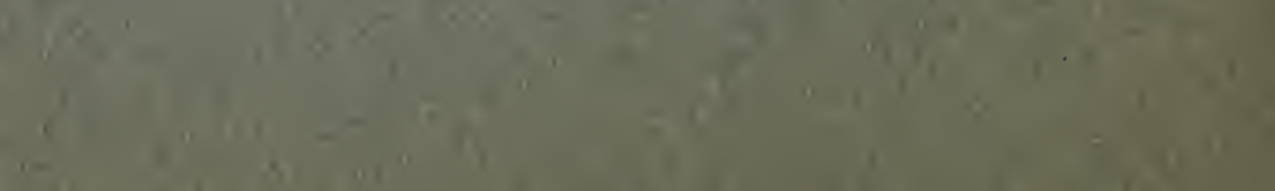

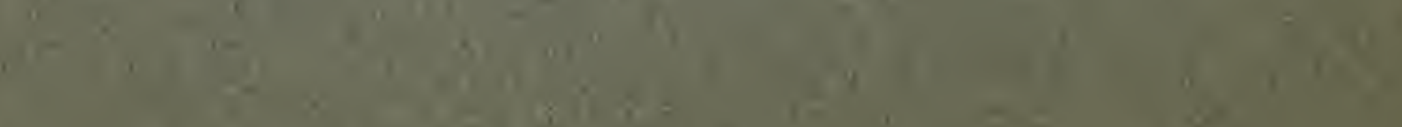

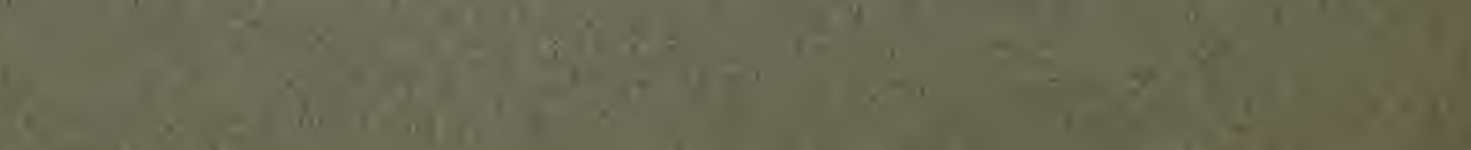

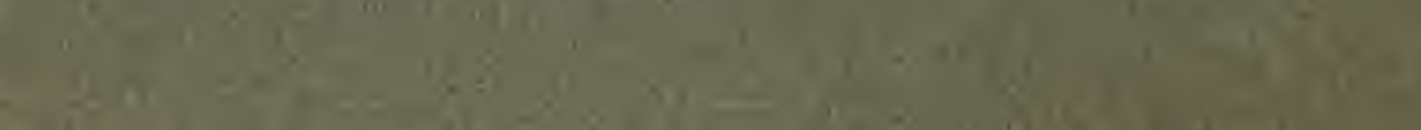

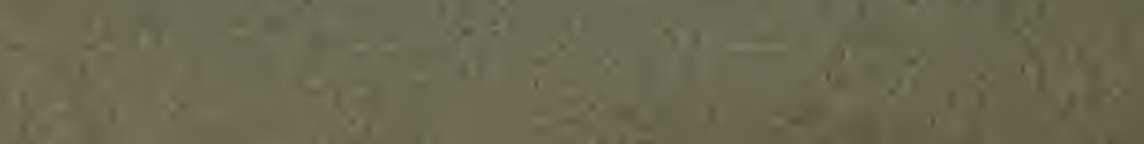





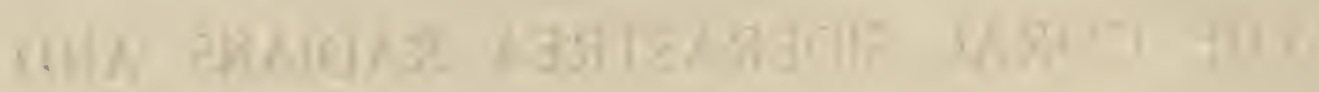

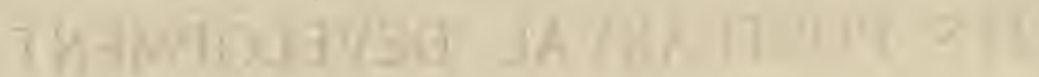

$$
\text { - int } 3 x+5
$$
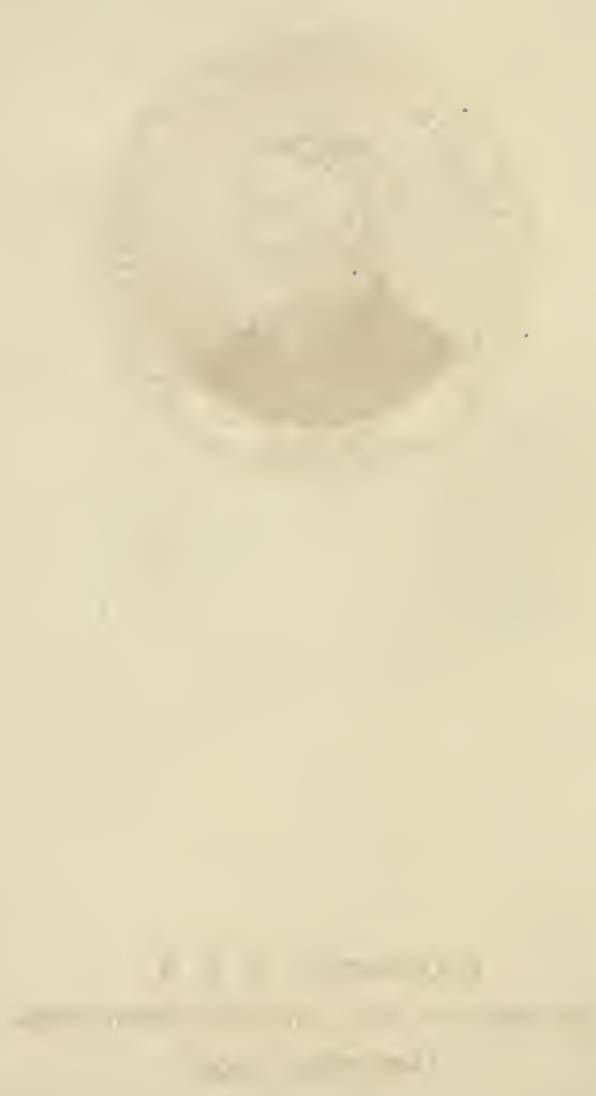
THE CORAL SIDERASTREA RADIANS AND ITS POSTLARVAL DEVELOPMENT.

BY

J. E. DUERDEN.

Cq

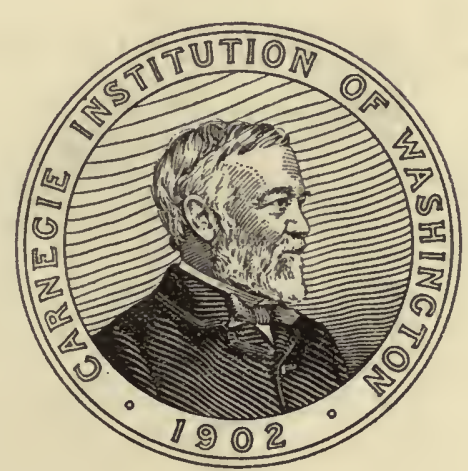

Washington, U. S. A.

Published by the Carnegie Institution,

December, 1904. 
Carnegie Institution of Washington,

Publication No. 20.

Press of Gibson Bros.,

Washington, D. C. 


\section{CONTENTS,}

Preface...............................................

Introductio

\section{Adult Colony.}

External Characters

Column wall.

Tentacles.

Disc and mouth.

Color.

Reproduction.

External characters on decalcification.

Anatomy and Histology

Column wall and disc

Tentacles.

Stomodæum

Mesenteries.

Mesenterial filaments

Skeletotrophic tissues.

Septal invaginations, interseptal loculi, and gastro-cœlomic cavity

Gonads.....

Corallum

Histology

Wall or theca

Septa.

Synapticula

Columella.

Dissepiments

Epitheca and basal plate.

\section{Postlaryal Development}

Larva

Young polyp...................................... 6r

7 Tentacles ........................................... 65

8 First cycle of exotentacles..................... 65

9 First cycle of entotentacles ................... 66

Secondary exotentacles........................ 69

Second cycle of entotentacles and third cycle of exotentacles.......................... $7^{1}$

Third cycle of entotentacles and fourth cycle of exotentacles......................... 73

Mesenteries.............................................. 76

First cycle of mesenteries (protocnemes)... 76

Second cycle of mesenteries (metacnemes) 79

Third cycle of mesenteries.................... 83

Corallum ............................................. 86

First cycle of entosepta and second cycle

- of exosepta..................................... 86

Second cycle of entosepta and third cycle of exosepta

Third cycle of entosepta and fourth cycle of exosepta.................................... 99

Basal plate.................................... 112

Epitheca ...................................... II5

Columella............................................ II7

Anatomy and histology of larva and young polyp................................................ II

Young polyps....................................... 122

References ........................................ 125

Explanation of plates........................... I26 



\section{PREFACE.}

The researches of the late Prof. H. de Lacaze-Duthiers (1873, I897), Prof. G. von Koch (I882, I897), and Prof. H. V. Wilson (I888) have made us acquainted with many of the early stages in the development of corals. They have served to establish such fundamental facts as the ectodermal origin of the madreporarian skeleton and the sequence of the primary mesenteries and septa, results which must ever possess an importance to the student of the Anthozoa. But for an understanding of many of the problems of adult coral morphology, especially those associated with the relationships of the mesenteries and septa, it has long been desirable that developmental stages later than those studied by the authors mentioned should be investigated. While resident in the West Indies I have followed day by day the postlarval growth of the coral Siderastrea radians (Pallas) for a third of a year, and secured the development of the tentacles and septa as far as the third cycle, and that of the mesenteries to the completion of the second cycle. The results are herein set forth.

In many respects the mature polyps of $S$. radians are of peculiar morphological interest, but have never been fully described. An account is therefore first given of the external characters and internal anatomy of the adult colony, and afterwards of the development of the young polyp from the free-swimming larva. The manner of appearance and the relationships of the tentacles, mesenteries, and septa are considered at some length, their establishment being the principal object of the investigation.

The work was commenced while Curator of the Museum of the Institute of Jamaica, continued as Bruce Fellow at the Johns Hopkins University, Baltimore, and concluded at the American Museum of Natural History, New York. For facilities afforded in carrying out the investigations I am under obligations to the Board of Governors of the Institute of Jamaica, Prof. W. K. Brroks, of the Johns Hopkins University, and Prof. H. C. Bumpus, of the American Museum of Natural History. The research has been assisted by an appropriation from the Carnegie Institution.

J. E. D.

University of Michigan, Ann Arbor, Mich., U. S. A.,

IITH NOVember, 1904. 



\section{THE CORAL SIDERASTREA RADIANS AND ITS POSTLARVAL DEVELOPMENT.}

BY J. E. DUERDEN.

\section{INTRODUCTION.}

The following are the more important references to and synonyms of this well-known species of coral:

Madrepora radians, Pallas, Elench. Zooph., 1766, 322.

Madrepora astroites, Linnæus, Sys. Nat., ed. xiI, 1767, 1276.

Madrepora galaxea, Ellis \& Solander, Nat. Hist. Zooph., I786, 168, pl. 47, fig. 7 .

Astrea galaxea, Lamarck, Syst. Anim. s. Vert., r801, 371; Le Sueur, Mém. Mus. Hist. Nat. Paris, t. vi, 1820, 285, pl. xvi, fig. 13; Lamouroux, Expos. Méth., 1821, 60, pl. xl.1x, fig. 7.

Astrae radians, Oken, Lehrb. Naturgesch., $18{ }_{15}$, bd. 1, 65; Milne-Edwards \& Haime, Hist. Nat. Cor., 1857, t. 11, 506; Gregory, Quart. Journ. Geol. Soc. Lond., vol. LI, I895, 277.

Astrea (Siderastrea) galaxea, de Blainville, Dict. Sci. Nat., 1830, tom. LX, 335 ; Man. Actin., 1834, 370.

Astraen astroites, Ehrenberg, Corall. roth Meer, Abhandl. kongl. Akad. Wiss. Berlin, 1832, 319.

Siderina galaxea (pars), Dana, Zooph. Wilkes Expl. Exped., 1846, 218, pl. x, figs. 12, 12b, $12 c$.

Siderastrae galaxea, Milne-Edwards \& Haime, Ann. Sci. Nat., 1850, tom. xII, I39; Pourtalès, Deep-Sea Corals, Ill. Cat. Mus. Comp. Zoöl., no. Iv, 1871, 81; Florida Reefs, Mém. Mus. Comp. Zoöl., 1880, vol.viI, pt. 1, pl. xI, figs. 14-21, pl. xv, figs. I-s2; Quelch, Reef Corals, Challenger Reports, 1886, vol. xvi, Ir3; Heilprin, Proc. Acad. Nat. Sci. Phila., 1890, 305.

Siderastra $[e] a$ radians, Verrill, Bull. Mus. Comp. Zoöl., vol. 1, 1864, 55; Vaughan, Bull. U. S. Fish Commission 1900, vol. 2, 1901, 309, pl. xv, pl. xv1, fig. 2; Samm. der Geol. R.-Museums in Leiden, Igor, Ser. II, bd. II, 6I; Verrill, Trans. Conn. Acad. Science, vol. xI, Ig01, 153, pl. xxx, fig. I.

The generic term has been thoroughly discussed in the recent papers of Gregory (I895, p. 278), Vaughan (r900, p. I54), and Verrill (r9or, p. 88). Vaughan, fortunately for coral taxonomy, shows that the name Astrae, first used binomially as a coral genus by Lamarck in r8or, can not be retained in madreporarian terminology, having been employed by Bolten in 1798 for a group of gastropod shells. In this conclusion he is supported by Verrill. The next generic name available is the Siderastrea of de Blainville, r83o. The specific term radians of Pallas ( 1766 ) has priority of the galaxea of Ellis \& Solander ( $\mathrm{I} 786$ ), and Vaughan holds that the Madrepora astroïtes of the twelfth edition of Linnæus is the same as $M$. radians of Pallas.

The species is very common throughout the West Indies, and is recorded 
from Vera Cruz and Colon on the mainland. It is equally plentiful on the Florida Reefs and flats, and around the more northern Bermudas. Gregory (I895, p. 277) records it as fossil from the Low-level Reefs of Barbados and the Pleistocene Reefs of the Bahamas.

A glance at the references shows that Siderastrea radians has been frequently described and figured, but mainly as regards the corallum; Le Sueur (I 820, p. 285), Pourtalès ( $187 \mathrm{I}, \mathrm{p} .8 \mathrm{I}$ ), and Verrill (I90r, p. I53) have, in addition, contributed brief notes upon the mode of occurrence of the living colonies and the characteristics of the polyps.

As Astraa radians the species is thus systematically described by Milne-Edwards \& Haime in their "Histoire Naturelle des Coralliaires" (vol. II, p. 506) :

Polypary often fixed upon the Voluta turbinellus of Linnæus, or spherical and free. Budding takes place at the point of union of several calices. Calices subpolygonal, appearing thickened at the borders as a result of the strong development of the septal system, although the walls are indicated only by fine lines. Columella formed by one or two compact tubercles, scarcely visible, more distinct in young individuals. Three cycles of septa complete, and, in general, a variable number of a fourth cycle, unequal. Interseptal chambers extremely narrow. Septa much serrated, strong, very regularly crenulated at the border, nearly equal, the primaries and secondaries a little larger. The teeth serrated, obtuse, and sub-equal. The septa of the second cycle are fused by their internal border to those of the preceding cycle. When the septa are broken from above they are found to be united by strong granules, the spaces between the granules resembling small foramina. A specimen in this condition has been considered by Lamarck as a distinct species under the name Astrcea punctifera. In a vertical section the columella is compact and strong, the septa are perfect lamellæ, covered with a radiating series of large granules; the dissepiments are rudimentary, horizontal, simple, and $0.5 \mathrm{~mm}$. distant from one another. The species sometimes forms large masses. The large diameter of the calices is from 3 to $4 \mathrm{~mm}$., their depth $2 \mathrm{~mm}$., or a little more.

An excellent engraving of a colony is given in Ellis \& Solander's "Natural History of Zoophytes" ( 1786 , plate 47, fig. 7), under the term Madrepora galaxea. In his report on "The Stony Corals of Porto Rico," Mr. Vaughan (I9OI) adds a photographic reproduction of a flat incrusting colony and also one showing the enlarged calices (plates $\mathrm{xV}, \mathrm{xVI}$ ): In the plates accompanying Prof. Louis Agassiz's "Report on the Florida Reefs" (r880) are reproduced (plate $\mathrm{xv}$ ) a dozen beautifully executed drawings representing the polyps and skeleton in some detail. Many of the actual details with regard to the tentacles and septa are different from those observed on the Jamaica $S$. radians, but there seems no doubt that the same species is intended in each case. The drawings of the polyps are interesting as showing for the first time the bilobed character of the tentacles and their irregular arrangement at varying distances from the center of the disc. 
The species occurs plentifully in Kingston Harbor, Jamaica, from the shore down to a depth of 5 or 6 feet. Here the colonies are small, and subspheroidal or irregular in shape, partly or wholly incrusting some dead shell or stone. Occasionally nearly globular colonies are obtained with the polyps equally developed all over the surface. Such colonies lie exposed on the sea-floor, or partly buried in beds of the aquatic phanerogam Thalassia marina, and are associated with other free corals, such as Manicina areolata (Linn.), Cladocora arbuscula (Le Sueur), and Porites divaricata (Le Sueur); sometimes they are found incrusting shells inhabited by the living mollusc or by hermit crabs: A flat incrusting form, growing upon stones and blocks of coral, occurs on the coral flats outside the harbor in the area of reef formation. Here the species may give rise to large fixed masses, 50 or $60 \mathrm{~cm}$. across, while in shallow water the free colonies rarely exceed a diameter of $10 \mathrm{~cm}$. On the reefs $S$. radians is associated with another common West Indian species of the same genus, viz, S. siderea (E11. \& Sol.). This latter may produce large hemispheroidal blocks, and in situ is readily distinguished from $S$. radians by the larger size of the polyps and their reddish brown color.

S. radians seems peculiarly hardy as regards the conditions under which it will thrive. The shore waters within Kingston Harbor are often muddy from the action of the strong day breezes, and at times the living polyps are covered by deposits of sand and mud. Around Jamaica, however, the colonies are rarely exposed to the direct rays of the sun, the fall of the tides being very restricted; but further north, where the difference between high and low tides is greater, both Pourtalès and Verrill have found specimens so situated that they are frequently subjected to the direct rays of the sun. With regard to the occurrence of S. radians in Florida, Pourtalès, in "DeepSea Corals" (I87I, p. 8I), writes:

In altitude it ranges higher than any other coral of the Floridian fauna, as small masses are found flourishing in pools left by the tide. I have even seen small clusters left partially dry in a hot sun, keeping up a communication with the water only by a few of the lowest polyps of the group. From their position they must frequently have been thus exposed without inconvenience. According to Prof. Agassiz the polyp has bilobed short tentacles at different distances from the center.

Prof. A. E. Verrill (Igor, p. I54) gives the following notes as to the conditions under which the species is found at the Bermudas:

This species, which is abundant at the Bermudas, is more hardy than most reef corals, for it can live and grow well in shallow water on mud flats, where it is laid bare by nearly every tide, and where most other corals would be smothered in the mud, though $S$. siderea 
and some forms of Isophyllia fragilis are usually found with it in such places. It is often partly buried in the white calcareous mud of the flats, and yet seems healthy there. It is also abundant in the small, shallow pools left on the flats by the tide. But it is equally common on the reefs, where it often grows larger. It is also found well grown in Harrington Sound. Exposure to the dry air, or even to the hot sun, for an hour or so, does not kill it, if it be wet beneath. Probably its porosity enables it to absorb sufficient water to prevent drying up.

The natural occurrence of the living coral under such varying conditions as to purity of water and exposure indicates that this species, at any rate, is not so extremely sensitive to its environment as corals generally are found to be.

The polyps are so small that their external characters can be fully made out only with the aid of a lens or a low-power microscope. Further, they differ so much in appearance, according to the amount of expansion and retraction, that to obtain their complete characteristics it is desirable to keep the colonies under observation for some time and subjected to various conditions. As the stocks often lie free on the sea-floor, they can be collected without any injury to the polyps, and are sufficiently small to be kept in the laboratory in ordinary glass vessels. With a little attention no difficulty is experienced in keeping the polyps alive. Indeed, the colonies continued to increase in size during confinement, and while kept under observation new polyps began to arise from the calices of previously dead areas.

The boring bivalve Lithodomus appendiculatus Phl." nearly always occurs within the corallum, often several in each colony. The siphon has a dark purple, funnel-shaped incurrent aperture and a small, tube-like excurrent aperture, and protrudes a short distance beyond the surface of the colony, the activity of the mollusc keeping up a strong circulation of water; larvæ and other small floating objects may pass in rapidly at one aperture of the siphon, and after a brief interval may be shot out from the other. Numbers of cirripedes (Pyrgoma) also frequently infest the corallum, and assist in maintaining a current of water over the living colony. It seems not unlikely that these infesting organisms may be of much importance in clearing away the mud and sand which accumulate on the surface of the polyps, and the currents produced by them may also bring food within reach.

During the greater part of the day the colonies in the laboratory were kept in the shade, or even in darkness, by placing the glass receptacles under some cover. Under these conditions the polyps remained partly expanded, but retracted when exposed for any length of time to the direct rays of the sun. In the early morning and towards evening the vessels were

* For the determination of this species I am indebted to Prof. L. P. Gratacap, of the American Museum of Natural History. 
removed for a short time into the full rays of the tropical sun, or kept for hours in diffuse light, when all the polyps expanded to their fullest degree, and seemed tingling with vitality; but in general, like most other corals and actinians, the polyps seem most vigorous in the shade and at night time. Detailed experiments on the phototropism of coral polyps are much needed.

When the colonies were exposed to strong sunlight for a time, in a limited quantity of water, bubbles of oxygen gas were seen to form within the cavity of the polyps and then to escape through the mouth. The production of oxygen is without doubt dependent upon the metabolic activity of the unicellular algæ or Zooxanthellæ present in great numbers throughout the endodermal tissues (p. 22). The filamentous green algæ found perforating the skeleton (p. 38 ) would doubtless have a similar activity, but the intensity of the light reaching their chloroplasts must be much less than that falling upon the more superficial Zooxanthellæ.

The oxygen produced from the combination of the physiological activities of the plant and animal was ample to keep a limited quantity of water in a proper state of aeration; and once the colonies were established the water in which they were living remained perfectly clear and sparkling without the addition of other plant life. Generally it was unnecessary to renew the seawater, but from time to time fresh water was added to replace that lost by evaporation. To make certain that the water contained sufficient calcareous salts in solution to enable the young polyps to build up their skeleton it was partly changed every few days. Like the adult polyps, the developing individuals contained many Zooxanthellæ within the endoderm.

For food the polyps were given small living worms, pieces of molluscs, crabs, or fish. These they took readily by first extending their tentacles and later their mouths over them. Sometimes a hapless polychæte would attempt to creep over a colony, when it was quickly killed and ingested; other small worms, wriggling with great vigor, were unable to free themselves when dropped upon a colony. The tentacles of the polyps fastened upon the annelid at one or more places, and its movements soon began to weaken, as if the creature were paralyzed. Each polyp immediately around the worm opened its mouth widely, while those more distant extended their peristomes towards it, as if all were moved by a common impulse. As many as half a dozen polyps would thus seize hold of a small worm at one time. Naturally a difficulty arose when two polyps commenced to engulf the same worm from opposite ends. The unfortunate annelid soon reached a state of tension between the polyps, and the peristome of each of the latter was drawn outwards to an unusual degree. For over an hour a worm was 
seen thus pulled at from each extremity. A large piece of a mollusc might also be seized upon and partly ingested by two polyps at the same time, and in the end their lips would approach and come into actual contact. A larval polyp only four weeks old was able to hold a wriggling fragment of a small worm and attempted to swallow it.*

For examination of their anatomy and histology some of the polyps were preserved in the partly expanded condition in 5 per cent. formol and others in a solution of corrosive acetic, after narcotization with menthol or magnesium sulphate. Shortly after preservation they were transferred to alcohol. Where decalcification was necessary this was carried out by means of weak solutions of hydrochloric or nitric acid, a few drops being added from time to time to maintain a slight effervescence. For such a dense corallum as that of Siderastrea the process of decalcification required three or four days. After the process the space heretofore filled by the skeleton was invariably found to be occupied by a fluffy mass, which on examination under the microscope was found to consist of delicate algal filaments along with fine organic particles. Microscopic sections of the corallum were made by embedding in Canada balsam and then grinding to sufficient thinness, as in the preparation of ordinary rock sections.

* Experiments conducted since this account was sent to the printer demonstrate that the mucus exuded by the ectoderm cells plays an important part in the feeding of coral polyps, particularly where the food particles are small. The latter falling on the polypal surface become embedded in mucus, and if not reversing the ordinary direction of movement of the stomodxal cilia they are slowly wafted away beyond the tentacles; nutritive particles and solutions bring about a reversal of the action of the stomodæal cilia, and, along with mucus in the form of strands or threads, are gradually drawn into the polypal cavity. 


\section{ADULT COLONY.}

\section{EXTERNAL CHARACTERS.}

The polyps are small and subpolygonal in outline, rarely exceeding $4 \mathrm{~mm}$. in diameter when retracted, and 5 or $6 \mathrm{~mm}$. on expansion. Six unequal sides constitute the basal periphery of large polyps, while there are only four or five in smaller examples. In general, the individuals in any colony are irregularly disposed. In some regions an arrangement in parallel rows can be made out, but usually this is interfered with by the intercalation of new polyps among those fully grown. In most branching corals, alcyonarians, and compound actinians, it is usual for the principal oral axis of the polyp to be symmetrically placed with regard to the axis of the colony, but no such regularity of orientation is manifest in the polyps of Siderastrea.

The superficial polypal tissues are so thin that the white corallum below shows through, and occasionally the internal arrangement of the mesenteries around the stomodæum can be followed. This is especially the case with polyps which have been preserved in formalin. Retracted polyps usually exhibit radiating lighter areas, which correspond with the cycles of septa below, and narrower alternating darker areas, which correspond with the interseptal spaces and internal attachment of the mesenteries (plate 6, fig. 32).

The living polyps making up a colony are separable from one another along a narrow polygonal groove which is always lighter in color than the rest of the polypal wall. Along this groove the column wall is connected with the corallum, not directly, but by the intermediation of the mesenteries, and to whatever degree the polyps become expanded the wall is here never much elevated. The polyps, however, are at no time raised far above the corallum. On full expansion they rarely assume the true cylindrical form with a flattened disc, like most coral polyps, but exhibit merely a dome-like elevation of the walls over the calice, 2 or $3 \mathrm{~mm}$. high (plate 6 , fig. $3 \mathrm{I}$ ).

At no place, except in simple larval polyps and at the margin of a colony, is the boundary of the column wall of the individual polyp directly connected with the skeleton; that is, it is nowhere continuous with the skeletogenic basal wall. The margin of the column of any polyp passes uninterruptedly into that of the surrounding polyps, and, as will be shown later, the mesenteries pass from the column wall to the skeletogenic tissues below, leaving narrow interspaces, which place the digestive cavities of all the polyps of a colony in communication. 
On partial retraction the column wall comes to rest upon the corallum, * but the central area of the disc and the tentacles remain a little elevated, the peristome especially so. On fullest retraction these also come to lie closely against the skeleton and follow it all the way, nearly to the bottom of the calice. Unlike the polyps of most corals, the column wall in Siderastrea is incapable of folding over the tentacles and disc upon retraction; both the column wall and disc are simply drawn down upon the skeletal tissues, leaving the tentacles and mouth exposed. Where, in other coral polyps, an overfolding of the polypal wall occurs, it is brought about by the action of the circular endodermal musculature of the column wall, sometimes in the form of a sphincter; but histological examination reveals that the columnar musculature in $S$. radians is of the weakest character.

The genus Siderastrea, in many respects, is allied to the mushroom coral Fungia, both being included within the section Madreporaria Fungida. The genus Fungia is not found in West Indian shallow waters, but the various figures by Dana (I846), Bourne (I887, I893), and Saville-Kent (I893), of different species of Fungia found elsewhere, show that in this genus also the column wall in retraction is not drawn over the disc. The West Indian species of the allied genus Agaricia are also unable to overfold the column wall.

Apparently the outer surface of the polyps of S. radians is not ciliated, for light particles dropped upon it remain there, and no ciliary motion is recognizable when the living polyps are examined under a moderate magnification. Similar particles dropped upon colonies of Manicina areolata are gently swept away and over the sides in such a manner as to plainly indicate ciliary activity, so that probably different coral species vary in this respect. The outer surface is always uniformly ciliated in larvæ (plate I, fig. I).

\section{COLUMN WALL.}

The columnar and discal areas of the polyps are not sharply separated from one another under any condition of expansion or retraction. The outer cycle of tentacles, which in ordinary cases marks the peripheral boundary of the disc, here forms but an irregular circle, and its members are comparatively widely apart (plate 6 , figs. 3 I, 32). Including as column all that part of the polypal wall between the polygonal line of attachment of the polyps to one another and the outermost cycle of tentacles, its extent is very limited, being

* The free superficial regions of the polyp (column and disc) never come into actual contact with the skeleton, as the living parts of the latter are always covered with the basal skeletotrophic tissues. When they are said to rest upon the corallum the tissues lining the corallum always intervene. 
represented by a zone not exceeding $2 \mathrm{~mm}$. across. When the polyps are expanded the proximal region of the column remains somewhat polygonal in outline, but distally it becomes circular in section, rarely assuming the true columnar form.

The column does not present the two topographical subdivisions, calicinal and pericalicinal, like most corals. Instead it extends directly from the edge of the calice, so that it is wholly within it; in other words, no "Randplatte" or "edge-zone" occurs in Siderastrea.

Structurally, the column wall is very thin, partly transparent, and smooth; on expansion vertical lines are clearly visible, indicating the internal attachment of the mesenteries.

TENTACLES.

The oral disc is divisible into an outer tentaculiferous region and an inner naked area or peristome, with the mouth in the middle. The tentacles are arranged widely apart, and thus occupy a comparatively broad zone of the disc, leaving only a very restricted smooth central area. As can be seen from plate 6 , fig. 32 , the tentacular region during retraction includes the greater proportion of the exposed part of the polyp, while the columnar area is very narrow, and little remains of the naked portion of the disc. This exceptional relationship of the columnar, tentacular, and discal areas results from the wide intervals which separate the different cycles of tentacles, a similar condition being apparently characteristic of the Fungidæ generally. In most coral and actinian polyps the tentacular cycles are placed close together, the bases of the tentacles of one cycle being partly embraced by the bases of the next cycle, and thus the tentacular zone is very narrow compared with the remainder of the disc.

The tentacles of $S$. radians are remarkable among all West Indian coral polyps on account of their form and arrangement. Under certain conditions of partial or even full expansion of the polyps the organs can be discerned with a lens as small sessile tubercles, arranged only approximately in cycles, some as pairs and others singly, and corresponding in position with the septa. In most cases they stand out as small, delicate, simple or bifurcated finger-like outgrowths of the disc. As seen externally each appears to originate over the central termination of the septum with which it corresponds, that is, before the margin of the septum commences to dip downward.

When the tentacles are fully extended and much enlarged they appear as shown on plate 7 , fig. 37 . The stem consists of a broad basal part which 
in most members of the inner cycles becomes bifurcated a little above midway, each half terminating in a light-colored knob which represents a battery of nematocysts; the outermost members, however, are simple, like those of the majority of coral polyps.*

In studying the internal anatomy of the polyp, it is found that the bifurcated members communicate with the entocœlic chambers, and the simple forms with the exocœlic chambers. Development shows that the double tentacles are at first simple, and such may be the condition of some of the onter entocœlic in nearly mature polyps. The number of tentacles always corresponds with the number of septa, the bilobed tentacles being situated over the entosepta, and the simple tentacles over the exosepta. Their order of appearance is described later in connection with the development of the larval polyps.

The tentacular walls are smooth, that is, devoid of the nematoblast tubercles which so frequently characterize the tentacles of coral polyps. The aggregation of large nematoblasts is restricted to the apical knobs. The stems are hollow and brown in color, the latter character due to the presence of Zooxanthellæ in the endodermal tissues. The knobs, on the other hand, are solid and colorless. The organs are adhesive and able to take particles of food from the tips of forceps. There is little difference in size among the tentacles of the various cycles, but the bifurcated members are larger than the simple.

During retraction, and even sometimes on full expansion of the polyp, the tentacles appear as unstalked, spheroidal tubercles, sessile on the disc. In the case of the bilobed tentacles, a knob is situated on each side of the septum with which the tentacle corresponds, while in the simple tentacles the knob is directly over the septum (plate 6, fig. 32). No stem can be recognized under such circumstances, and sections show that it is not invaginated, but has become part of the discal wall (plate 7 , fig. 40). Such a condition of the tentacular stems is often found in corals, but rarely among the larger tentacles of actinians. When the tentacles are fully expanded they stand obliquely to the surface of the disc, and are bent outwardly. The organs have never been found invaginated, a phenomenon which frequently occurs in coral polyps and alcyonarians.

\footnotetext{
*Verrill (190r, p. I54) makes the following remarks with regard to the tentacles of S. radians: "the tentacles are small, short, cylindrical, or clavate; they form several circles, and'appear somewhat scattered, those of successive cycles being in different circles and decreasing in size. But they are not bilobed, nor trilobed, as Agassiz and Pourtales supposed. This appearance is due to a smaller one standing on one or both sides of a larger one, and close to it." From the part italicized it would appear that the tentacles in Verrill's Bermudan specimens must have been altogether different from those in Jamaica polyps, which, moreover, agree with those observed by Agassiz and Pourtales.
} 
The hexameral cyclic arrangement of the tentacles is by no means easy to establish, and would be almost impossible to ascertain without anatomical aid or assistance from the septa below. According to the usually accepted cyclic formula for hexactinian polyps employed in systematic works, $S$. radians would be said to have three cycles complete and a fourth incomplete, and the cyclic formula would be $6,6, \mathrm{I} 2, \mathrm{x}$, where $\mathrm{x}$ may be any number from I to 24 .

On the living polyp six bifurcated tentacles can usually be distinguished as constituting an inner or primary cycle, which is widely separated from the other cycles; the remaining tentacles are more closely disposed and their arrangement is somewhat obscure, simple and double members being intermingled. Among them a second cycle of six bilobed tentacles can sometimes be recognized, alternating with the first and remote from it. Beyond this there is no true hexameral plan determinable. In most polyps a few members of a third cycle of bilobed tentacles are present, but the full complement of twelve entotentacles, necessary by the laws of actinian symmetry to complete the alternation with the two previous cycles of six each, appears never to be developed. The outer simple exocœlic tentacles correspond in number with the sum of the members of the primary, secondary, and tertiary entotentacles with which they alternate, but some belong to the third cycle and some to the fourth. Only the first and second cycles are completely hexameral; the third and fourth are incompletely so.

In transverse sections through the polyps (plate 6, fig. 34 ) it is found that the first and second cycles of mesenteries consist of six pairs each, but the third cycle rarely or never contains the next number in the hexameral sequence, namely, twelve. The number of entocœlic chambers corresponds with the number of exocœlic chambers, therefore the number of entotentacles will correspond with the number of exotentacles, as a tentacle communicates with each mesenterial chamber. Whatever number of entotentacles be lacking to complete the third cycle of I2, a like number of exotentacles will be wanting to complete the fourth cycle of 24 . Thus, considered morphologically, the tentacular formula will be $6,6, \mathrm{x}, 6+6+\mathrm{x}$, where $\mathrm{x}$ will be the same in the two cases, and may be any number from I to I2; the series $6,6, \mathrm{x}$ will represent the number of entotentacles, and $6+6+\mathrm{x}$ the number of exotentacles. A polyp with 38 tentacles will have the morphological formula $6,6,7$, I9; a polyp with 44 tentacles the formula 6, 6, 10, 22.

Where, in mature polyps, the hexameral sequence is incomplete, it seems preferable to employ the morphological formula as compared with the ordinary cyclic formula. In the first we have the true nature of the tentacles indicated; 
in the second the penultimate cycle is assumed to be complete, whereas it is made up of two different series of tentacles-entotentacles and exotentaclesand simply represents an arrested stage in the hexameral plan.

Fig. $I$ is a diagrammatic representation of the arrangement of the tentacles in a polyp of Siderastrea with the morphological enumeration added. In the two inner cycles (I, II) six bilobed tentacles are complete, while only five tentacles of the third cycle (III) are yet developed; alternating with the members of the three inner cycles of bifurcated tentacles is a simple tentacle

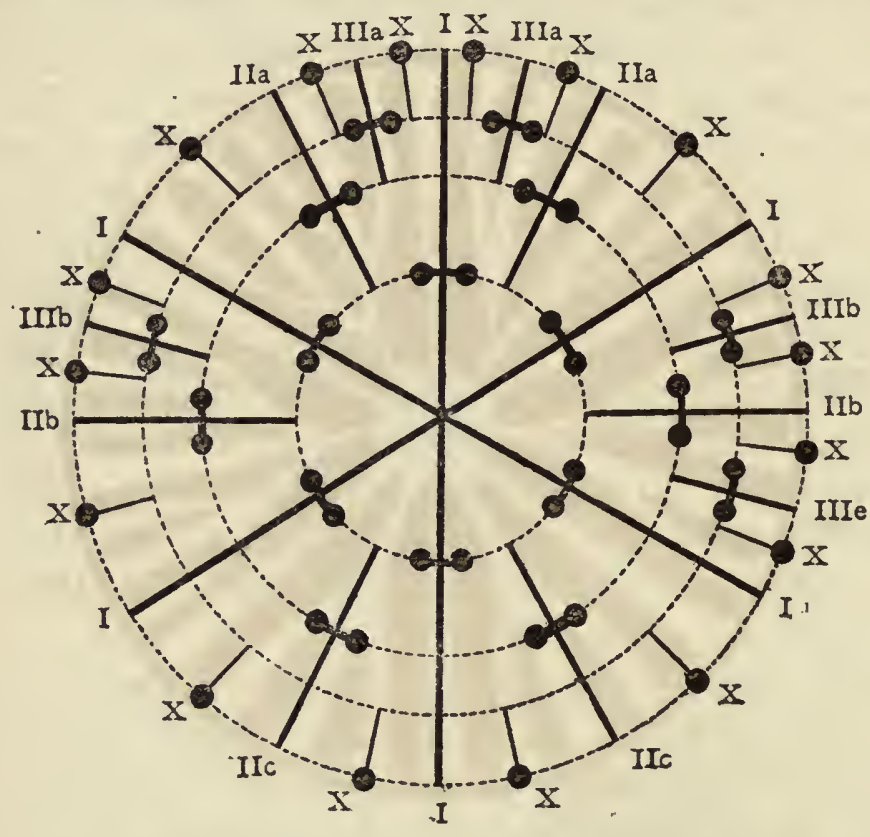

Fic. 1.-Diagram showing the relationships of the septa and tentacies in the same polyp as that from which fig. 34 , plate 6 , was taken. All the entotentacles are shown with a double apex and the exotentacles with 2 single apex. The exotentacles are all arranged as if forming the fourth or outermost cycle, whereas some will belong to the third and some to the fourth cycle, according as a third cycle entotentacle is present or not.

(x) belonging to the outermost series, but not forming a true cycle. The septa, indicated by the thick radiating lines, show a corresponding arrangement. For purposes of comparison the same polyp is also shown in transverse section on plate 6 , fig. 34 , while the septa are diagrammatically represented in fig. 2 , p. 13 . By comparing figs. I, 2, and plate 6 , fig. 34 , it is seen that the three inner cycles of tentacles communicate with the entocœles and correspond with the entosepta, while the members of the outermost cycle communicate with the exocœles and correspond with the exosepta.

The tentacles of $S$. siderea are of the same character as those of $S$. radians, 
only somewhat larger; the entotentacles are bifurcated, and the exotentacles simple. In the genus Agaricia, also belonging to the Madreporaria Fungida, the tentacles are all simple, but in their wide distance apart they resemble those of Siderastrea.

The fully expanded tentacles of most species of Fungia seem to be small and club-shaped, but in $F$. crassitentaculata they are much larger than is usual for the organs in corals generally. This is well shown in the figure

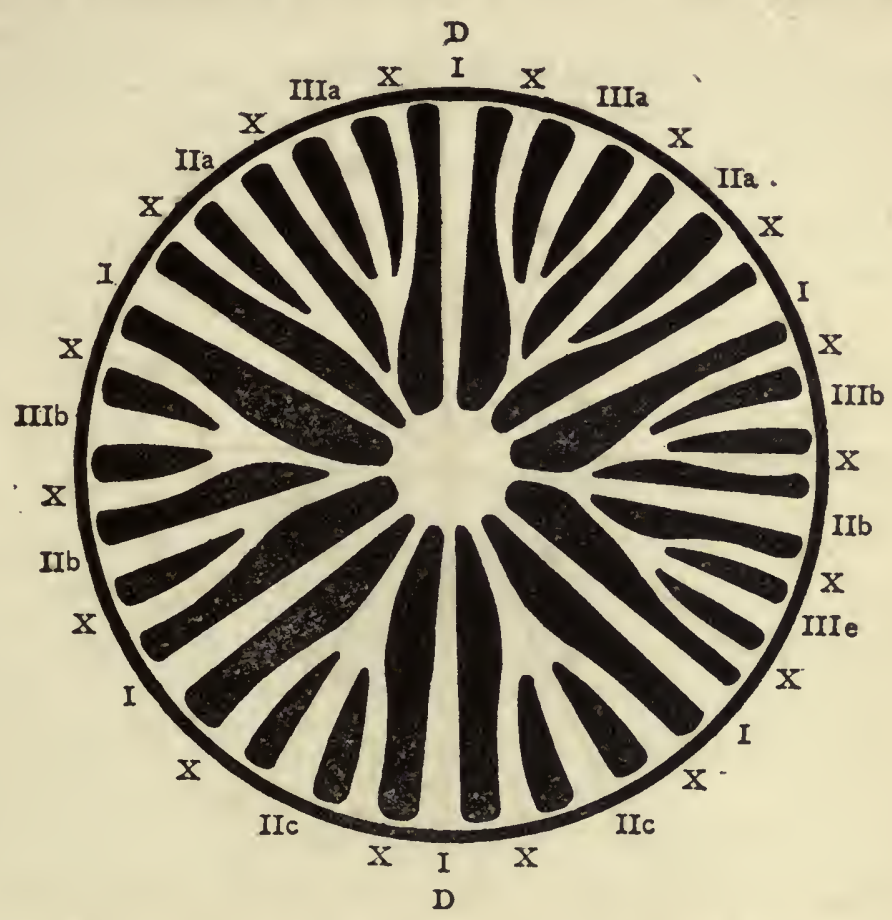

Frg. 2. - Diagram showing the relationship of the septa to one another in the same polyp as that of fig. 3 .

of $F$. crassitentaculata in Saville-Kent's "Barrier Reef." In all Fungia the organs are widely apart, and, as in Siderastrea and Agaricia, occupy nearly the whole discal area.

The wide separation of the tentacles in the genera mentioned usually tends to obscure their hexameral cyclic plan. The two polyps of Siderastrea represented on plate XV in Agassiz's "Florida Reefs" are evidence of this, and also the remarks of Verrill, given in the foot-note on p. Io. Such is also the case with Dana's figure of Fungia lacerta, but Bourne found the tentacles of $F$. clavata to be arranged in distinct cycles. The positions usually assumed by the tentacles of Siderastrea enable one to understand how such 
confusion may arise; indeed, the polyps were for a long time under observation before any regular arrangement could be established with certainty. It was only after observing the Jamaica polyps under various phases of expansion that the cyclic plan of the first tentacles could be determined, while, as regards the two outer cycles, such an arrangement is more theoretical than actual. The tentacles on plate 6 , fig. 32 , from a camera drawing of a preserved polyp, do not readily suggest a hexameral cyclic plan.

Siderastrea is apparently the only madreporarian genus with true dimorphic tentacles, the peculiarity having been first recognized by Agassiz. The independent origin of the two moieties of the bifurcation, as described later, is also a remarkable feature in the tentacular development of the Zoantharia. Dimorphic tentacles are occasionally met with among the tropical Actiniaria, e. g., Rhodactis, Phymanthus; but here they are the disc tentacles as compared with the marginal tentacles which show the distinction, and the morphological value of the former is uncertain. At any rate, the disc and marginal tentacles of actinians are not comparable with the entotentacles and exotentacles of Siderastrea.

\section{DISC AND MOUTH.}

The naked portion of the disc is very limited in extent. It is smooth, circular, and usually partly depressed within the calice. So transparent is the wall that the cyclic arrangement of the internal mesenteries and septa can be easily followed. The central part or peristome is not separable from the rest of the disc, except that it is usually elevated in a conical manner, and, owing to a greater concentration of the endodermal Zooxanthellæ, it appears darker than the rest of the polyp.

The mouth is small and slit-like when closed, oval or circular when open. The lips are not specially marked off from the peristome by any tumidity, such as occurs in many anemones. In living polyps the mouth sometimes closes along the middle by the approximation of the lips, but leaves a small opening at each end. The apertures, however, can not be regarded as representing a siphonoglyph or gonidial groove, for microscopic examination reveals no difference in the character of the stomodæal wall between the sides and extremities. On narcotization the circular muscles of the disc relax, and the oral aperture remains widely open and circular; the stomodæal wall is then seen to be smooth, without ridges and grooves. 
COLOR.

The polyps on the under, unexposed surface of colonies may be colorless, but vary elsewhere from light to dark brown. Owing to the partial transparency of the tissues the white corallum always shows through, and gives rise to an alternation of light and dark radiating areas and to a light polygonal line separating one polyp from the other. Sometimes the disc presents a velvety green color along the mesenterial radii, and the oral aspect of the tentacles and the angles of the mouth also may be of the same color. The stomodæal walls and knobs of the tentacles are white, while the stems of the latter are usually brown. More rarely the elevated peristome may be rose-colored, and in some cases purple.*

The different shades of brown exhibited by the polyps are entirely due to the presence of Zooxanthellæ or unicellular algæ within the endodermal layer. The chromoplasts within these are brown, yellow, or greenish yellow, and when the algæ are but few in number they give a light brown color to the walls of the polyps, whereas when present in great numbers, overlying one another, the polyps appear a dark brown. For this reason the thin tissues of fully expanded polyps are much lighter in color than the tissues of retracted polyps.

Examination of the walls of colorless polyps on the under surface of a colony proves that the Zooxanthellæ are either absent or occur very sparingly in the endoderm. When, however, the colorless areas are exposed to light, the polypal tissues begin slowly to assume a brownish color, and in a few days yellow cells are to be found in abundance.

On examining a living tentacle under the microscope the outer ectodermal layer is seen to be quite colorless, but the yellow Zooxanthellæ are revealed by focusing through to the internal endodermal layer. The whiteness of the spheroidal tips of the tentacles, compared with the brown color of the stems, is also due to the fact that the knobs are wholly formed of ectoderm, the endoderm lining the cavity of the stems not being prolonged into them. The superficial green or purple color is somewhat evanescent, and wliolly ectodermal in origin.

Different shades of yellowish brown are the prevailing colors of the coral areas in Jamaica, and whether in the palmate or branching growths of

* Le Sueur (1820, p. 286) describes the color of the specimens seen by him at Guadeloupe as "d'un rouge mêle de violet." The color of S. siderea as given by the same author is also very different from that of the Jamaica specimens. Verrill (I90r, p. 154) writes thus of the Bermuda S. radians: "The general color in life is dull gray, yellowish gray, ocher-yellow, or rusty brown, sometimes tinged with a purplish rosy tint; the polyps are paler, with the lips and tips of the tentacles whitish." 
Acropora (Madrepora), the hydrozoan Millepora, or the zoanthid Palythoa, all owe their origin to the presence of unicellular algæ with yellow chromoplasts within the endodermal cells."*

Stanley Gardiner and Hickson have both drawn attention to the part which commensal algæ probably play in the nutrition of the polyp. The organisms are actually inclosed within the endodermal cells, and there can be scarcely any doubt that the polyp receives from them nutritive carbohydrates, produced in the course of the metabolic activity of the vegetable cells under the action of sunlight; further, the Zooxanthellæ are constantly increasing in number by fission into two and then four, and perhaps some are utilized as food directly by the polyp. The liberation of free oxygen, already shown to take place by the activity of the chlorophyll within the algal cells, must also be of importance in the vital activities of the polyps.

In many corals and actinians, however, Zooxanthellæ are altogether absent, hence their presence can not be considered as necessary to the life of the polyp; also, corals grown in the shade are colorless from absence of the algæ. Further, both actinians and corals will ingest almost any variety of animal food that is offered them.

\section{REPRODUCTION.}

New polyps arise asexually as intercalary buds, usually at the point of junction of three or more polyps, so that it is impossible to say whether one polyp more than another is to be regarded as the parent, or as to how far the structures in the bud arise in organic association with those of the older polyps. Over the general surface of any colony bud polyps in different stages of development are usually present, and for some time they remain much lighter in color than the others, owing to a less growth of Zooxanthellæ; also, around the margin of colonies the addition of new polyps is generally in rapid progress. These latter serve to enlarge the lateral boundaries of the colonies, while the intercalary polyps occupy the spaces produced as the coral grows in height, and, of course, in superficial area. Instances of reproduction by the process known as fissiparous gemmation $\dagger$

* In his recent vice-presidential address before the Section of Zoology of the American Association at St. Louis, Prof. C. W. Hargitt comes to the conclusion that the colors in cœlenterates and many other groups of invertebrates have probably no adaptive or protective significance, and are in main the result of the metabolic activity of the animal. The rich profusion and beauty of color in coral polyps certainly seems to have no protective or warning significance, but those due to the presence of commensal algæ have of course an altogether different physiological importance from the other colors.

t The term is applied to a method of asexual reproduction occasionally found in gemmiferous colonies. It appears as if an enlarged polyp simply divides into two. The method, however, is altogether different from growth in fission colonies generally. ("The Morphology of the Madreporaria-IV. Fissiparous Gemmation." Ann. Mag. Nat. Hist., ser. 7, vol. xI, rgo3.) 
are very rare, but occasionally much enlarged calices are seen undergoing binary fission. The detailed study of the development of young bud polyps has not been carried out, as the species is unsuited for the purpose. It has been established, however, that the manner of appearance of the tentacles, mesenteries, and septa agrees closely with that of larval polyps to be described later.

In what seem to be dead parts of a colony, new polyps may arise within the old calices. Outwardly these polyps are at first wholly separated from one another and from the other living tissues of the colony, and are usually transparent and colorless, due to an absence of Zooxanthellæ. Similar renewals of growth have been found in other corals, and give rise to the successive deposits of skeletal matter on dead, corroded surfaces, sometimes met with when masses of coral are broken across. The continuity of any one corallite is frequently maintained throughout the vertical extent of the mass, notwithstanding the corroded surfaces here and there.

The renewal of the polyps within old corroded calices of a coral is a subject for further investigation. So far as could be made out from external observation alone such polyps in Siderastrea are altogether independent of one another, and also unconnected with other living tissues of the colony. It may be that within the deepest parts of the old calices there still remained living remnants of the original polyps, and that from these new polyps were formed as buds; on reaching the same size as the original polyps the buds would fuse with one another by their peripheral borders and present a continuous covering of soft tissues. New skeletal deposits would cover over the old surface, and the presence of the latter would afterwards be determinable only on breaking the colony across.

Renewals of this character, by the production of independent buds, are to be distinguished from the growth at the living margin of colonies which is frequently seen encroaching over dead areas. The latter is of the same character as ordinary marginal gemmation from the parent stock, even though it extends over old corroded surfaces. Such new growth is very frequent in branching stocks of Acropora, but may occur in almost any colonial species.

The death of the polyps over any restricted area of a colony may be brought about by many causes, such as the colony becoming partly covered by or embedded in sand or mud, or by adherence or contact with other foreign bodies, or by exposure. Local death is very frequent in such large hemispheroidal colonies as those of Maandrina and Orbicella; the middle portion of the blocks may be dead and disintegrating while the sides are in 
full vigorous growth. In addition to this, the death of colonies as a whole, without any obvious environmental cause, is not infrequent. Stanley Gardiner has recently drawn attention to this subject. During his investigations on the coral reefs in the Maldives and Laccadives the impression was gathered "that practically all the colonies of a species in any one area died, or that there were only the isolated deaths of individual large colonies," apparently without environmental cause. Gardiner is impelled to believe that "The ripening of the generative organs of a large number of polyp colonies of the same species in a single locality or habitat, followed by the subsequent death of all these colonies, is a regular phenomenon."

In the course of my experience in the coral regions of the West Indies I have met with no instance of the regional death of all the colonies of any species, but frequently individual stocks have been encountered of which all the polyps seemed to be in a state of maceration. This was particularly the case with Porites astraoides. Isolated colonies were obtained seemingly alive and normal in color, but upon examination with a lens no distinct polyps or tentacles were recognizable. The whole of the soft tissues seemed to be a gelatinous mass in process of decay, the coloration being due to the persistence of the yellow pigment cells characteristic of this species. Such colonies were under exactly similar conditions to others living around them, and without further investigation any suggestion as to the cause of death of the polyps can be only the merest conjecture.

My own experience leads me to suppose that coral polyps do not die after the ripening of the generative products, but that, from the same individual, one series of larvæ may follow another, for in numerous instances (Favia, Porites) in which polyps charged with larva, all at the same stage of development, have been examined, there were still many nearly ripe ova within the mesenteries, as if preparing to give rise to another batch of larvæ.

Sexual reproduction in Siderastrea takes place by the formation of planulæ from fertilized ova. The planulæ undergo partial development, as far as the appearance of the first four pairs of mesenteries, while within the body-cavity of the parent, and are then expelled. After swimming freely for a shorter or longer time they settle and give rise to young polyps. Larvæ were extruded toward the end of June and during July.

\section{EXTERNAL CHARACTERS ON DECALCIFICATION.}

Certain of the external features of the polyps can be studied only after the latter have been freed from the skeletal matrix. The corallum of Siderastrea is very dense, and the process of decalcification requires several days. 
At the close of the process a delicate mass of algal filaments remains in the spaces previously occupied by the corallum, but is readily removed. The exposed polypal wall then reveals a smooth surface, very complicated in form, but everywhere continuous.

After removal of the skeleton the individual polyps are seen to be wholly free from one another, except at the surface of the colony. No other connection or communication between one polyp and another exists. Each polyp appears as if made up of a deeply lamellated column, attached above to a flattened layer which represents the column wall and disc. A middle tubular space, formerly occupied by the columella, extends for some distance upwards, when it terminates blindly. The lamellæ represent the tissues which occupied the interseptal spaces. They are now wholly free from one another below, but in the upper region are united centrally. They are easily torn apart along their central and upper lines of attachment. One of the separated lamellæ, slightly enlarged, is represented on plate 6 , fig. 33 .

The whole of the external wall liberated by decalcification is the morphological base of the polyp. Though columnar in form it in no way corresponds with the column of the skeletonless Actiniaria, but represents the flattened basal disc which, everywhere continuous, has become much infolded and subdivided in correspondence with the upward growth of the septa and columella. Thus the column of a decalcified retracted polyp is really the vertically elongated, much subdivided basal disc. The true column wall, corresponding with that of an actinian, is here represented by the narrow periphery of the flattened or concave superficial disc which constitutes the upper end of the polyp. To understand the form ultimately assumed by the originally flat basal disc, the arrangement of the septa and columella in the individual corallite must be borne in mind, as every part of these is covered by the basal wall. An early stage in the basal complexity is represented in the section of the young polyp on plate 9 , fig. 53 .

The upper part of the liberated tissues appears delicate and somewhat clear and transparent, but as the aboral termination is approached the walls become denser and more opaque white. Such an alteration in the external character of the embedded tissues is met with in nearly all corals, and is usually more marked than in Siderastrea. It is found to be associated with a corresponding thickening and histological modification of the endodermal layer (p. 32).

The polyps when set free are subpolygonal in outline, and, as already mentioned, are wholly distinct from one another, except at their uppermost 
termination, where they are all in communication and joined along the polygonal boundary lines of the column wall and skeletogenic tissues immediately below. An interval of only about I $\mathrm{mm}$. separates laterally the columns of contiguous polyps. The leugth of the polyps liberated from the skeleton varies somewhat, but whatever the thickness of the corallum the polypal tissues are always superficial, never extending downward for more than about $5 \mathrm{~mm}$. The largest polyps vary from $4 \mathrm{~mm}$. to $5 \mathrm{~mm}$. in length after decalcification, while young buds extend much less within the corallum. The diameter also varies from $3 \mathrm{~mm}$. to $5 \mathrm{~mm}$, and in mature polyps is practically the same throughout the column. The soft tissues of young buds, before any columella has appeared, are more obconical, that is, longer centrally and shortening as they pass to the periphery. Mature polyps are more cylindrical and terminate somewhat abruptly, all the lamellæ being of practically the same vertical length. Owing to the presence of synapticula, the actual base of the individual lamellæ is not always as regular or even as in corals resting upon a smooth dissepiment; the lower surface of a lamella may, in fact, be partly folded round a synapticular bar, as in plate 6 , fig. 33 .

The individual interseptal lamellæ, like the septa themselves, belong to different cycles and are of different radial lengths. Some are simple, while others are subdivided peripherally into two or three parts. For the greater part of their vertical length, that is, as far as the columella extends, the lamellæ are free, either singly or in groups of two or three, but towards the upper extremity they are all joined to one another along their inner margins (plate 6, fig. 34).

Any simple lamella when seen in surface view appears as a flat, subrectangular plate, nearly of the same thickness throughout, and corresponding, of course, with an interseptal space (plate 6, fig. 33). It is perforated by rows of circular or oval apertures, arranged roughly in one to four vertical series, the number varying with the cycle to which the lamella belongs. In lamellæ extending all the way from the periphery to the columella three or four rows occur, while in narrower lamellæ only one or two rows are present. The perforations represent the spaces occupied by the calcareous synapticula which stretch across the interval from one septum to an adjacent septum. Numerous granulations occur on the septal walls (plate ro, fig. 63), but only the large more peripheral ones bridge the interspace between two adjacent septa, and, in doing so, necessarily perforate the soft tissues lining the septal walls and the mesenteries contained within. The smaller granulations merely cause indentations in the lining tissues.

Transverse sections through the lamellæ show that they consist of the 
two lateral walls which line the adjacent faces of two contiguous septa, and inclose between them a narrow chamber, broken up by the synapticular perforations in such a manner as to present a complex canal-like condition (plate 6, fig. 34, and plate 7 , figs. 38,39 ). The chambers represent the interseptal loculi less the thickness of the lining wall, but will, however, be spoken of as interseptal spaces. The upper half of each contains a single mesentery, but below they are empty. Moreover, only at the uppermost extremity of the polyp is the mesentery found to extend outwardly as far as the peripheral boundary. In the upper region of the polyp the inner border of each lamella is open so that the chamber, along with all the others, communicates with the central cavity of the polyp, while below all the chambers are closed centrally, or are only in communication toward their centripetal edges (plate 7 , figs. $38,39)$. Where the chambers are wholly cut off from one another the calcareous septa extend throughout the radial length of the polyp, and are centrally united with others or with the columella (plate 7 , fig. 39); when the chambers are only partly separated, communicating towards the center, then the septa between them do not extend as far as the middle of the calice.

\section{ANATOMY AND HISTOLOGY.}

COLUMN WALL AND DISC.

In radial sections of retracted polyps the column wall and disc appear as a continuous layer, and, histologically, the two are nearly alike throughout. The wall as a whole is very thin, except where the knob of a tentacle is included, when the ectoderm becomes thickened (plate 7, fig. 40 , and plate 9, fig. 53); to a less degree the layer is also thickened along the line of attachment of the mesenteries. In sections the three cœlenterate layers, ectoderm, mesoglœa, and endoderm, together, measure only about 0.07 mm. in thickness.

The chief constituents of the ectoderm of the column wall are supporting cells and clear mucous gland cells, while small nematocysts occur somewhat sparsely. The unicellular gland cells are most conspicuous toward the periphery of the layer, where they appear oval, with clear or vesicular contents. The nuclei of the various cells are oval, and arranged as a whole within the inner half of the ectoderm, a few, more circular in form, being found near the mesoglœa. There is no trace of any ectodermal musculature on the column, but a system of weak fibrils is developed over the disc, their direction being radial. No evidence of external ciliation can be detected even in the best preserved examples.

The mesoglœa in the column, as elsewhere throughout the polyp, is 
feebly developed. In the column and disc it appears only as a thin dividing lamella between the ectoderm and endoderm, but in the mesenteries it becomes a little broader. It is homogeneous in structure, except for the presence of minute connective-tissue cells. The mesoglœa of corals generally appears perfectly homogeneous, but in several West Indian species the layer is found to contain migrant connective-tissue cells, such as occur in the larger actinians.

The endoderm of the column and disc is a little broader than the ectoderm, and its cells contain numerous Zooxanthellæ, which are altogether absent from the latter. The endodermal cells are much vacuolated, and distinct cell outlines can be made out. The commensal algæ are more numerous in some regions of the endoderm than in others, though there seems to be no regularity in their distribution. Where they are absent, or nearly so, the endoderm is somewhat thinner, its cells are less vacuolated, and the layer as a whole stains more intensely, the nuclei forming a more regular band.

A delicate circular muscle layer can be discerned over the inner face of the mesoglœa of the column and disc, but no concentration, such as can be regarded as constituting a sphincter muscle, occurs at any region of the column. When studying the living characters it was found that the polyps are unable to fold the column over the disc, hence the presence of a special circular or sphincter muscle, as met with in most anemones and some few corals, would be scarcely expected.

In sections which have been passed through Delafield's hæmatoxylin the deeper part of the endodermal layer throughout the polyp, but particularly the epithelial lining of the mesenteries, contains some substance which stains intensely, and has a very irregular distribution. The appearance, as seen in sections of mesenteries, is represented on plate 8 , fig. 50 , and in the lining of an interseptal loculus on plate 8, fig. 47. Small, irregular, deeply staining patches lie next the mesoglœa on both sides, and prolongations extend for varying distances among the endodermal cells, occasionally reaching almost to the surface. In tangential or oblique sections through the endoderm an appearance of somewhat irregular longitudinal canals is presented. The substance stains and behaves altogether in the same manner as the contents of the mucous cells. No evidence of structure is presented, nor is there any cellular character suggested. I conceive that the appearance is due to intercellular spaces filled in the living condition with mucus or some similar substance, capable of staining strongly in hæmatoxylin; perhaps a hint of the lymphatic spaces of the higher animals.

This is the first time that such a system of apparently intercellular 
spaces has been observed in the Zoantharia. Its appearance in sections of Siderastrea stained in hæmatoxylin is very characteristic, and its presence should be looked for in other forms.

\section{TENTACLES.}

When the polyps are preserved in the retracted condition, with the tentacles sessile, the columnar and discal walls come to lie upon the skeletotrophic layer of the septal edges, and the two knobs of the bifurcated tentacles are far apart, one on each side of a septal ridge (plate 7 , fig. 40), while the knob of the simple tentacles lies immediately over the septum with which it corresponds. In this condition the stem of the tentacle has altogether disappeared as such, having become part of the disc. As a result the tentacles are recognizable in vertical sections of polyps as mere hemispheroidal thickenings of the ectoderm. In the case of the entocœlic tentacles a thickening occurs on each side of a septal elevation of the disc, while a single elevation directly over the apex of the septum represents an exotentacle. In the thickenings long nematocysts extend nearly across the ectoderm, and smaller ones crowd the periphery. The two forms of nematocysts are represented on plate 7 , fig. 44. Histologically the portion of the wall joining the two tentacular knobs on plate 7 , fig. 40, and representing the stem of the tentacle, differs in no way from that of the disc.

In sections of polyps preserved with the tentacles extended the organs appear as tubular outgrowths of the disc, terminated by knoblike enlargements. The stem seems to differ in no respect histologically from the disc, not even in the greater number of nematocysts; the apex alone constitutes a battery of stinging cells. The cut ends of a delicate ectodermal nuscle layer can be distinguished in transverse sections of the stems, and a feeble circular endodermal layer in longitudinal sections. The tentacular musculature is continuous with that of the disc, and a very definite nerve layer occuirs at the apex of the tentacles (plate 8, fig. 49).

\section{STOMODEUM.}

The stomodæum is a short, thin-walled, depending tube, strongly ciliated all round, and without any permanent ridges or grooves. Usually it is oval in transverse section, and along its endodermal surface six pairs of mesenteries are attached at equal distances apart. Histologically it is of the same structure all the way round, there being no modification opposite the directive mesenteries such as can be regarded as a siphonoglyph or gonidial groove. This is also the case in all madreporarian polyps yet described. 
The absence of a siphonoglyph in Madreporaria affords an interesting contrast with the one or two grooves usually present in actinian and alcyonarian polyps. A siphonoglyph is generally wanting only in the lowest actinians and in alcyonarians, and its absence in coral polyps would suggest their more primitive nature. This is further borne out by the absence of ciliated bands or Flimmerstreifen from the mesenterial filaments (p. 29).

The stomodæal ectoderm is thicker than that of the disc, and differs much from it in structure. Large nematocysts are distributed throughout, but the main constituents are long, narrow, ciliated supporting cells, the nuclei of which are arranged in a broad zone. The ciliation, which is uniform all round, generally persists in preserved material. Clear mucous gland cells are not numerous, while here and there a granular gland cell stands out very prominently by reason of the deeply staining character of its contents. A distinct nerve layer is recognizable next the mesoglœa, but no muscular fibrils can be detected. The endoderm is similar to that lining the upper part of the polypal cavity.

At its lower opening into the polypal cavity the ectoderm of the stomodæum is reflected up the inner or endodermal surface, and then extends horizontally for a short distance along the free edge and each face of the perfect mesenteries, becoming continuous with their mesenterial filaments.

\section{MESENTERIES.}

The number and arrangement of the mesenteries in mature polyps are as follows: (a) Six pairs are united with the stomodæum, including two pairs of directives attached at the opposite extremities; $(b)$ an alternating cycle of six pairs, the members of which are free from the stomodæum throughout their length; $(c)$ a variable number of third-cycle mesenteries, alternating with the two previous cycles, but very rarely, if ever, with the whole cycle of twelve pairs developed (plate 6, fig. 34). Thus two cycles of mesenteries are always developed, and a variable number belonging to a third cycle. They may be represented by the formula $6,6, \mathrm{x}$, where $\mathrm{x}$ represents any number from $I$ to $I 2$.

Within each intermesenterial space, whether an entocœle or an exocœle, an invagination of the polypal wall occurs which separates adjacent mesenteries from one another. Except in the uppermost region these septal invaginations extend centrally further than the mesenteries, while in the lower parts of the polyp they extend so far as to meet in the middle and fuse, dividing the gastro-cœlomic cavity into distinct chambers, each of which contains a mesentery (plate 7 , figs. 38,39 ). 
The mesenteries extend from above downward for about two-thirds of the total length of the polyp, the younger outer pairs terminating in advance of the older inner pairs. Below they become very short transversely, and are only slightly folded at their free extremity. Except in the uppermost region of the polyp, their peripheral portion is everywhere perforated by the synapticular bars. Further, they are. connected outwardly with the wall of the polyp only in the upper part of their course; the connection breaks down below, and the organs are seen in transverse sections with both their inner and outer ends free. Thus at an early stage the peripheral portion of the mesentery undergoes degeneration or resorption much in advance of the more central part. The mesenteries, in fact, occupy only the middle and upper part of the gastro-vascular cavity; the proximal and peripheral regions are practically destitute of them.

The mesenterial mesoglœa is usually narrow, but there is much variation in the different polyps as to its thickness and hence that of the mesentery as a whole. In the upper region the mesoglœa presents vertical folds for the support of the retractor muscles (plate 7, fig. 4I). Generally the foldings are diffuse and somewhat complicated, and extend along the entire face of the mesentery; in other cases they are stronger and more restricted to the middle area. The oblique musculature is very weak throughout, but occasionally the fibrils can be seen cut obliquely in transverse sections. As would be expected, no basilar or parieto-basilar muscles occur. The mesenterial endoderm is everywhere richly supplied with Zooxanthellæ, and also with clear gland cells and others containing large granules. As described in connection with the endoderm of the column wall and disc (p. 22), what seems to be an intercellular system of mucous spaces occurs in the deeper parts of the epithelium on both mesenterial face.

The arrangement of the mesenteries may be studied in more detail. As represented on plate 6 , fig. 34 , and also in the diagrammatic figure on page 26 , the number of pairs within each of the six primary systems or sextants varies from one to three. The members of a pair can be easily distinguished by their similarity of size and by the retractor muscles being on the faces turned towards each other. In each of the two ventral systems only one pair of mesenteries (II) is developed, while in the middle and dorsal systems two pairs (II, III) are present, with the exception of the right middle system, which contains three pairs. Where only one pair occurs, it represents one of the six pairs of first-cycle metacnemes (II), and this cycle is complete in all the mature polyps examined. Where two pairs are present, one pair (III) is shorter than the other and is a member of the third cycle. It will be observed that 
in each sextant the third-cycle pair (III) is situated on the dorsal aspect of the second-cycle pair (II). In the right middle sextant, where two pairs of third-cycle mesenteries occur, a pair is present on both the dorsal and ventral aspects of the longer pair. It is shown later that the mesenteries of the first and second cycles are developed in a very definite sequence, and such would probably be the case for the members of the third cycle were the polyps isolated and free to develop normally all around. The individual polyps in a colonial coral like Siderastrea, however, are so closely arranged

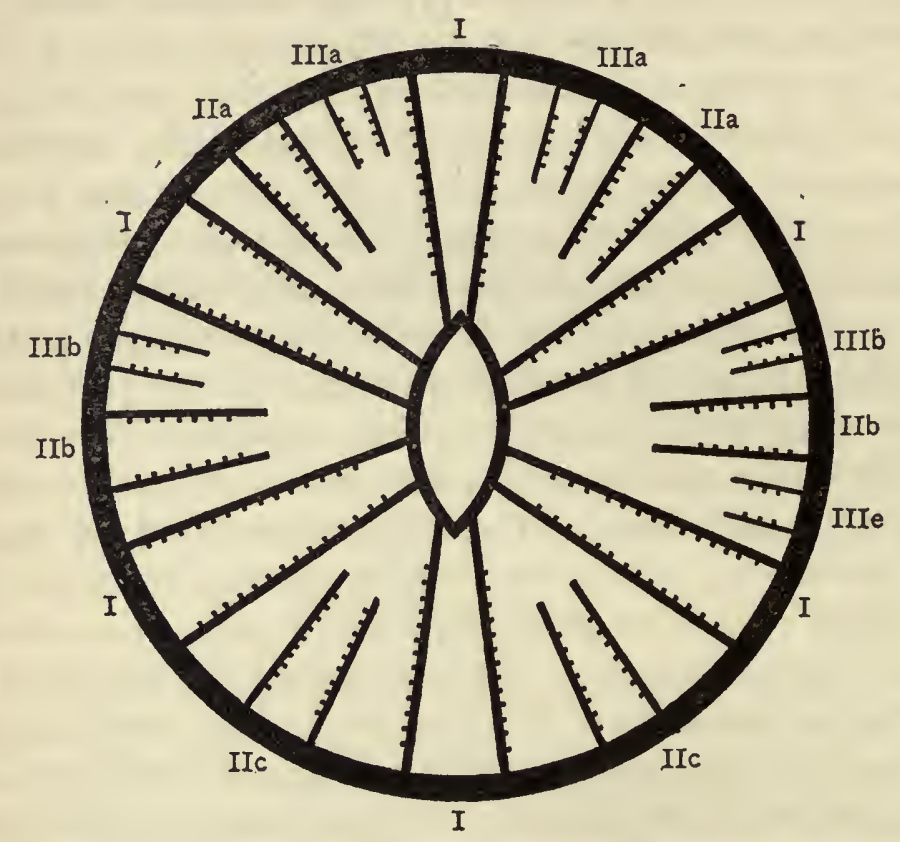

FIG. 3.-Diagram of mesenteries of fig. 34 , plate 6 (ff. figs. $x$ and 2, pp. 12,13 ).

that their growth after the first two cycles becomes largely influenced by spatial necessities. Hence, in the particular polyp from which plate 6, fig. 34 , is taken, one region, the right middle sextant, has progressed farther than the others. Throughout the studies little constancy has been found in the order of development of the members of the third cycle. The amount of variability in the number and disposition of the mesenterial pairs is repeated in the septa (p. 48). In no two polyps, among a dozen or so studied in transverse sections, was the mesenterial plan the same for the third cycle; also, in none was the full complement of twelve pairs present. The normal sequence of the mesenteries is more fully described in connection with the development of the polyp. 
The radial length of the mesenteries varies greatly in passing transverse sections in review from the oral to the aboral extremity of a polyp. ' In an expanded polyp the complete mesenteries extend from the column wall, then across the disc, and finally unite with the stomodæum, down which they pass ; the members of the incomplete cycles, on the other hand, stretch from the column wall only partly across the disc, and terminate at a greater or less distance from the middle of the polyp. When the level of the corallum is reached, all the mesenteries begin to lose their peripheral connection with the polypal wall, and in transverse sections hang freely, unconnected either peripherally or centrally, except where pierced by a synapticulum. Even at the level of the stomodæum in partly retracted polyps the mesenteries are greatly shortened transversely, so that the peripheral parts of the septal loculi are empty (plate 6, fig. 34). Where the loculi are interrupted transversely by a synapticulum, a mesentery will sometimes stretch from an inner chamber of the loculus to the next chamber, but in no instance, as shown on plate 6 , fig. 34 , is one found to extend right to the periphery of an interseptal loculus. Instead of this, most of the peripheral chambers are empty, the mesenteries having become resorbed. The organs have a much less radial or peripheral extent on plate 7 , fig. 38 , resorption having been continued further than at the level represented by plate 6, fig. 34 . Mesenteries are wholly absent on plate 7 , fig. 39 , except in one or two isolated instances. The stages prove conclusively that the mesenteries extend but a very short vertical distance within the region of the synapticula, but are longer centrally. The same fact is also well shown on plate 6 , fig. 36 , representing the upper part of a tangential section of a polyp.

The descriptions given by Bourne $(1887$, I 893 ) of the anatomy of the synapticulate coral Fungra indicate similar degeneration phenomena of the mesenteries within the region of the synapticula in this genus. At first both the primary and secondary mesenteries extend to the very base of the corallum, but afterwards they are confined to the upper moiety of the calice, though in Fungia no dissepiments are formed which cut off the polyp from the basal plate. Bourne's figs. IO, I3, and I 5 in his first paper show that the mesenteries very rarely extend along the interseptal loculi all the way from one synapticular perforation to another, but in practically all the canals long or short remnants of the mesenteries are adherent to the synapticular wall, and serve for the attachment of separate bundles of the longitudinal muscles. In these cases the middle part of the mesentery within each chamber has been resorbed, leaving only its two extremities. In Siderastrea there is nothing corresponding to the mesenterial muscle bundles in 
the synapticular region which Bourne describes for Fungia and Fowler (1888, p. 9) for Stephanophyllia Jormosissima; muscular degeneration proceeds along with that of the mesentery in the West Indian form.

The actual process of resorption of the mesenteries, from the periphery inwards, can be readily traced. It commences in the peripheral region of the polyp even as high as the level of the retracted stomodrum. The part of the mesentery undergoing degeneration narrows and breaks up into separate fragments; the mesoglœa is often very thin for some distance, and the muscular fibrils lining it form only an irregular, discontinuous layer. Generally the portion of the mesentery some little distance from the peripherally fixed part is the first to pass away, thus leaving an interval in the actual continuity of the organ. The endoderm may disappear first, and the naked mesogloea then extends a little beyond and thins out (plate 7 , fig. 43), but usually the epithelium persists the longest. Free fragments of the degenerating tissue are often found in the interseptal chambers, and other fragments are occasionally seen absorbed by the endoderm lining the chamber.

Mesenterial resorption must of course take place proximally in all corals which continue to grow upwards as the lower part of the polyp is cut off below by dissepiments. But in Siderastrea the peripheral parts begin to disappear first, and the disappearance as a whole extends upwards proportionally much further than in most corals. Perhaps this is in some way connected with the presence of the synapticula in the peripheral region. In other coral polyps the lower edge of the mesentery appears to be resorbed more uniformly.

The mesenteries are too small and too completely inclosed within the interseptal chambers to permit of their being dissected out and examined as a whole, but by means of serial sections it can easily be seen that the synapticula actually perforate the mesenteries. In the first place, the complete loculus shown on plate 6 , fig. 33 , reveals that the synapticula really perforate the walls, and necessarily anything inclosed within the two lining walls in the same areas. Then certain of the synapticular perforations included in plate 6, fig. 34, show that a mesentery is continued from each wall bounding the perforation, passing centrally on the one hand and peripherally on the other. On following such a mesentery both upward and downward in serial sections it is found that when the synapticular perforation disappears, having been followed through its vertical extent, the two moities of the mesentery again become continuous. Clearly such conditions can result only from the presence of actual fenestræ in the mesentery. Similar relationships can be also followed in the series of sections represented on plate 9. 
Owing to the early disappearance of the mesenteries aborally and peripherally the organs are, at any one time, necessarily perforated for a very restricted part of their course. Furthermore, as a result of the presence of these synapticular bars, any mesentery must be capable of less retraction than in species where the whole length of the organ is free to respond to the action of the retractor muscle.

Desmocytes, continuous with the mesoglœa of the lining of the interseptal chambers and the attached mesentery, are usually numerous around the perforations of the synapticula (plate 7 , fig. 4I, and plate 8, fig. 45).

\section{MESENTERIAL FILAMENTS.}

Filaments occur on the mesenteries of all three cycles, though usually they are imperfectly developed on the members of the third. On the incomplete mesenteries the organs commence a short distance above the lower end of the stomodæum, and are continued throughout the vertical extent of the mesentery ; on the complete mesenteries they start from the lower termination of the stomodæum, the ectoderm of the latter being continuous with the filament. As in all Madreporaria yet described the filaments consist of only a median lobe, supported basally on an expanded mesoglœal axis (plate 7 , fig. 42). Trilobed mesenterial filaments having lateral lobes supported on a mesoglœal axis and bearing ciliated bands (Flimmerstreifen), like those found in most Actiniaria, are not known to occur in corals.

The fully developed filaments of $S$. radians are sharply separated from the mesenterial endoderm by a well marked constriction on each side. The endoderm is usually slightly swollen immediately behind the filament, but rarely assumes the form of a definite lobe as in many other coral species. In addition, the outline of the filament in section varies somewhat in the case of the first-cycle mesenteries. At first it is cordate, and, histologically, is quite uniform all round; but soon it becomes nearly circular, and the cellular constituents of the middle part differ from those of the lateral ( $c f$. plate 7 , figs. 42, 43).

The cellular constituents of the filaments are mostly ciliated supporting cells, but with these are mingled large, clear, and granular gland cells and nematocyst bearing cells, especially in the middle region of the sections. Towards the sides and posterior borders the cells diminish in height and are nearly all supporting cells (plate 7 , fig. 42). At least two kinds of nematocysts occur-a long, narrow, thick-walled form, similar to that in the tentacular knobs, and a large, oval, thin-walled form, with the spiral thread strongly marked (plate 7 , fig. 44). 
The free end of the mesenteries and, consequently, the filaments also are somewhat exceptional among corals in the small degree to which they are convoluted in the lower regions. In most cases they pass vertically in a straight course from their upper to their lower extremities without any folding. Upon irritation the living polyps of most corals are able to extrude, through temporary apertures in the body-wall, masses of contorted filaments along with the portion of the mesentery to which they are attached, but this phenomenon has been observed on only one occasion in Siderastrea.

The question of the ectodermal or endodermal origin of the filaments is alluded to in the description of the larva.

\section{SKELETOTROPHIC TISSUES.}

The skeletotrophic or skeletogenic tissues constitute by far the greatest proportion of the soft parts of the polyps, including as they do the lining of the calicinal wall, septa, and columella throughout. They represent the original flat basal disc of the polyp, which has become greatly infolded in correspondence with the skeletal ingrowths. Both the endoderm and ectoderm present certain structural peculiarities compared with the same layers in the column wall and disc, and in some respects the calicoblast layer of $S$. radians differs from that in most other corals.

The polypal wall lining the uppermost parts of the skeleton is extremely delicate, especially over the edges of the septa. In sections the combined ectoderm and endoderm vary from 0.015 to $0.003 \mathrm{~mm}$. in thickness, both layers being about equal (plate 8 , fig. 47 ). The endoderm is a syncytium showing no signs of cellular divisions, and the cytoplasm has at first few or no vacuoles, though below they become somewhat numerous. The contained nuclei are large, round or oval, and closely arranged in a very regular row. Zooxanthellæ also occur, their diameter being often equal to the thickness of the layer. Irregular mucous spaces, similar to those described in the endoderm (p. 22), are also seen, except where the layer is at its thinnest.

The mesoglœa, both here and elsewhere throughout the skeletogenic tissues, is rarely distinguishable as a distinct layer, but constitutes a mere line of division between the ectoderm and endoderm. Where the mesoglœa of the mesenteries is united with the skeletal covering the calicoblast ectoderm is nearly absent, and the mesoglœa may then become swollen and continued into the well-known structures which have been termed desmocytes by Bourne (1899). The combined mesenterial and skeletotrophic mesoglœa here broadens in a fan-like manner, is striated, and stains more deeply than usual (plate 8, fig. 45). Sometimes the desmocytes appear as more distinct 
triangular or wedge-shaped structures, with the narrow apex towards the mesoglœa.

The function of the desmocytes or desmoidal processes, so closely associated with the mesoglœa, is considered to be that of attaching the soft polypal tissues to the hard corallum, and they are always most numerous along the line of union of the mesenteries with the basal wall. As the mesenteries in Siderastrea are attached to the skeletogenic tissues only in the uppermost part of the polyp, desmocytes are developed somewhat sparingly; furthermore, they are rarely found over regions where the mesenteries are not attached. In such areas a broad calicoblast layer usually intervenes between the mesoglœa and the skeleton. Where the skeletogenic tissues, including the mesenteries, are perforated by the synapticula, desmocytes are usually present along the line of attachment of the mesentery.

Bourne (I899) has worked out in a very masterly manner the origin of the desmoidal processes from the single calicoblast cells. These cells, which are strictly the desmocytes, later become connected with the mesoglœa, and the structure takes on a feebly striated character. Although a careful search has been made in sections of Siderastrea prepared in various ways, I have found no certain stages in the formation of the desmoidal processes. Cells of various forms occur within the calicoblast layer in regions where desmoidal processes are already present, or may be expected, but none which could be determined with certainty as desmocytes. Anyone familiar with the details of madreporarian histology will appreciate the credit due to Bourne for working out the development of these structures with such a degree of completeness. In their fully formed condition they are undoubtedly continuations of the mesoglœa, and it is remarkable that they should have originated independently and later come into fusion with the middle layer. Gardiner states (1902, p. I38) that in the polyps of Flabellum rubrum the first appearance of any desmocyte could be seen in a granular mass of protoplasm against the corallum, to which, from the first, it seemed to be attached. Subsequently, by growth inwards, it joins the structureless lamella, which may be thickened so as to meet it.

The actual calicoblast layer of $S$. radians, like the endoderm, is at first very narrow, and in the growing areas of the skeleton shows no evidence of cell limitations. The cytoplasm appears continuous, non-granular, and with or without mucous spaces, the whole staining a bright yellow in picric acid. The nuclei are nearly as numerous as in the endoderm, and are large and finely granular. The margin towards the skeleton is usually irregular in 
outline, often with many adhering particles which stain differently from the layer itself (plate 8, fig. 47).

Away from the actual growing apices of the skeleton, both downward and peripherally, the skeleton-lining tisșues at once begin to undergo a marked alteration; both ectoderm and endoderm become greatly thickened until they are three or four times their former size (plate 8, figs. 45-48). The thickened endoderm is reticular, with many oval nuclei arranged in a regular zone towards the margin; Zooxanthellæ are also numerous, and distinct mucous accumulations appear.

Vacuoles extend nearly across the layer, and usually appear clear and perfectly transparent, but when stained with iron hæmatoxylin they present a grayish reticulum. They are evidently mucous in character, and would seem to represent individual cells. In sections stained with Delafield's hæmatoxylin and picric acid the vacuolar spaces stand out conspicuously, the boundaries and reticulum being stained a dense blue, as with mucous cells generally, and appearing as if enclosed in a yellow granular matrix. Usually the mucous spaces do not extend as far as the outer margin of the layer, and not always to the mesogloeal boundary.

The general cytoplasm of the calicoblast ectoderm is finely granular throughout and does not stain readily except in blue-de-Lyon, which colors the particles a bright blue. The nuclei are comparatively small and less numerous than in the upper part of the layer, or in the endoderm. In addition to the granular, matrix-like cytoplasm, cells with coarse granules occur here and there which stain differently from the other granules and appear to be altogether distinct structural elements. In sections stained with carmine and blue-de-Lyon they stand out a conspicuous red against the ordinary blue granules. They rarely if ever extend wholly across the layer and seem comparable with the other coarsely granular cells found elsewhere throughout the ectoderm and in the mesenterial filaments.

Scattered throughout the calicoblast ectoderm are also a few small oval nematocysts with a close spiral thread. Sometimes several may occur together, but usually they are found singly. Different stages in their development also can be observed. In the earlier stages they are large, with homogeneous contents, and stain rather deeply, whereas when mature they stain feebly, if at all.

The presence of nematocysts within the calicoblast layer, where apparently they can be of no service to the polyp, is somewhat remarkable. It is to be borne in mind, however, that the calicoblast layer is but a modified part of the ectoderm which, over the column wall and oral disc, always bears 
stinging cells; and further, the cysts are usually present in numbers at the aboral extremity of the larva which becomes the basal disc when the larva settles. So far as can be made out from sections, without isolation by maceration, the nematocysts in the calicoblast layer are similar to those in the ectoderm of the column wall. Bourne (1899), in his studies of the calicoblast layer of the Madreporaria, also encountered oval bodies which suggested to him degenerate nematocysts. The close spiral thread found in those of Siderastrea, and their general behavior at different stages towards reagents, leave no doubt as to their true nature.

The structure of the calicoblast ectoderm, as above given, differs somewhat from that usually met with in corals. As described in the papers of Bourne, Fowler, and Gardiner, the layer is thickest in the regions of active growth, and becomes very thin or nearly disappears elsewhere. Such is also its condition in most of the species of corals examined by me (I902, p. 482). It may appear either as a columnar epithelium (Madrepora) or have the character of a syncytium. A well-developed cellular tissue, with abundant protoplasm, would be expected where active formation of the skeleton is in progress. Here, in Siderastrea, the layer is thickest in those regions where the secretory activity would be considered to be at a minimum. The granular character of the cytoplasm, the small size of its nuclei, and the strong vacuolization would not, however, suggest that the deposition of skeletal matter was actively proceeding in the lower regions, as compared with the large nuclei and more hyaline cytoplasm along the edges of the septa.

It seems doubtful as to how far the thinness of the endoderm in the upper region is to be associated with a similar condition of the calicoblast endoderm. Over the spines of the columella, which are situated in the lower regions of the polypal cavity, and are probably in a growing state, the two layers present a great difference in this respect. The ectoderm is as thin as in the uppermost growing parts of the polyp, while the endoderm is greatly thickened, measuring as much as $0.05 \mathrm{~mm}$. across, which is nearly equal to the combined thicknesses of both ectoderm and endoderm in the lower regions.

None of the writers on the anatomy of coral polyps have referred to the marked alteration undergone by the skeletotrophic endoderm in passing from the upper to the lower parts of the polyp. It is, however, characteristic of practically all West Indian corals, the contrast being usually greater than that shown by Siderastrea.

In his study of the minute anatomy of the polyps of Flabellum rubrum, Gardiner (I9O2) found the calicoblastic ectoderm to be in many respects like that of $S$ radians. The layer is everywhere complete and persistent, 
even in the most roughly decalcified specimens, and no definite cell limitations could be distinguished; but over the greater part of the corallum it is an extremely thin, finely granular layer, and as the edges of the septa are approached the layer thickens, nuclei become more frequent, and tend to exhibit a definite network. Where secretion may be supposed to be going on most actively the layer is more hyaline, elsewhere it is granular. The protoplasm is much vacuolated, as in Siderastrea, except where secretory activity prevails.

Where decalcification has been carefully carried out, a layer of the organic matrix within which the skeleton is deposited usually remains behind, and is closely adherent to the calicoblast layer, as shown at the left side of plate 8 , fig. 45 . The matrix usually appears perfectly homogeneous, very variable in width, and recalls the mesoglœa in its behavior towards stains. Bourne (I899) found such a layer in many of the forms examined by him, and regards it as a fine membrane-" limiting membrane"-separating the calicoblasts from the corallum, and comparable with the sheath which incloses the spicules of the Alcyonaria. It is evidently a secretion of the ectodermal layer, and at the apical points of rapidly growing corals, such as Madrepora, I have found the deposit to be continuous throughout the whole thickness of the corallum, and presenting just beyond its border the fibrous scale-like appearance of the early skeleton (I902, p. 484). It is manifest that the mass should be regarded as a homogeneous, mesoglœa-like matrix within which the minute calcareous crystals forming the skeleton are laid down, to be compared with the matrix which Bourne has demonstrated for the skeletal spicules of Alcyonaria. As a continuous structure it early disappears, and in the older parts of the skeleton is represented merely by the fine organic particles remaining after decalcification. Only under the most favorable circumstances is it present as a continuous mass in sections of the newest formed parts. Usually all that remains of it after decalcification is the delicate membrane bordering the calicoblast layer on its skeletal aspect. When of sufficient thickness to have contained skeletal fibers, now dissolved away, this membrane appears fibrous, but immediately bordering the calicoblast layer it is homogeneous.

SEPTAL INVAGINATIONS, INTERSEPTAL LOCULI, AND GASTRO-CELOMIC CAVITY.

The septal invaginations (refoulements septaux of Delage \& Hérouard) are the vertical, somewhat wedge-shaped infoldings or upgrowths of the basal wall which in the living condition cover both sides of the septa, and have been produced pari passu with them. Their presence results in 
much subdivision and complexity of the lower part of the polypal cavity, as compared with that of an actinian, where the basal disc retains its primitive flatness. In the coral polyp radial parts of the basal disc are pushed vertically upwards into the polypal cavity, concurrently with the deposition of calcareous matter, so that some portions of the aboral wall are of the height of the septa. The earliest stages in the formation of the basal infoldings over the septa are shown on plate 9, fig. 53. In the later processes of growth the lower edge of the column wall is also carried upwards to about the same height as the septal invagination, * hence it results that the basal wall is represented by so many vertical lamellar infoldings, the column wall and disc appearing as a mere superficial covering to these.

In transverse sections the invaginations are found to occur between every two mesenteries, that is, they are both entocœlic and exocœlic in position, the two series being equal in number, the exocœlic extending less centrally than the others (plate 6 , fig. 34 ). In the upper region of retracted polyps the invaginations do not extend as far centrally as the primary mesenteries, though in the stomodæal region they are continued beyond the secondary and tertiary mesenteries. As the lower regions are approached the foldings stretch centrally beyond all the mesenteries until, in the end, the walls of adjacent invaginations unite with one another and thus completely inclose each mesentery in a separate interseptal loculus, the skeletal deposit being also continuous from the periphery to the middle (plate 7 , fig. 39).

As shown in the various figures, the septal invaginations do not remain truly radial. At their inner extremities the exocœlic members turn laterally to unite with an entocœlic invagination, and the entocœlic of the third cycle are united with the entocœlic of the second. In this way continuity of the invaginated walls in transverse section is broken, and the skeletal matter within one invagination is likewise continuous with that in another. On plate 7 , fig. 39 , it is seen that some of the septa are continued radially as far as the central columella, while the others extend centrally only indirectly by fusing with the first. As a result of these many fusions the cyclic plan of

\footnotetext{
* In many corals, e. g., Cladocore, Manicina, the proximal margin of the column wall is lower than the upper edge of the septa, and the latter are generally united peripherally in the thecal wall; the septa have grown upwards into the polypal cavity, leaving the lower boundary of the column wall behind. The mesenteries still remain attached to the outer column wall, but internally they have been pushed upwards, as it were, along with the upward growth of the thecal wall. Owing to this, parts of the polypal cavity and mesenteries are peripheral or outside the calice (extracalicular or pericalicular) and the remainder is within the calice (intracalicular). The portion of the polyp outside and around the calice is what is known as the "edge-zone" or "Randplatte," but, as noticed on p. 9, there is no edgezone in Siderastrea, the polypal cavity and mesenteries being wholly intracalicular when the polyps are retracted.
} 
the invaginations is not readily established; in fact, it would be almost impossible to determine it without the assistance of the mesenteries. In addition, complications are produced by the fact that the invaginations are perforated by the synapticula, and thus, in sections, their walls appear discontinuous.

The gastro-cœlomic cavity in Siderastrea is very complicated in character compared with that of an actinian polyp, or, indeed, with that of many other corals. A double series of divisions, mesenterial and septal, are to be considered, except when the polyp is fully expanded and the column wall and disc are raised wholly beyond the corallum. In this latter condition the polypal cavity is merely divided into entocœlic and exocœlic chambers by the mesenteries, as in an ordinary actinian polyp. Each chamber is prolonged into a tentacle, but there has been found no lateral communication between one mesenterial chamber and another, such as frequently occurs in actinians by means of stomata.

The cœlomic cavities of the many polyps making up a colony are only partly independent of one another. At the periphery of each polyp apertures are found between the united edges of the contiguous column walls and the skeletotrophic tissues, but no apertures or canals elsewhere connect the different polyps. The communicating spaces are intermesenterial in position, the polyps being more or less cut off from one another mesenterially (plate 6, fig. 35). The spaces divide the superficial column wall from the basal disc. Hence in colonial polyps the column wall and base are nowhere in direct continuity with one another, except at the free part of the marginal polyps; elsewhere they are connected only indirectly by the mesenteries as these pass from column wall to basal disc.

When the level of the corallum is reached the polypal cavity is encroached upon radially by the septal invaginations, and divided peripherally into interseptal chambers or loculi, each of which contains a single mesentery. At first all the chambers communicate with one another toward the middle of the polyp, which is still free from any calcareous deposit (plate 7 , fig. 38 ). At the level of the columella the middle region of the polypal cavity is encroached upon, the septal invaginations extend from the periphery to the center, and the entire cavity is broken up into distinct loculi (plate 7 , fig. 39). These are continued as far as the aboral end of the polyp, where each loculus terminates blindly.

In addition, the interseptal spaces of Siderastrea, as of other fungids, are encroached upon concentrically by the synapticula which stretch across from septum to septum, and in sections give the discontinuous canal-like character to the polypal cavity seen towards the periphery of figs. 38 and 39 , on plate 7 . 
In many corals the endoderm in the lower regions becomes thickened to such a degree as to occupy the entire interseptal loculi, but in S. radians a narrow space remains as far as the aboral termination.

\section{GONADS.}

Among all the polyps which have been examined anatomically ova only have been found to occur. The polyps studied-were taken from colonies other than those which extruded larvæ. The gonads are situated below the stomodæal region, only one ripe ovum as a rule being present on each mesentery (plate 7, fig. 43). They occur about the middle of the transverse length of the mesentery, and are found on the members of both first and second orders. The ova are usually longer in diameter along the radial axis, and are indented where the septal granules have intruded upon the narrow interseptal chambers. Along with the single large egg may be two or three developing ova without yolk, but the conditions are not favorable for studying their origin from the ordinary endodermal epithelial cells.

The absence of male sexual elements from the examples studied can by no means be taken as indicating a diœcious character of the species. Wherever thus far in West Indian corals sexual differentiation is suggested the gonads have been found to be female, but where the ova are best developed spermaria have been found to accompany them; spermaria have never been found alone in any polyp. Hence there is much which suggests that coral polyps are protogynous. Mr. Stanley Gardiner, however, has recently discussed the subject of protandry in corals (Proc. Camb. Phil. Soc., XI, I902). From an investigation of a large number of developmental stages in Flabellum rubrum he has been able to show that in this form spermaria arise first on the mesenteries and that ova appear later, when the production of sperm acini ceases. "The ova grow enormously, with the final result that the mass becomes entirely female, consisting of usually 2 or 3 large ova, flattened on their sides against one another and occupying the whole area of the former testes." Protandry is thus clearly established in Flabellum rubrum. The claim for protogyny in the West Indian corals hitherto studied rests upon the fact that spermaria have never been found alone, but always in association with large numbers of ova; on the other hand, many polyps have been found with ova alone, often fẹ in number, as if sexual maturity were but beginning.

Were a general protandry to be assumed, we should have to suppose that all the polyps containing only ova had passed beyond their male period and extruded all their spermatozoa, becoming wholly female. Probably, as in other groups of animals and plants, no hard and fast rule is 
followed by the different species of corals; some will be protandrous while others will be protogynous.

It is clear from the evidence adduced that a diœcious character can not be assumed from the presence of only ova or spermaria until the entire developmental history of the species has been followed; a polyp having at one time only one kind of sexual cells may later show both kinds.

\section{CORALLUM.}

Freshly macerated coralla are generally white or yellowish in color, but frequently they are somewhat green, either as a whole or in patches. On breaking a green corallum across the coloration is found to extend some little distance below the surface, and, after decalcification, there remains behind a green mass of fluffy texture, which, on examination under the microscope, is found to consist of filamentous algæ. Even where the skeleton presents no superficial green coloration, a filamentous mass remains behind on decalcification, and chlorophyll may be present in small quantities, or the filaments may be dead and altogether devoid of protoplasmic contents. Under the microscope fragments of the skeleton frequently show fibers crossing the interseptal spaces or meandering over the surface, and sections of the corallum are sometimes perforated by similar filaments (plate II, fig. 66). Thus the algæ actually bore their way into the skeleton as well as spread over the surface. They are particularly abundant in decaying masses of coral.

The coral-boring algæ liberated by decalcification are represented by both a non-septate and a septate form, the filaments of both varying greatly in size. Associated with the algal filaments are clusters of a Leptothrix-like bacterium; but whether its threads actually perforate the skeletal matter, or merely grow over its surface, living upon the traces of organic matter, seems uncertain. In a former paper I have pointed out the almost universal presence of boring algæ in corals, and their importance in disintegration (Bull. Amer. Mus. Nat. Hist., XVI, I9O2).

In addition to the parasitic algæ, organisms such as cirripedes, molluscs, or tubiculous worms usually occur, either inclosed within the skeleton or adherent to its surface. These associated organisms are particularly numerous on specimens obtained from muddy shores as compared with those from the clearer waters of the reefs, and often interfere with the regularity of form of the corallites of the colony. The cavities resulting from the activity of the boring molluscs weaken the skeleton greatly, so that the colonies can be readily broken into fragments.

Numbers of the parasitic cirripede Pyrgoma sometimes occur, exhibiting 
all stages in the growth of its protective shell. The older specimens are completely inclosed and fused within the corallum, only the mouth of the shell being exposed at the surface of the colony. Its outer surface is covered by an irregular growth of the coral skeleton, and, being raised a little above the general surface of the corallum, gives a marked irregularity to the colony as a whole. The external ridges on the shell of the parasite have a curious resemblance to the septa of the coral, and in the later growths it is somewhat difficult to distinguish one from the other.

On certain macerated colonies many early stages were obtained showing the manner of attachment of the cirripede within the living calice. At first the presence of the small shell of the crustacean has produced no modification of the coral; it is simply adherent to a few of the septa. But later the lower ridges on the surface of the cirripede, which closely simulate septa, became fused and partly overgrown with the septa, thus causing the obliteration of the middle of the calice. In every case the intruder has fixed itself within a calicinal cavity, never on the ridge connecting two calices. Apparently the cirripede larva enters the polypal cavity and then bores through the living tissues to the corallum, and in the process of growth the skeletons of the two become fused. Afterwards the two organisms continue growing together, the coral skeleton almost wholly inclosing the crustacean; the latter has no boring action. In the later stages the presence of the Pyrgoma results in the production around it of imperfectly developed polyps.

On breaking through a colony it is frequently found that the corallum is made up of growths of different periods, arranged upon one another in irregular layers, instead of a continuous increase in thickness from the middle to the circumference. An old corallar surface has become dead and partly corroded, and then a later skeletal deposit has been formed upon this, and so on for several successive stages, the vertical axis of the corallites of the two or more periods of growth usually corresponding. The secondary origin of polyps in old calices has been already described (p. I7). The growth of the corallum seems to be more continuous in blocks of the larger S. siderea than in $S$. radians.

The actual degree of calcification of the corallum, if one may thus express it, varies much in different colonies, and also in different regions of the same colony. In some examples the septa are comparatively thick, leaving but narrow interseptal spaces, and the calices are shallower than usual, the columella being solid and prominent. In others the septa are thinner, the interspaces correspondingly wider, the calices deep, and the columella either absent as a definite projection or represented by one, two, or three prominent 
granules on the floor of the calice. Probably these differences are determined by the varying conditions of growth of the polyps, whether rapid or slow. The growing marginal corallites are always of the less calcified variety. Such possible variations should be borne in mind, for if extreme coralla only were available for study they might be almost regarded as distinct species.

Examination of the surface of the corallum, and also of sections, shows that the individual calices of a colony are separated from one another only by fusion of the peripheral edges of the septa. There is no thecal formation distinct from that of the septa. The fusion is complete and continuous, however, and results in the entire lateral separation of one calicinal cavity from another. This is clearly shown in the various figures of the corallum on plate Io; and, as further proof, it may be recalled that on decalcification the tissues of the different polyps so far as they are inclosed within the corallum are wholly cut off from one another.

The septa of adjacent corallites correspond peripherally, end to end, or they may alternate; and between these two extremes are all intermediate conditions (plate Io, figs. 62, 64). At the periphery the thickness of the septa is usually greater than the width of the interseptal spaces, so that where the septa of adjacent corallites alternate it is clear that a distinct wall of separation is produced between one calice and another; but where adjacent septa are end to end a shallow interval may remain on each side of the two continuous septa, and the septa are then feebly exsert.

The exsert condition of the septa is most marked toward the margin of colonies, that is, in the region of new growth. Elsewhere the intervals are generally filled by calcareous deposits, so as to bring the calicinal edge to the same level as the septa. The usual superficial appearance is as if each septum became bifurcated at its outer edge and then each half united with a similar half of two adjacent septa belonging to a contiguous corallite. The result is a very narrow zig-zag partition wall between adjacent corallites. Usually the calicinal boundary as a whole reaches the same height as the septa, but occasionally it is depressed, and the septal edges are inclined towards it.

\section{HISTOLOGY.}

The different parts of the corallite will be now described, but first the microscopic structure of the skeleton must be briefly considered. In connection therewith the writer has to express his indebtedness to the valuable work of Miss Maria M. Ogilvie (Mrs. Ogilvie-Gordon) who, in her paper, Microscopic and Systematic Study of Madreporarian Types of Corals (1897), has done more than any other investigator to further the histological study 
of the madreporarian skeleton, following along lines initiated by Pratz (Palæontographica, vol. xxix). Mr. T. Wayland Vaughan has given a résumé of the subject in the introduction to his paper on The Eocene and Lower Oligocene Coral Faunas of the United States (I900).

When the larger septa of Siderastrea are examined sideways, under a low magnification, they present the appearance of the three septa shown on plate I0, fig. 63. The peripheral vertical boundary of each septum consists of a narrow, continuous, nearly straight ridge, which is the broken surface of the thecal wall, really a part of the adjacent septum. Next this is the synapticular area, the synapticula being arranged rather closely in several vertical rows. The surface as a whole is striate, becoming distinctly ridged and grooved as the margin is approached. The septum terminates centrally and above in a strongly serrated margin, the teeth being almost conical in shape, continuous with the ridges, and varying but little in size. Minute granules, usually terminating in one or more sharp points, occur over the whole surface, including the synapticular area and even the marginal spines.

On septa of the second and third orders may also be seen a vertical row of synapticulum-like structures near their inner border. They are shown on the right (central) margin of the left septum on plate Io, fig. 63 , and represent the line of fusion or coalescence of the next adjacent septum in the seriesthe third with the second, and the fourth with the third. They do not occur on septa of the first order, as none of the other septa fuse with these ( $c f$. plate Io, fig. 64). The disconnected character of the bodies serves to demonstrate that the central union of one septum with another by the internal margin is not continuous, but interrupted in character. It is best regarded as taking place along the spinous or toothed edge of the smaller septum, in the same way as the complete septa of the first and second orders fuse in an interrupted manner with the columella by their spinous margins. In Siderastrea Miss Ogilvie (I897, p. I79) regards the direct lateral coalescence of the septal surfaces belonging to different septal cycles as homologous with the synapticular union of septa, but it may be pointed out that the fusion is altogether on the part of one of the septa, not a simultaneous growth from two adjacent septa, as in synapticula proper. The interrupted coalescence of the septa, both with one another and with the columella, necessarily leads to the production of foramina near their inner edge, some of which are shown to the left in plate Io, fig. 63 .

The septal striæ are directed upward and inward in a half faul-shaped manner, starting from the vertical thecal wall. Those on adjacent septa belonging to contiguous calices radiate in an opposite manner, each towards 
the center of its own calice (plate ro, fig. 63 ). The thecal ridge is thus the area of divergence of the striæ of adjacent septa. It is further found that the striæ on opposite sides of the same septum correspond with one another, as can be seen by looking edgewise at the inner margin of an individual septum; hence opposite striæ terminate in one serra. The synapticula and granules are set mainly along the ridges of the septal face, but the former may be so broad as to extend over more than one stria.

In many corals lighter lines run transversely across the striæ, parallel to the dentate septal edge, and mark successive septal margins, corresponding to distinct periods of growth in the life of the polyp. The part between two successive curves represents the addition made to the septum during a single period of polypal growth, and is called by Miss Ogilvie (p. Iro) "the growthsegment of the septum" or "a septal segment." The septa of Siderastrea very rarely exhibit such lighter cross lines; by Miss Ogilvie the synapticula are considered an essential part of every growth segment in this genus.

A magnified transverse section through a portion of the corallum shows that the septa, columella, and synapticula are built up of the same structural elements or units (plate Io, fig. 65). These appear in sections as so many distinctly round or polygonal bodies, fused together into a compact continuous whole. Each unit of structure under low power reveals lighter and darker parts arranged in a concentric manner, and under high power is found to be made up of radiating calcareous fibers (plate II, fig. 66). The fibers seem to start some little distance from a center, which is either clear or dark, and practically homogeneous in structure; further, they are seen to be arranged in close concentric lamellæ, and the boundary between each two layers is often indicated by dark, finely granular particles, similar to those at the centers of calcification.

Employing the terminology of Miss Ogilvie, each structural unit is a trabecula, here seen in transverse section. The radiating bundles of fibers are fascicles, the light or dark centers from which the fibers radiate are centers of calcification, and the concentric layers are growth lamella.

In transverse sections of the septa of Siderastrea the centers of calcification are some distance from one another, and each bears radiating calcareous fibers all round; but in the majority of corals the centers are closer, and often appear in sections of the septa as a more or less continuous dark line or band along the septal axis-the dark line of calcification. In this case the separate fascicles or bundles of fibers are more distinct, and arranged in a feather-like manner along each side of the dark line or layer.

Much discussion has taken place with regard to the nature of the center 
or dark line of calcification. Writers on fossil corals particularly have devoted their attention to the subject. For a complete account the reader is referred to various sections of Miss Ogilvie's work. By some anthors the median dark layer has been interpreted as a primary septum, upon the faces of which the lighter layers, then termed stereoplasm, have been deposited, the two formations making up the septum proper. Miss Ogilvie considers that the dark appearance of the centers results from the presence of the carbonized residue of the originally unchanged parts of the calicoblasts within which she considers the madreporarian skeleton to be formed. It must be stated, however, that the dark appearance is only seen when sections are viewed by transmitted light. With reflected light the middle region appears lighter than the rest of the septum, and thus can scarcely be occupied by black organic matter.

Undoubtedly the middle line of the septum is often of a different structural nature from the two sides, and varies much in character in different species. In Paleozoic corals I have occasionally found the middle part to be dissolved away, making the individual septum appear as if formed of two distinct lamellæ, more or less completely separated. Furthermore, in the very young septa represented on plate II, fig. 70, the center of each trabecula is clearly seen, under high power, to be devoid of any inorganic matter. In the rather thick section one can focus down each center for some distance, which would certainly not be the case were it occupied by a calcareous deposit. I conceive that the so-called center of calcification is really the organic center or axis around which the skeletal matter is deposited in a radiating or feather-like manner, and that, at an early stage in the living, growing skeleton, the center is occupied by the mesoglœa-like matrix within which it has been shown that the calcareous fibro-crystals are deposited (p. 34). The organic matrix of the centers is probably in all cases impregnated later with calcareous matter, differing in character and crystallographic orientation from the true skeleton (stereoplasm), as shown by its different appearance in sections and different solubility. Bourne has remarked (I899, p. 539): "I suspect that the dark 'centers of calcification' will be found to be the expression of a core of organic filaments, just as the central dark line in the Alcyonarian spicule is the expression of the central core of threads." Results published since Bourne's paper seem to confirm his conjecture, only the core is probably homogeneous, and later becomes impregnated with inorganic matter, probably from solution, not from calicoblastic activity.

The centers of calcification in $S$. radians are distant from one another on an average about $0.125 \mathrm{~mm}$. and the trabeculæ show a corresponding 
diameter. The latter are very variable in size in the columella (plate ro, fig. 65). Sometimes two centers of calcification, diverging from one another in the median plane, are present in one concentric system, and the trabecula then appears double and is elongated in outline. Fusion between adjacent trabeculæ is usually indicated by a narrow, dark line.

A synapticulum may have either a separate center of calcification (true synapticulum) or be formed from the fascicles of trabeculæ in adjacent septa which extend beyond the septa until they meet in the middle of the interseptal space (false synapticulum, p. 52). Bundles of fibers or fascicles from individual centers also pass into the granulations over each face of the septa.

The growth lamellæ in the individual trabeculæ are not always clearly indicated, but sometimes they come out with remarkable distinctness, having a black, finely granular margin (plate II, figs. 66, 68). Around the centers of calcification they are strictly concentric, but towards the edges of the septa they more nearly follow the septal outline. In transverse sections they are distant from one another about $0.0025 \mathrm{~mm}$. The black, finely granular margin is probably organic residue of the same character as that at the centers of the trabeculæ.

A thin vertical section of part of two contiguous septa is represented on plate II, fig. 67 , and displays a series of elongated bands. One of these, the continuous median band, represents the thecal wall, and from it the constituent parts of each septum diverge. The darker circular or oval areas also seen in the section are the transversely cut surfaces of synapticula, and each originates in connection with a band.

The broad radiating bands are the septal trabeculæ as they appear in longitudinal section. Where the section passes through the middle of a trabecula a row of close centers of calcification is revealed, and fascicles of fibers pass from them obliquely upwards on both sides. Peripherally the fibers of adjacent trabeculæ meet all the way in a distinct thin line, so that a compact septum is the result. Fresh trabeculæ are seen to be inserted at intervals between the old. The trabeculæ are continued upward to the septal margin and there constitute the terminal teeth, each tooth corresponding with a single trabecula, but the preparation from which plate $\mathrm{I}$, fig. 67 , is taken was not sufficiently wide to show the teeth. They vary but slightly in width, being about $0.125 \mathrm{~mm}$. across towards the margin of the septum. From the inclined arrangement of the trabeculæ it is obvious that a transverse section of the septum will cut only the more peripheral at right angles; the others will be represented in varying degrees of obliquity.

Each separate dark area along the middle of a trabecula represents a 
center of calcification, and from it fascicles of fibers radiate on both sides, the black, finely granular matter extending but a very short distance. Each center of calcification, therefore, represents a single growth period in the upward progress of the septum. They are distant from one another about $0.013 \mathrm{~mm}$. A trabecula is thus a vertical series of fibrous groups, each group of fibers being deposited around a distinct axis of calcification. A trabecular part is the name given to the separate groups of-fibers formed by the fascicles at one center of calcification. Each stria seen under low power on the surface of a septum represents a single trabecula, and the tooth in which an opposite pair of striæ terminates at the edge of the septum is the growing apex or organic center of the trabecula. Around this organic center new calcareous matter is constantly being added by the activity of the calicoblasts.

\section{WALL OR THECA.}

The wall or theca of a simple coral or of a corallite is defined by Vaughan (I900, p. 48) as "that part of the skeleton that cuts off more or less completely the interseptal loculus from peripheral communication with the outside." In Siderastrea the thecal wall at first appears indistinct, as if represented only by the united peripheral edges of the septa of adjacent corallites. Some of the septa of contiguous calices are in the same straight line, in which case it is difficult to distinguish just where the calicinal boundary comes; in other places a septum of one corallite corresponds with an interseptal loculus of the other, when the distinction between the two calices is quite clear. Usually it appears as if the septa were forked peripherally, and the two limbs of one septum unite in a zigzag manner with two adjacent septa in the next calice.

The nature of the wall is best seen when a corallum is fractured vertically, and adjacent corallites can be viewed lengthways. As indicated on plate Io, fig. 63 , the theca is then represented by a narrow, vertical, continuous ridge, which completely separates the interseptal loculus of one calice from that of the other. Further, in the section shown on plate II, fig. 67, this vertical ridge is found to consist of a distinct trabecula, and from it the trabeculæ of adjacent septa diverge.

Miss Ogilvie (I897, p. I80) has given a figure of Siderastrea (sp. ?) somewhat similar to that of plate Io, fig. 63 , but the thecal wall (pseudotheca) is there represented as a discontinuous ridge, as if comparable with a row of synapticula, and in such a way as would permit of communication between one calice and another. This, however, is not its condition in S. radians. In all instances $I$ have found the wall to be continuous, and the fact that 
when a colony is decalcified adjacent polyps are found altogether cut off from one another would prove that their cavities are not in lateral communication, as would be the case were the boundary wall interrupted.

The terms pseudotheca and eutheca of von Heider (I886) are well known to coral students, the former referring to a theca produced by the septa becoming so much thickened peripherally that they fuse together, while the latter. is applied to a theca formed from separate trabeculæ between the peripheral ends of the septa. Vaughan (I900, pp. 48-52) has considered very fully the value to be applied to these distinctions, and comes to the conclusion that "From the great variation not only in the same species, but in a section of a single corallite, no special systematic importance can be attached to the theca being of the so-called true or false variety. True theca marks the Anlagen of new septa, as von Koch and Bourne have shown, or occurs in calices where the septa are distant from one another and their outer ends are not sufficiently thickened to effect peripheral fusion."

The theca of Siderastrea is described by Miss Ogilvie as a pseudotheca, and, as above shown, it is certainly formed at the peripheral extremities of the septa. On the other hand one, or rarely more, distinct centers of calcification occur laterally in the interval between one septum and another, though not to be distinguished from those of the septa except by being inclined to them at an angle. In her figs. $43 a, 43 b$ (p. I8r), Miss Ogilvie represents such centers of calcification, but regards them as synapticular. Although presenting the same appearance in transverse sections, plate Io, fig. 63 , and plate II, fig. 67 , show that this is not their true character; rather, the thecal trabeculæ are continuous vertical partitions. According to the accepted definitions it would seem that the theca of Siderasirea should be regarded as a true theca, having a separate trabecula between the ends of adjacent septa from which the trabeculæ of the septa radiate.

An independent thecal wall, however, is found to be wanting in the corallum of larval polyps, the epitheca being in no way comparable with this. In the simple corallum, as far as reared, the septa remain free and exposed peripherally, except in so far as they may be united by synapticular growths or covered by the epitheca (see plates 4 and 5). Likewise the outer septal edges of the marginal polyps in a colony extend for a considerable vertical height, exposed all the way.

SEPTA.

The detailed characteristics of the septa have been already described, so that it only remains to discuss their arrangement and relationships. 
All the septa of a corallite are well developed, both as regards their thickness and radial extent; even the members of the outermost cycle extend centrally for about half the radius of the calice, and are but little narrower than the others. The individual septa are usually thicker than the width of the interseptal loculi separating one from another, so that, compared with most other corals, the septal system is very compact, and the calicinal cavity as a whole is correspondingly diminished. The septa vary but slightly in thickness according to the cycle in which they belong.

The outer septa are not strictly radial throughout their transverse length, but incline along their inner edges and fuse at intervals with the lateral faces of the septa of the second and third cycles, thus forming groups of three, five, or rarely seven (fig. 2, p. I3). The grouping, however, is not always obvious at the surface of a colony. Thus Verrill (I90I, p. I54) states that the septa of the Bahama representatives are nearly all straight and

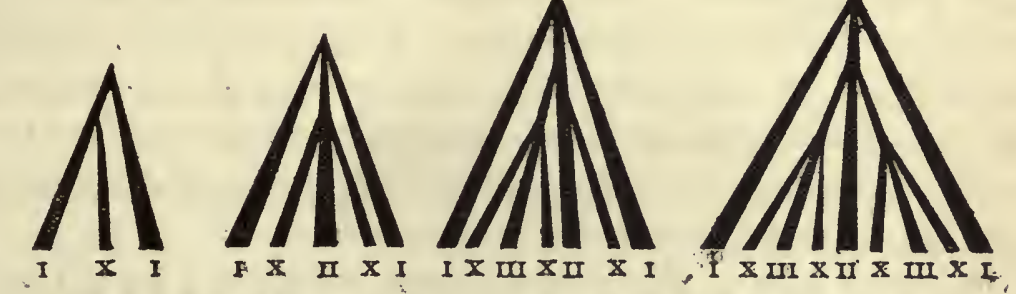

FIG. 4.-Grouping of the septa within a sextant (I-I) according as one, three, five, or seven septa are present. The Roman numerals $I-I I I$ indicate the order of the septa and $x$ the exosepta.

seldom fused. It is, however, always a marked characteristic in sections of the corallum from a little below the surface downward (plate Io, fig. 64).

When examined in detail the grouping is found to be as follows: The twelve largest septa, constituting the primary and secondary orders, extend as far as the middle of the calice and are united directly with the columella. Of these the six primary septa pass uninterruptedly all the way from the periphery to the columella without any connection with the others except, of course, through union by synapticula. The six secondary septa, on the other hand, are also radial, but with them are united the members of the third order, which never reach the columella. The members of the fourth or ontermost cycle fuse one on each side with a tertiary septum. Where only one secondary septum occurs within a primary system the two outermost septa are fused with it, and a grouping of three is produced. Where a tertiary septum and a secondary septum are within a sextant the grouping is in fives, and where two tertiary septa and a secondary occur the grouping is in sevens. The relationships are clearly shown in the series of figures above and also in fig. 2, p. I3. 
In the course of development of the septa it is shown that from the beginning the exosepta always constitute the outermost cycle, and are fused with the entosepta immediately preceding them. Thus, when only two cycles of septa are present (plate 4 , fig. 23), the outer exosepta fuse with the inner entosepta. Where three cycles are developed (plate 5 , fig. 28 ) the exosepta unite with second-cycle entosepta; where four cycles, they fuse with the thirdcycle entosepta. At the early stage of development, represented in plate 5 , fig. 28 , the second-cycle entosepta are fused with the first-cycle entosepta instead of with the columella as in the adult. The union here takes place in such a manner as to give a decided bilateral symmetry to the corallum.

The hexameral cyclic plan of the septa is not so manifest in $S$. radians as in many corals, partly owing to the incompletion of the third and fourth cycles; but with a little care it can be established by the differences in size of the septa and their other relationships. In mature corallites two inner alternating orders (primary and secondary) of six septa each are always present, while the third and fourth orders are represented by a varying number of septa. Owing to this varying incompleteness of the last two orders a study of the septal arrangement yields some interesting results in connection with the manner in which the later additions of septa take place, and also in the relationships of the entosepta and exosepta.

The hexameral plan is found to be strictly followed so far as concerns the first and second orders, and for the third and fourth orders so far as these are developed. Were the third and fourth orders to be completed the total number would be 48 , arranged in the formula $6,6,12,24$; but this number appears to be rarely, if ever, reached in $S$. radians, though frequently exceeded in $S$. siderea. In one of the largest corallites 44 septa were present, but the numbers generally vary from 30 to 36 .

The six members of the primary cycle are readily separable from the others on account of their greater radial extent and thickness; they pass all the way from the thecal wall to the columella without any of the other septa coalescing with them. They serve to distinguish the six primary systems within which are enclosed varying numbers of smaller septa. The outermost exosepta are also recognizable by their smaller size, one occurring between every two adjacent members of the first, second, and third orders. Less certainty prevails in distinguishing the members of the second and third cycies, though frequently the second-cycle septa are larger and more prominent than those of the third.

In mature corallites three septa at least are always present within each primary system, while there may be five or seven (fig. 2, p. I3). Where only 
three septa occur in a system the middle member belongs to the second order, and the two lateral ones are exocœlic; where five septa are present, one belongs to the second order, another to the third, and the three alternating with these to the exocœlic cycle; in the rarer instances in which seven septa are developed the middle member is a second-order septum, the two next in size are tertiary septa, and the four alternating septa belong to the fourth or exocœlic cycle. The members of the outermost cycle fuse in an interrupted manner by their inner ends with the members of the second and third cycles, but not with those of the primary cycle; the tertiary septa in their turn unite with the secondary.

The actual ordinal relationships of the septa can be best understood when taken in connection with the mesenteries, as revealed in transverse sections of the polyp.

Plate 6, fig. 34, represents a transverse section from the lower stomodæal region of a partly retracted decalcified polyp. The drawing was made with the help of a camera lucida, but in the process of decalcification and the preparation of the section slight displacements of the lamellæ have taken place. Still the general relationships remain as in the living condition, and for all practical purposes the invaginations of the polypal wall correspond with the septa which have been dissolved away. Fig. 2, p. I3, is a diagrammatic representation of the septa of the same polyp, the synapticula and spinous projections being omitted for the sake of clearness.

In the transverse section (plate 6, fig. 34) a large septal invagination (entosepta, I, II, III) occurs within the interspace inclosed by the two members of each pair of mesenteries, and a smaller one in the interspace between every two adjacent pairs (exosepta, x). The entosepta inclosed by the two pairs of directive mesenteries are known as directive septa, but in the corallite itself there is nothing to distinguish these from the other primary entosepta. They indicate the dorso-ventral (postero-anterior, sulculosulcar) axis of the corallite, and can only be determined with certainty when in association with the mesenteries.

The six interspaces between the six primary mesenterial pairs contain a variable number of pairs of mesenteries: the two ventral systems each contain one mesenterial pair (II), the right middle interspace three pairs (III, II, III), and the remainder two pairs each (III, II). The six pairs of secondary mesenteries (II) are easily distinguished from the tertiary mesenteries (III) by their greater size and more central position. Of the latter there are only five pairs in this particular polyp instead of twelve, as considerations of hexameral symmetry would suggest. 
The septa are therefore related to the mesenteries in the following manner:

The six primary septa are inclosed within the entocœles of the primary cycle of six pairs of complete mesenteries, the six secondary septa within the entocœles of the second cycle of mesenteries, the five tertiary septa within the entoccles of the third cycle, while the members of the outermost or quaternary cycle of septa are all exocœlic, one between each two pairs of mesenteries. The primary, secoudary, and tertiary septa are all entosepta; the members of the fourth cycle are exosepta. Further, the number of exosepta equals the sum of the entosepta, and the number of cycles of septa is one more than the number of cycles of mesenteries. Considering the septa as entosepta and exosepta, the true septal formula is $6,6, \mathrm{x}, \mathrm{I} 2+\mathrm{x}$, where $\mathrm{x}$ may be any number from one to twelve. The variations in the number of septa within the different calices are in pairs-an entoseptum and an exoseptum-and affect only the members of the third cycle and their corresponding exosepta. These two cycles always show a corresponding variation which is not explicable on the usual supposition that the cycles of septa are developed in the order of their importance. The order of appearance of the septa and the relationships of the entosepta and exosepta will be discussed more fully in connection with the development of the septa in larval polyps.

It will be shown that morphologically the exosepta are to be regarded not so much as a separate cycle, appearing after the others are established, but rather as the bifurcated continuations of the original cycle of exosepta, or perhaps as new formations arising along with the entosepta which they inclose; each entoseptum has an exoseptum corresponding with it, which is formed nearly at the same time. Exosepta are found to arise along with each cycle of entosepta or even with each individual entoseptum; but as new cycles of entosepta are formed they are, as it were, shifted outwardly, so as always to constitute the outermost cycle. Until the adult condition is reached the exosepta are but temporary predecessors of the permanent entosepta. The same relationship is found to hold between the entotentacles and the exotentacles.

The above relationship between the cycles or orders of septa and mesenteries holds for most species of corals which have been examined. In certain forms the exosepta are absent, e.g., Pectinia, Manicina, when the cycles of septa correspond in number with the cycles of mesenteries.

Where the hexameral cyclic sequence of a corallite is not completed it is preferable to speak of the exosepta merely as exosepta or as septa of the outermost cycle, not as a third or a fourth cycle; for ontogenetically some 
belong to the third cycle and some to the fourth. They have no ordinal value comparable with the entosepta.

In descriptive works on corals, when giving the number of septa characteristic of any calice, it is usual to consider all the inner cycles as hexamerously complete and then to regard all the missing septa as wanting from the last cycle. Thus Milne-Edwards, in describing the septa of the present species, says : "Three cycles of septa-complete, and, in general, a variable number of a fourth cycle." Also Verrill (I9or; p. I53): "They [the septa] form three complete cycles, with part of the fourth cycle developed, so that the number is usually 36 to $40 . "$ From the relationships here set forth, and more fully discussed in connection with the development of the septa, it is clear that such cyclic plans do not express the true ordinal or morphological relationships of the septa; the last and penultimate cycles vary in the same degree, and the latter contains both entosepta and exosepta.

The septal invaginations on plate 6 , fig. 34 , indicate how the exosepta in most instances fuse with the third septa, but in the two ventral systems, where no members of the third cycle are developed, they unite instead with the secondary septa. In the serial sections the invaginations also show that the fusion of the exosepta with the entosepta is not continuous throughout their vertical length, but is effected only at somewhat regular intervals.

The section of a fragment of a corallum represented on plate Io, fig. 64, includes the whole of one corallite and portions of the six surrounding corallites, and shows their relationships to one another. The thecal wall separating one corallite from those adjacent to it is seen to be very limited in thickness. At this level in the complete calice twelve septa, representing the first and second cycles, are united directly with the columella. The six primary septa are distinguished by the fact that they extend all the way from the periphery to the columella without fusion with any of the smaller septa. In three of the primary systems there are only three septa-a secondcycle entoseptum and two complete exosepta fused with it; in the remaining - three sextants are five septa-a second-cycle entoseptum with one exoseptum and a third-cycle entoseptum fused with it, the latter having two exosepta in union with it.

Comparison may be here made with a somewhat similar horizontal section of a corallite of S. radians, introduced on plate XV (fig. I2) of Agassiz's "Florida Reefs." Nine distinct, complete septa are represented, and in the interspace between each two occurs a group of three septa, the two lateral united with the middle, which, in its turn, extends to the columella. The 
arrangement of the septa in groups of three is continued all the way round, and the hexameral plan is altogether obscured. Such an interpretation of the septal plan is at variance with what is established above for the Jamaica representatives of the same species.

As seen at the surface of a colony the septal edges extend almost horizontally for a short distance from the periphery, and are then inclined downward and inward somewhat sharply to meet the columella which forms the floor of the middle of the calice. The actual depth of the calice varies somewhat in different colonies, but is usually about $2 \mathrm{~mm}$.

\section{SYNAPTICULA.}

Viewed with a lens from above, the septa are seen to be joined to one another laterally by thick transverse bars-the synapticula. In any transverse section of a calice one to three, rarely four, synapticula are seen crossing the space between every two adjacent septa, but are limited in their distribution to the peripheral half of the calice (plate Io, fig. 64). In a view of the lateral surface of the larger septa they are found to be arranged in two or three, rarely four, somewhat irregular vertical rows, each synapticulum being circular or oval in section, and projecting at right angles from the septal surface (plate Io, fig. 63). The presence of so many connections between the septa gives a porous or reticular character to the more peripheral part of the calice.

The synapticula are formed by the ultimate fusion across an interseptal loculus of two opposite granulations on the faces of adjacent septa, the calcareous matter being deposited in a manner similar to that of other parts of the corallite. In Siderastrea it is only the granules in restricted spots on the septal faces which become thus enlarged. The synapticula have a limited distribution, and the other granulations on the septal face remain comparatively small, there being no intermediate examples. It is clear that in the course of their growth the enlarging granules must first indent the skeletotrophic tissues which line them, then bring the two opposite layers together, and finally perforate them, as shown on plate 6, fig. 34 ; also, as described on p. 28 , the mesentery inclosed within the loculus is perforated at the same time.

Sections through the synapticula show that they are formed as lateral processes of the septa, either by an extension of the septal trabeculæ or from a center of calcification of their own. In the former case a boundary in the middle of the synapticulum indicates where the bundles of fibro-crystals from one septum have met those from the opposite septum. In the other case it 
appears as if the fibers from the synapticulum itself were bracing the two septa. The first are known as false synapticula and the second as true synapticula, but, as all recent writers have pointed out, there is no morphological distinction between the two. Both kinds appear in any section of a corallite. Whether one or the other form is present depends mainly upon the interval between the two septa. Where sufficiently close, as towards the middle of the calice, the interseptal space can be bridged without the formation of a new center of calcification, while such is necessary when the interval is wide, as towards the periphery.

Miss Ogilvie (I897, p. I68) considers that in Fungia the synapticula are formed by special interseptal invaginations of the basal wall of the polyp subsequent to the septal upgrowths, without ever perforating the mesenteries, and assumes such to be the case with Siderastrea. Bourne (1886, p. 47) has already shown that in Fungia the mesenteries are really pierced by the synapticula, Fowler (I888, p. 8) has accomplished the same for Stephanophyllia formosissima, and I for Siderastrea siderea (I902, p. 487). The conditions revealed by the liberated lamella on plate 6 , fig. 33 , prove that the synapticula are the products of definite areas of the original skeletogenic layer producing the septa, not of special secondary basal upgrowths. Delage \& Hérouard (I9OI) have accepted Miss Ogilvie's interpretation of synapticular formation, giving diagrammatic figures to illustrate how the upgrowth is supposed to take place.

\section{COLUMELLA.}

The columella is represented in the mature calice by a more or less compact, column-like structure forming the floor of the middle of the calice. In decalcified polyps it is found to have elevated the central part of the skeletogenic tissues in a tubular manner considerably beyond the peripheral parts. Its superficial appearance varies much in different calices; it may be either papillose or smooth, dependent upon the degree of calcification of the colony. Sometimes only one large, tooth-like papilla occurs, or there may be two close together; in others, again, there are two or three large or chief tubercles along with several minute projections, or it may be formed wholly of small, scarcely perceptible granules, when, to the naked eye, it appears compact and smooth. This latter condition is found in coralla of which all the parts are strongly calcified. In these the columella is conspicuous, raised for a short distance above the septa, and its free surface nearly smooth.

Where several prominent tubercles are present some seem as if continuous with the teeth of the septa, suggesting that the columella is formed 
from the united edges of the primary and secondary septa. Others of the projections seem, however, to be quite independent of the septa. Secondary calcareous matter is deposited among the projections, and this gives the more compact character to the structure as a whole. The section represented on plate Io, fig. 65 , shows the relationship clearly. The columella is here quite solid and distinct, and is structurally the same as the septa united with it, having its own centers of calcification. In sections a little higher it is spongiform, as the trabeculæ are free from one another.

With such structural details alone available it is practically impossible to say whether the columella of Siderastrea is a true or a false columella (pseudocolumella) as these terms are understood in coral literature. Miss Ogilvie (r897, p. r79) describes it as a "paliform pseudocolumella." A true columella is considered to arise as an independent structure from the middle of the basal plate, though the septal edges may secondarily unite with it. A false or pseudocolumella, on the other hand, is an irregular skeletal tissue formed from union of the inner or central ends of the septa, sometimes bound together by a secondary deposit. Recourse to the developing coralla shows the true nature of the columella in S. radians. As described later, and illustrated by the figures on plates 4 and 5 , independent skeletal upgrowths are first formed from the basal plate, but later come into intimate relationship with similar formations at the edges of the septa, and afterwards the two groups are united into a solid, compact column by a deposit of calcareous matter.

Developmentally, therefore, the columella of Siderastrea is a true columella, compact all the way, or compact below and spongy above.

Histologically the columella usually shows two or three large circular trabeculæ arranged in a row and surrounded by a number of smaller trabeculæ (plate ro, fig. 65). The larger probably represent the true elements of the columella, which arise directly from the basal plate, while the smaller are the septal teeth which also take part in its constitution.

Viewed from the surface the columella is usually nearly circular in outline and affords no aid in determining the principal axis of the corallite; but in sections some distance below the surface it generally presents a longer and a shorter axis, and the former evidently corresponds with the directive or principal axis of the corallite. To each extremity of the longer axis a septum of the first order is attached, and the two are, no doubt, the directive septa, though, owing to the difference in the number of septa on each side, they are not always in the same plane (plate Io, fig. 64). The oval columella may thus afford an important aid in the orientation of the septa and of the corallites in a colony. 


\section{DISSEPIMENTS.}

The dissepiments are extremely thin and delicate transverse partitions which serve to cut off the living polyps from the dead part of the skeleton below. In section they are only o.or mm. thick. Along with the columella they serve for the time being as a support for the basal part of the polyp, the dissepiment being morphologically comparable with the basal plate of the larval polyp. In some cases the partitions are horizontal, but in others they are deeply convex upwardly. They are situated at somewhat different levels in different interseptal loculi, and in the same loculus vary from $0.25 \mathrm{~mm}$. to $0.5 \mathrm{~mm}$. apart. The distance apart of two adjacent dissepiments in a loculus represents a period of growth of the polyp in its march upward, the polyps throughout their lifetime retaining approximately the same vertical length and transverse diameter. As a result of the very narrow interseptal loculi in Siderastrea the dissepiments are rather insignificant features of the corallum, but as a basal support they are probably as important to the polyp as in other species of corals in which they are more prominent. Occasionally a dissepiment is found intersected by a synapticulum, when both may be considered as constituting the basal support of the particular lamella. Such was probably the case in the interseptal lamella represented in plate 6, fig. 33. Usually. the lamellæ present a more nearly straight basal extremity than is here represented, showing that the polyp is cut off below in a regular manner by the formation of dissepiments which alternate with the synapticula. The dissepiments may thus correspond or alternate with the synapticula, the latter being formed independently and in advance of them.

The dissepiments are easily studied in tangential sections of corallites, and it is found that their histological structure is different from that of septa. They possess no centers of calcification, but are thin and laminated, composed of fibro-crystals standing at right angles to the surface. They thus recall the microscopic structure of the basal plate and epitheca, and like these they are lined by the calicoblasts of the polyp only on one side.

Miss Ogilvie (I897, p. I78) assumes that the synapticula and not the dissepiments constitute the principal basal support of the polyp in Siderastrea. This would follow were the synapticula formed, as she assumes, within special interseptal invaginations of the aboral body wall; but, as shown on p. 53, such is not their origin. They are produced by special areas of the septal invagination, ultimately resulting in perforation of the polypal wall. As the synapticula actually perforate the polyp they may be conceived as also affording it support; but only incidentally, as happens to be the case 
in the lamella shown in plate 6 , fig. 33 , is this basal. The synapticula do not take the place nor assume the function of dissepiments.

EPITHECA AND BASAL PLATE.

The most careful observation of the margin of adult coralla fails to reveal the presence of an epitheca or covering of the peripheral septal edges. This is somewhat remarkable considering that such a skeletal formation is developed in young polyps reared from the larva, and this whether the polyps are isolated or growing contiguous to others (plates 4,5 ). In these larval polyps, however, the extent of the upward growth of the epitheca has been found to vary greatly. In some specimens, apparently stationary as regards growth, it formed a comparatively high external wall to the polyp, wrinkled and diminishing somewhat in diameter from the base upwards, but overtopping all the septa (plate 5, fig. 27), while in others, the largest, actively growing corals, it was either absent or represented only by a low, narrow rim (plate 5, fig. 28). Evidently it is a structure of importance only in the early stages of growth.

Where, as frequently happens, a part of the growing margin of a colony is free from the incrusted object, a flat, plate-like deposit covers and unites externally the basal edges of the septa. Such a formation by the bud-polyps will correspond with the basal plate of the larval polyp, but its peripheral edge is rarely, if ever, upturned so as to cover the free vertical edges of the septa, as in the case of an epitheca proper. 


\section{POSTLARVAL DEVELOPMENT.}

\section{LARVA.}

Five different colonies of S. radians were collected in Kingston Harbor, Jamaica, on the 6th of July, many of the polyps of which contained free planulæ. Although similar colonies had been obtained from this locality on former occasions, and examined with regard to their fertility, this was the first time that larvæ were secured. On a second visit a week later two or three other ripe colonies were collected, and others which on being sectionized were found to contain ova.

On every colony the fertile polyps were in somewhat restricted patches, not all the individuals coming to maturity at the same time. One, two, or three planulæ were plainly visible through the nearly transparent tissues of the parent, and were often observed to pass into the tentacles, which thereby became greatly distended, remaining so even when the polyps were retracted. At times the planulæ would glide into the lower regions of the polypal cavity, and were then lost to view. While within the parent cavity it was impossible to determine whether the movement of the larvæ was, like that of the food particles, dependent upon the ciliary activity of the lining endoderm or was a result of the larva's own activity. Immediately upon being set free, however, the larvæ were able to swim about, the ectoderm being already provided with a layer of cilia.

The larvæ were shot out suddenly, but the actual place of extrusion was not determined, although prolonged observation was made. From their persistent entrance into the tentacles it would seem that they made their escape through these organs, and not through the mouth, which was usually closed and depressed. In other instances,.e. g., Mancina areolata and Favia fragum, the sexual products and larvæ have been seen to be given out through the oral aperture, the proceeding being accompanied by a peculiar jerking motion of the adult polyp. Von Koch (1897), however, found the larvæ of Caryophyllia cyathus to be expelled through the tips of the tentacles, and Lacaze-Duthiers (I873, p. 308) occasionally observed the same in Astroides calycularis. Sections show that the knobbed tip of the tentacles in Siderastrea is without any permanent terminal aperture.

Larvæ were freely extruded at the time of collection of the corals, and continued to be discharged from time to time for about a month. Under ordinary conditions one or two would be set free at intervals, but upon disturbance 
of the colony a score or so would be shot out together. Often when the disc had become retracted a larva would remain within the upper peripheral region of the polyp, fixed between the edges of a septum and the wall of a tentacle.

The larvæ were able to swim about immediately upon being discharged, and gyrated through the water first in one direction and then in another. There was evidence of a feeble negative geotropism. During the first day they kept near the surface of the water, or gathered around the sides of the vessels; afterwards they traversed the water as a whole, though in the main keeping near the surface.

To the unaided eye some of the planulæ appeared as minute, opaquewhite, spheroidal bodies; others were oval; but the majority were elongated and pear-shaped, as shown in plate I, fig. I. Under the microscope the ciliation was found to be uniform over the whole surface. The broader pole (oral) was deeply pigmented and invariably posterior in swimming; no oral aperture could be detected at first, but extrusions of Zooxanthellæ, yolk, and cell débris took place later, showing that the mouth was already functional. Under the microscope the brownish yellow of the broad end was seen to be due to the presence of numerous Zooxanthellæ within the ectodermal layer; otherwise the ectoderm was colorless, while the endoderm was dark and nontransparent. The narrow anterior end (aboral) was perfectly colorless, its ectoderm being free from commensal algæ. In some larvæ the colorless end (aboral) was larger than the other. The elongated specimens were able to retract and extend themselves, and upon irritation or preservation altered their shape so as to become nearly spherical. The ordinary pear-shaped individuals were about $2 \mathrm{~mm}$. long.

Thronghout their free existence the majority of the larvæ remained as wholly opaque objects, and no trace of mesenterial divisions could be seen from the outside. Some specimens, however, were so far developed as to be distended at birth, or became so shortly afterwards. The tissues of these latter were more transparent than the rest, and eight mesenterial divisions were obvious, though not all of the same vertical length (plate r, figs. 3 and 4). The latest extruded larvæ, after the colonies had been kept under somewhat unfavorable conditions for two or three weeks, were nearly devoid of external Zooxanthellæ and therefore colorless.

After the first day or two many of the larvæ showed positive geotropism and sank to the bottom of the vessels, lying there motionless ; later, some of these resumed their activities. By the evening of the second day a few had fixed themselves by the narrow, anterior, colorless end to the bottom or side of the vessel, or to objects placed within it. At first the larvæ would adhere 
by means of the actual tip of the narrow end (plate I, fig. 5); this would then flatten ont, and the whole body become much shorter, a small round or oval aperture being visible at the free extremity (plate $\mathrm{r}$, fig. 6).

Whether or not any individual larva would settle seemed very uncertain, for out of several hundreds set free comparatively few became permanently fixed. Those which settled appeared to be the larger, better developed specimens. Smaller vessels, glass slides, and cover glasses floated by means of cork were placed within the receptacles so as to afford additional surfaces for adhesion; in other cases larvæ were distributed within vessels coated with paraffin. If fixation were not accomplished within the first few days, it seemed to be impossible afterwards, though the larvæ might continue active for several weeks. In one instance about a score of planulæ were isolated and kept in a glass dish, and although they appeared healthy and swam freely for a period of twenty days, externally they underwent no change whatever.

Sometimes a larva would fix itself in a position apart from others; but in general many would settle close together at one and the same time, their walls in some cases actually pressing one against another. Plate I, fig. 5 , represents three larvæ in the first stage of fixation, in this case to a small pebble. The narrow extremities nearly touch, and it is obvious that when the larvæ shorten and their bases flatten, the latter will exert a mutual pressure as a result of their closeness. In plate I, fig. 6 , seven larvæ already settled and fully expanded are represented, as seen from above by reflected light. All were closely adherent to a fragment of stone, and formed a miniature colony. To the under surface of a small pebble thirty-eight other specimens were aggregated in groups of two, three, or more, the members of any group touching along their margin. One of these groups contained a dozen or more young polyps, all in contact with one another, the mutual pressure producing a distortion of the normally circular base.

During a single night another group of thirty-two became adherent to the surface of a small glass dish. In this case nearly all the members were touching to a greater or less degree. One of the aggregations, consisting of fifteen polyps, is represented in fig. 5, p. 6o, as seen from the under surface of a fragment of glass to which the individuals were attached. The colony when drawn was two or three months old, and the skeleton was already in process of development, being represented by a variable number of septa and by basal and epithecal formations.

The aggregated larvæ, or young polyps, as they may be called after settling, remained closely associated during their subsequent growth, and in 
all respects resembled a distinct colony. Siderastrea radians thus exhibits the phenomenon of a coral reaching its colonial stage by direct union or aggregation of a number of independent larvæ, the larvæ being at first free swimming and wholly unconnected with one another. The close association is probably to be understood as a thigmotactic phenomenon, and calls for a more extended study with abundant material. The subject of "Aggregated Colonies in Madreporarian Corals" has been more fully discussed in "The American Naturalist," June, I902. It is there shown that similar associations are at times met with in other corals.

Externally the opaque larvæ seemed all alike, but sections reveal slightly different stages of growth as regards the number of mesenteries and their connection with the stomodæum. The sections further demonstrate that the

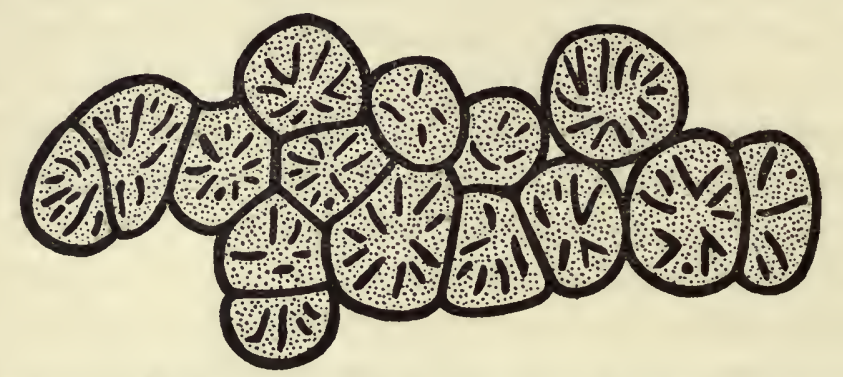

FIG. 5. - Aggregation of fifteen polyps derived from the same number of originally free-swimming larva. Only the basal skeletal appearance is represented.

opacity is due to the thickness of the endoderm and the numerous Zooxanthellæ within its cells. Furthermore, the gastro-cœlomic cavity is yet unformed, or very limited in extent, the larvæ being a nearly solid mass of cells. The distended larvæ, on the other hand, already showed from the outside different stages in the development of the mesenteries, and the internal cavity was more fully established ( $f$. plate I, figs. 3, 4).

After fixation all the larvæ became distended, the walls more transparent, and mesenterial divisions, twelve in number, were rendered conspicuous. From the beginning of fixed life some few were more advanced than others. These were the individuals born in an already transparent state. On settling they were nearly as large again as the other larvæ, and their development throughout was more rapid.

A few abnormal larvæ were extruded and swam about like the rest. The oral extremity of these was double and the aboral single, the bifurcation taking place about the middle of the length (plate $I$, fig. 2). Lacaze-Duthiers (I873, p. 3I2) likewise found such double monsters to be somewhat frequent 
in Astroides. In these the oral end was sometimes bifurcated and sometimes the aboral.

No trace of any calcareous deposit or skeletal formation was apparent in any of the larvæ before fixation, but calcareous matter was laid down soon afterwards, the distinction between basal disc and free polypal wall, or skeletogenic and non-skeletogenic tissues, being then established for the first time.

It is convenient to describe the general course of the development and character of the young polyps before proceeding with the detailed growth of the individual organs - tentacles, mesenteries, and septa.

YOUNG POLYP.

Some of the larvæ became adherent to small pebbles, others to pieces of glass, while most were fixed to the sides and bottom of the glass vessels in which the colonies were placed. In this last case the vessels were sacrificed in order to obtain the young polyps in a condition favorable for examination under the microscope. By carefully breaking the glass suitable fragments were secured with the polyps attached, and these could be transferred from one aquarium to another, or placed in dishes small enough to rest on the stage of the microscope. In this way the growing polyps could be examined at any time from both their upper and under aspects, their partial transparency allowing the development of the mesenteries and septa to be followed day by day. Thus the growth of the polyp and the skeleton could be observed together and their various relationships studied.

Once the larvæ were settled they seemed vigorous and hardy, and scarcely any of the young polyps arising therefrom succumbed, although subjected to the somewhat adverse conditions of small aquaria.

The different organs, polypal and skeletal, began to appear shortly after fixation, the various stages in the development of the tentacles, mesenteries, and septa being represented by the drawings and photographs on plates I-5. The young polyps were early capable of expansion and retraction. For the most part they remained in the expanded condition, with the tentacles stretching out horizontally, or even overhanging. Sometimes the column would extend vertically upwards and remain equal in diameter throughout; at other times the lower part of the walls would shrink over the corallum and the remainder appear as a narrow column upon a broad pedestal. Upon retraction the tentacles still remained exposed, but restricted to the central region (plate 2). Even in the adult the tentacles have been found to remain visible upon the fullest retraction, the column being incapable of folding over them. On one occasion only a larval polyp was found with the 
columu wall completely overfolding the tentacles and covering nearly all the disc (plate 3 , fig. 18).

After the first few days the polyps were able to feed upon small pieces of molluscs or chætopods placed upon the disc by means of forceps or a needle. The tentacles would close upon the fragment and hold it as the forceps were withdrawn. If the pieces offered were small enough they were taken bodily within the gastric cavity, but when too large to be engulfed a portion only would be drawn within the stomodæum, remain there for two or three hours, and then be pushed away over the side of the disc.

For some time Zooxanthellæ were present within the ectoderm of the disc and upper part of the column, and rendered these regions nearly opaque ; but later they wholly disappeared from the outer layer, and, as in the adult, were restricted to the endoderm. As the polyps grew larger their walls became thinner and more transparent. The internal yellow cells were thickly distributed along the two sides of the mesenteries and within the endoderm of the stalk of the tentacles, but were sparse towards the lower part of the column. They formed an important aid in determining the course of the mesenteries within the living polyps.

The young polyps displayed great power of recovery from injury. In two or three instances the glass to which they were attached was broken in such a way that a polyp was completely divided into two, the halves adherent to different fragments; yet the two parts continued to live, and each became a distinct, though smaller, polyp, nearly circular on healing, and restoring in every way the normal form.

On the polyps attaining partial transparency, the internal cavity could be seen to contain granular matter and Zooxanthellæ in a regular rapid movement, and, by focussing at different heights, it was possible to make out the complete course of the circulation. The particles passed directly upward along the column, then transversely across the disc, downward along the endodermal surface of the stomodæum, and thus right into the central cavity of the polyp; they then continued radially across the base outwards towards its periphery, and once more up the column. The regularity of the course was a little disturbed at the opening of the tentacles into the gastric cavity. Some of the particles would circulate around this region in an eddy-like manner, or pass a little within the tentacular cavity, and afterwards be wafted along in the general current. The course is indicated in fig. 6 .

Occasionally the lips of the stomodæum would meet in the middle and remain open at each end, but no incurrent or excurrent streams were ever detected through the apertures thus formed. A bolus of organic débris, 
containing Zooxanthellæ, would at times be seen whirling round and round within the stomodæum, and would afterwards be jerked out and lost to the polyp. Even after three months such extrusions would still take place.

The young polyps varied much in their rate of growth, especially in the later stages ; indeed, in some instances, development seemed to be wholly arrested. The isolated polyps progressed most rapidly, but among these many differences were recognizable. The polyps forming colonies made scarcely any progress after the first week or two. In the group represented in plate I, fig. 6 , no increase beyond the six tentacles and twelve simple septa occurred up to six weeks, when the colony was preserved.

The development of the various organs was characterized by certain well-marked intervals of rest and growth. A week or two might pass without any conspicuous change taking place, and then progress would be somewhat rapid. The order of appearance of the organs varied somewhat in different individuals ; at first some organs of a system were developed a cycle at a time, and the remainder in successive pairs from one border of the polyp to the other. Perhaps under the artificial conditions the duration of some of the intervals was partly determined by the state of the water and the amount and character of the food supplied. Still, there were certain definite resting stages appearing in all

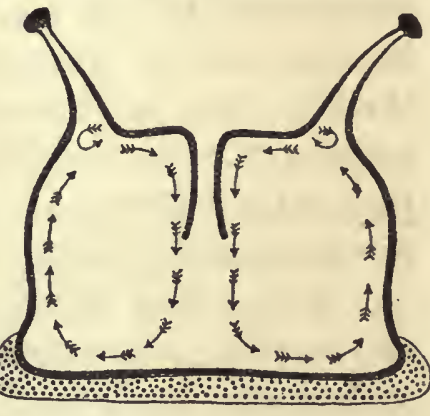

Fig. 6.-Diagram showing the course of the circulation within the internal cavity of a larval polyp. the polyps and seeming to possess a phylogenetic as well as an ontogenetic significance.

The following were the most conspicuous phases of growth: Of the mesenteries the protocnemes were established at the time of settling of the larvæ, and the six pairs are shown to develop in a regular consecutive manner without any marked intervals (p. 76). Four of the six bilateral pairs of protocnemes were connected with the stomodæum from the commencement of stationary life, but at the termination of seventeen weeks the fifth and sixth protocnemic pairs had not become complete. No further change in the number of mesenteries took place for nearly four weeks, when, in the larger polyps, the metacnemes began to appear. The different pairs of these followed somewhat quickly upon one another from the dorsal to the ventral aspect of the polyp, until the complete cycle of six pairs was established (plate 3, fig. 14). The polyps remained at this mesenterial stage for the rest of the time they were under observation-about two months. There was no hint of the appearance of the third cycle. 
As regards the tentacles, six primary exotentacles appeared simultaneously, shortly after fixation (plate I, fig. 6), followed by an interruption of two or three weeks before the entotentacles began to arise. These were at first simple outgrowths of the disc, and a long interval took place before a second moiety appeared in connection with each and thus established the mature form (plate 2, fig. II). The longest interruption, however, was after the completion of the primary twelve tentacles, for in the most forward polyps about three months elapsed before additional members appeared, when those of another cycle began to arise in a successive manner.

Of the septa the six entocœlic representatives appeared as a complete cycle at a very early stage (plate I, fig. 7), followed shortly by the six alteruating exocœlic members; these latter were developed in some instances as a complete cycle, but usually in successive pairs (plate 2 , figs. 8,9 ). Without any marked rest other fragments or nodules were added to each system, but in such a way as to render it doubtful as to which cycle they belonged (plate 2, fig. I2). On the whole, the growth of the septa was more continuous than that of either the mesenteries or the tentacles.

Undoubtedly the most conspicuous interruption for all the systems of organs was that between the protocnemic and metacnemic stages, and the great differences between the manner of appearance of the two series of mesenteries, septa, and tentacles further establishes this as the most important ontogenetic and phylogenetic interval in madreporarian development. Its significance is discussed later.

The time of appearance of the organs varied somewhat in different polyps, sometimes even to the extent of several weeks; but with regard to the actual order followed no important differences were observed in the mesenteries and septa, though less constancy prevailed amongst the tentacles. Where development was not in complete cycles the succession was bilateral, proceeding from the dorsal to the ventral borders of the polyp. Contrary to what is generally assumed, bilaterality, not radiality, was a conspicuous feature of the growth from beginning to end; and in most of the systems of organs the bilateral symmetry prevailed for lengthened periods, even where the radial condition was ultimately assumed.

Many of the young polyps were preserved at different stages-while still adhering to their original pieces of glass-and were prepared for microscopic examination as a whole. The process was as follows: After narcotization by means of magnesium sulphate or menthol the polyps were killed by pouring a solution of formaldehyde over them, and, still adherent, they were transferred to alcohol, afterwards stained, dehydrated, cleared, and mounted 
in Canada balsam as permanent preparations. The young coralla from which the photographs on plates $4-5$ were taken were prepared by macerating the polyps in caustic potash and afterwards washing or carefully brushing away the soft, loosened tissues. After maceration the skeletons could generally be freed from the glass to which they were attached by gently tapping the latter, but in some cases it was necessary to insert the edge of a razor between the basal plate and the surface of the glass.

The young polyps intended for sectionizing were detached after preservation by dissolving away the calcareous deposit with weak hydrochloric acid. In one case a living polyp of fourteen weeks became detached along with the whole skeleton, and, thus free, continued its growth for some time.

In the course of their growth the polyps increased from I to $2 \mathrm{~mm}$. in diameter, the oldest polyps reared being but $2 \mathrm{~mm}$. across the base.

TENTACLES.

FIRST CYCLE OF HXOTENTACLES.

The tentacles began to make their appearance two or three days after fixation of the larvæ, as rounded upgrowths over alternate mesenterial chambers. At this stage only the six primary pairs of mesenteries were present, giving rise to six entocœlic and six exocœlic chambers (plate I, fig. 7). Six tentacular prominences appeared simultaneously, equal in size and distance apart. They early showed an opaque white, knob-like apex distinct from a short, more transparent stem. The single cycle which they constituted served to delimit the larva for the first time into oral disc and column wall, no indication of the boundary between the two areas being hitherto determinable.

The stems of the tentacles were hollow, broad below, narrow distally, and perfectly smooth, that is, without nematoblast tubercles. The endoderm within could be seen to be richly supplied with Zooxanthellæ, while the ectoderm was colorless; the knob was solid and colorless, without Zooxanthellæ, and constituted wholly of ectoderm with numerous radiating nematoblasts.

At first the actual mesenteric chambers from which the tentacles protruded could not be determined with certainty, owing to the opacity of the polyps. Soon, however, as the polyps grew larger and the walls more transparent, the outgrowths were seen to communicate with the exocœlic chambers. As noticed below, this relationship is contrary to the general rule of tentacular development hitherto observed among the Zoantharia, and therefore the greatest care was exercised to establish it beyond a doubt. Externally the entocœlic and exocœlic mesenteric chambers could be readily determined 
from their relation to the longer oral axis and from the known relation of the complete and incomplete mesenteries at the Edwardsia stage of development; the two terminal chambers which include the longer oral axis are always the directive entocœles, and the two alternating chambers on each side between these are the lateral entocœles, while all the intermediate divisions are exocœles. Most of the young polyps were so situated as to permit of all these details being clearly observed, and in no instance were the first six tentacles developed as outgrowths of the entocœles, but were always disposed as in plates $I$ and 2 , figs. $7-9$.

As shown in plate I, fig. 7 , the six tentacles first to appear alternated with the first septa, the latter being entocœlic in position; the smaller septa which arise later (plate 2, fig. 9) correspond with the first tentacles, that is, are exosepta.

$$
\text { FIRST CYCLE OF ENTOTENTACIES. }
$$

A long interval elapsed between the appearance of the primary cycle of six exotentacles and the development of any others. Toward the close of the fourth week additional small protuberances of the disc began to appear in the interspaces between the primary series and a little nearer the center of the disc. Like the first they soon showed a distinction into apical knob and stem. In most polyps the six new tentacles arose simultaneously, constituting a second inner cycle and alternating with the first; but in some cases the members developed successively, though no dorso-ventral or other regular sequence could be established. Any intervals which occurred in the appearance of the different members were very brief, except in one instance where a fortnight passed between the appearance of the dorso-lateral and the ventro-lateral pairs.

There were now twelve tentacles present, arranged in two alternating cycles of six each; an outer cycle of six large exotentacles, the first to arise, and an inner cycle of six smaller entotentacles appearing later (plate 2, fig. I I).

Close examination soon revealed that the individual members of the inner cycle were not disposed symmetrically midway in the interspaces between those of the older cycle, but, as represented in plate 3 , fig. $\mathrm{I}_{3}$, were a little to one side. Even the tentacles arising from the axial entocœles were somewhat to the one or the other side of the principal axis of the polyp. In most cases the four small lateral tentacles were all situated toward the dorsal aspects of their corresponding interspaces, while the tentacles over the directive entocœles might be to the right or to the left of the directive axis. This peculiar arrangement of the young entotentacles was best observed when the polyps were only partly extended; during full expansion they appeared 
almost symmetrically disposed with regard to the outer cycle and the entocœlic chamber below (plate 2, fig. II).

The simple character of the entocolic tentacles on their first appearance is in marked contrast with their bifurcated form in mature polyps. As already mentioned in describing the adult colony, the genus Siderastrea is unique among West Indian corals in that its polyps possess dimorphic tentacles. The entocolic members consist of a simple stalk, divided above the middle into two smaller halves, each of which is terminated by a white, swollen knob; the exocœlic tentacles, on the other hand, consist of a simple stem with an apical knob. It was also found that in nearly mature polyps the newly formed entocœlic tentacles of the higher cycles are sometimes simple, while the older members are double (plate 6, fig. 32).

A few days after the completion of the second (inner) cycle of tentacles in the young polyps, the double character of its members began to assert itself. From certain of the entocœlic interspaces another knob-like protuberance arose beside the first tentacle, which in time became a distinct tentacle with stem and capitulum like the other member (plate 2, fig. I2). The two moieties thus formed were for some time different in size, but later became equal. The appearance was as if two small tentacles had become intercalated between, but a little central to, the interspaces of the firstformed tentacular cycle.

The second moiety of the inner tentacles exhibited no constancy in its order of appearance from the different entocœles. In plate 3 , fig. I 3 , the ventral axial member has appeared and also the two dorso-laterals, while over the dorsal and ventro-lateral entocœles the simple tentacle alone is present. In four other polyps the dorsal axial tentacle was the first to become doubled, and all the others remained single for a few days longer. In another polyp the additional outgrowth first appeared over the two axial entocœles.

The new outgrowth was at first wholly independent of the old, and to all appearances the two were to be regarded as distinct tentacles, side by side, each with its own peduncle. Later, however, a single proximal stem was found to arise, which, uniting the two as by a single stalk, raised them some distance above the disc, and the organ thus assumed the form of the entotentacles already described in connection with the mature colony (plate 3 , figs. 15, I 7 ).

The adult bifurcated entocœlic tentacle is thus seen to be primarily represented by two distinct tentacles, which only later are united by the growth of a common peduncle. It represents a unique method of tentacular growth among the Anthozoa. The double character appeared on only a few 
of the most forward larval polyps, and, for the time they were under observation, was in no instance established for all the six members.

For another period of six weeks or two months no further tentacular increase took place, though in the meantime the second cycle of mesenteries had made its appearance.

So far, four distinct stages are recognizable in the development of the twelve prototentacles of Siderastrea, each stage separated by marked intervals of rest. They are represented diagrammatically in the figures $a-c$ on p. 72 as they would appear when fully completed.

I. The stage with six exocœlic tentacles, forming a single cycle. The members are equal and appear simultaneously.

2. The stage with twelve simple tentacles, constituted of an outer cycle of six large exotentacles and an inner alternating cycle of six small entotentacles. The latter appear either simultaneously or successively in an irregular sequence. They are not situated midway over the mesenterial chambers. The four lateral members are disposed a little towards the dorsal or ventral half of the interspaces, while the directive members are somewhat to one side or the other of the principal oral axis of the polyp.

3. Six additional members of the inner entocœlic cycle appear, so that the cycle is constituted of twelve independent tentacles in six pairs. They arise in no definite sequence.

4. A single outgrowth arises over the middle of each entocœle and forms a common peduncle for each pair of entotentacles. Thus the tentacular outgrowths from each entocœle come to resemble a bilobed adult tentacle.

The appearance of the exocœlic tentacles in advance of the entocœlic in Siderastrea radians is unique in the tentacular development of Zoantharian polyps according to the researches of Lacaze-Duthiers, Faurot, von Koch, Appellöf and others, who have made us acquainted with the post-larval development of many species of anemones and corals. In the corals Caryophyllia cyathus, Manicina areolata, and Favia fragum the twelve prototentacles, constituting an inner and outer cycle, appear simultaneously, or at most there is only a short interval between one and the other; but wherever such an interval occurs, the inner entocœlic cycle appears in advance of the outer exocœlic, and the entocœlic members are larger than the exocœlic (entacmæous). In general it will be found that the production of other entocœlic structures-tentacles and septa-in corals is in advance of the exocœlic.

In actinian larvæ it is more usual for eight tentacles to appear first, arranged either as a single cycle or as an inner and outer cycle of four each. 
These correspond with the eight interspaces between the four pairs of Edwardsian mesenteries; later, as the fifth and sixth pairs of protocnemes increase in size, other two pairs of tentacles arise, and the whole become arranged in two cycles of six each. Of the primary eight tentacles in actinians six are the entocœlic members, and they early assume predominance over the exocœlic series (e.g., Lebrunia, 1899).

Clearly the number of external tentacles first appearing is determined by the number of internal mesenterial chambers already formed, seeing that the cavities of the former are continuations of the latter. Where, as in the actinian Lebrunia (I899), only four pairs of mesenteries are present when the tentacles make their appearance, it is manifest that only eight tentacles will be developed, and that the other four will be formed only when the growth of the fifth and sixth mesenterial pairs has given rise to four additional mesenterial chambers. In the species of coral larvæ so far fully investigated the six pairs of primary mesenteries-four pairs of macrocnemes and two pairs of microcnemes-are fully established at or shortly after the time of fixation and before the tentacles begin to protrude; hence six or twelve tentacles arise simultaneously, one from each mesenterial chamber.

The long interval which elapses before the more complex entocœlic tentacles are fully formed may perhaps account for the appearance in Siderastrea of the exotentacles in advance of the entotentacles. The young polyp after fixation has to provide for itself, and for this purpose its weapons of offense and defense, represented by the tentacular nematoblasts, are necessary from the beginning.

The origin of the bifurcated entotentacles from two independent moieties which appear at different times and are later elevated upon a common peduncle is a second unique feature in tentacular development. Obviously the presence of a double battery of nematocysts on each tentacle, in place of a single battery, will be of advantage to the polyp; and the growth of one moiety in advance of the other is probably to be taken as indicating an ancestry in which only one was present.

SECONDARY EXOTENTACLES.

Much interest attaches to the manner of appearance of the tentacles beyond the prototentacles, as, from the exceptional sequence of the first two cycles, it is impossible to predict from the known development of other forms how or where the next members will arise. One of the earliest stages is represented by the fully expanded disc in plate 3, fig. 15. The secondcycle mesenteries are seen stretching along the disc, decreasing in size 
successively from the dorsal to the ventral aspect. The six new pairs of mesenteries have given rise to six additional entocolic and six additional exocœlic chambers, from which further tentacles may arise; so that manifestly the mesenteries with their mesenterial chambers are formed in advance of their tentacular prolongations. At the stage represented in plate 3 , fig. I 5 , all the primary entotentacles are yet simple except the two dorso-lateral members, each of which consists of a broad stem unequally bifurcated at the dorsal extremity. The dorsal and ventral exotentacles are simple, and the broad base of each communicates with the second-cycle entocœle below as well as with the exocœle on each side of it. An additional tentacle is seen on the ventral aspect of the middle primary exotentacle on each side of the polyp, and as yet they are smaller than the exotentacles first formed. The new tentacle has pushed the older a little to one side, and both are obviously exocœlic in position, though in the figure appearing to extend over into the entocœle. There are now eight exocœlic tentacles forming an outermost cycle.

A somewhat older stage is represented by the next figure (plate 3 , fig. 16). The two middle exotentacles are equal in size and quite free from one another, and both are now seen to be wholly unconnected with the median second-cycle entocœles. Another exocœlic member has also appeared on the ventral aspect of the dorso-lateral exotentacle, on both the right and left sides of the polyp, but as yet they are a little smaller than the primary exotentacles. The four new exotentacles are situated at the same distance from the center of the disc as the primary cycle of six exotentacles, and therefore, instead of forming a new cycle, they merely add to the number of members in a cycle already established. The outer cycle of exotentacles thus consists of ten practically equal tentacles; the two wanting to complete the hexameral plan belong to the ventral system, which region is usually found to lag behind the dorsal and middle systems in the extent of its development.

The two stages (plate 3 , figs. I5, I6) demonstrate the important fact that the primary six exotentacles remain exotentacles, and always constitute part of the outermost cycle; further, any new exotentacles formed become equal in size with the primary exotentacles and are so disposed as to be members of the same cycle. The primary exotentacles do not become entotentacles when new pairs of mesenteries arise in the same radii, as from their original position might have been expected. On the appearance of the second cycle of mesenteries, they seem for a time as if communicating with their entocœles (plate 3 , fig. I 5), but this condition is only temporary. When additional exotentącles arise and the mesenteries are further developed, both 
the older and the newer tentacles are seen to communicate only with the exocœles, and the second-cycle entocœles are for a time without any tentacular outgrowths. The cycle of exotentacles when complete would at this stage consist of twelve members, of which six are primary and six are later formations, the latter appearing after the second cycle of mesenteries (fig. 7, d, p. 72).

The tentacular development of $S$.radians thus conforms with the law of substitution established by Lacaze-Duthiers (1872, '73) and Faurot (I895) for actinians-exotentacles remain exotentacles, and throughout the growth of the polyp they continually change their relationship to the entotentacles in such a manner as always to constitute the outermost cycle, and all are uniform in size.

As in the case of the two cycles of primary tentacles the secondary exotentacles appear in advance of the corresponding secondary entotentacles, so that now the cycle of exotentacles contains double the number of members of the cycle of entotentacles. In the several species whose development was carried thus far by Lacaze-Duthiers and by Faurot the exocœlic and entocœlic members appeared together along with a new pair of mesenteries, or the entotentacles were in advance of the exotentacles; later the entotentacles became larger than the exotentacles.

SECOND CYCLE OF ENTOTENTACIES AND THIRD CYCLE OF EXOTENTACLES.

Clearly the stage beyond that represented in plate 3 , fig. I6, will be one in which the tentacles begin to make their appearance over the second-cycle entocœles. Such a condition is represented in plate 3 , fig. I 7 , taken from the same polyp as plate 3 , figs. I 5 and 16 , when about a fortnight older than the stage of plate 3 , fig. I6. It is also the oldest stage reared. From the middle second-cycle entocœle on each side a simple tentacle has arisen, intercalated a little beyond the primary cycle of entotentacles, but yet within the cycle of exotentacles. The two tentacles are the first representatives of the secondcycle tentacles of the adult polyps, and the greatest interest attaches to the fact that they have displaced, as it were, some of the members of the second cycle (exotentacles), so that they now form a third cycle.

If the development of the polyps had been continued, there is every reason to suppose that a new tentacle would have appeared over each of the dorsal second-cycle entocœles. Also in the further growth of the two ventral systems another exotentacle would have appeared on each side, and then a tentacle over the second-cycle entocœle, just as in the middle systems; then all the simple second-cycle entotentacles would in time have become bifurcated 
like the members of the first-cycle entotentacles. In general, the sequence of the entotentacles would follow that of the mesenteries with which they are associated, although in plate 3 , fig. $I 7$, the growth within the middle sextants is in advance of that of the dorsal sextants.

The completed system of tentacles would consist of: $(a)$ Six bifurcated entotentacles constituting the first cycle; $(b)$ six alternating bifurcated entotentacles forming the second cycle; $(c)$ twelve alternating exotentacles, which have appeared at two wholly distinct periods, making up the third cycle.

The developmental relations between the six second-cycle entotentacles and the twelve third-cycle exotentacles are somewhat different in Siderastrea

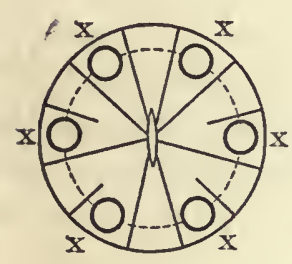

$a$

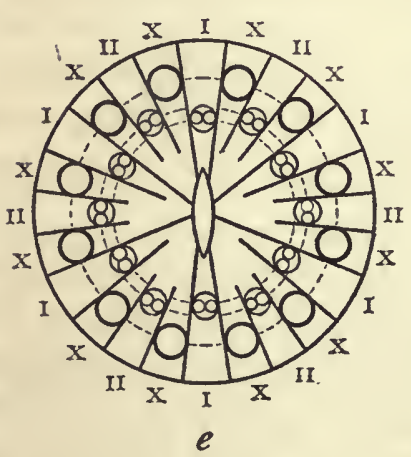

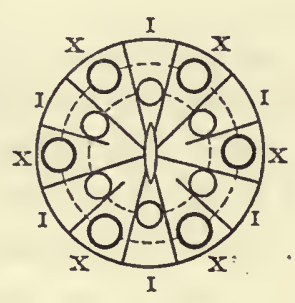

$b$

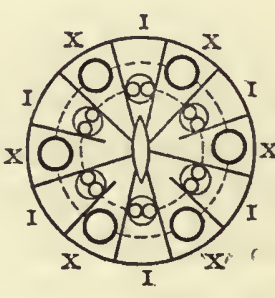

$c$

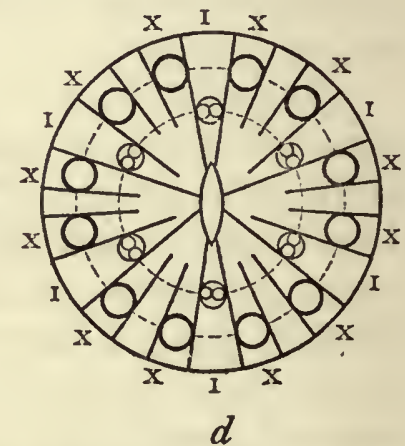

$d$

Fig. 7. - $a-e$, series of diagrams illustrating the order of appearance and relationships of the first three cycles of tentacles. The numerals $I$ and II indicate the orders of entotentacles and $\mathrm{X}$ the exotentacles.

from those hitherto met with in actinians. LacazeDuthiers (1872) first found that after the completion of the first two cycles of tentacles (six entotentacles and six exotentacles), the tentacles of the third cycle do not arise peripherally, alternating with the members of the first and second cycles, as would be naturally supposed, but that six new pairs are insinuated between the two primary cycles at six intervals only. One member of each of the six new pairs increases in size more than the other member, and ultimately constitutes the second cycle of tentacles (entotentacles), displacing the primary second cycle of exotentacles; the other member of each new tentacular pair attains the same size as the displaced exotentacles, and along with them forms the third cycle of twelve tentacles. The third cycle is thus formed of six tentacles from the original second cycle and six tentacles which are later formations; the members of the permanent second cycle are all new formations which have displaced the older second-cycle members. Lacaze-Duthiers expressed these relationships under the term "law of substitution." 
In Siderastrea the second cycle for a time consists of twelve exotentacles, six of which are primary formations and six are later outgrowths. The latter appear in advance of the corresponding entotentacles, not along with them, as seems to be the case in most actinians. Afterwards, however, a new cycle of six entotentacles is intercalated between the original first and second cycles, displacing the latter to the third cycle, and itself constituting the permanent second cycle. The law of substitution thus holds for Siderastrea as for actinians, though the relative time of appearance of the entotentacles and exotentacles differs from that usually followed. Faurot (I895) shows that in Ilyanthus parthenopeus the entotentacle from a new mesenterial pair arises in advance of the exotentacle, exactly the reverse of that in Siderastrea.

THIRD CYCLE OF ENTOTENTACLES AND FOURTH CYCLE OF EXOTENTACLES.

As the larval polyps were not reared beyond the beginning of the three-cycle stage, it will be necessary, in order to complete the survey of the tentacular development, to have recourse to bud polyps of a colony. From what has been established above it is manifest that the problem is not to determine the manner according to which the fourth cycle of the adult polyp will arise, but how a third cycle of entotentacles originates and is intercalated between the previously formed second and third cycles. The exotentacles as a cycle are shown to have no ordinal significance in studies of tentacular sequence; this importance belongs to the entotentacles. Regarded cyclically the exotentacles are but temporary predecessors of the entotentacles of the adult polyp.

On any colony are numerous polyps in which the tentacles vary from twenty-four to nearly forty-eight. In the polyp represented on plate 6, fig. 32 , there are three third-cycle entotentacles, each with a corresponding exotentacle. The former are yet at an early stage of development, only one moiety of the tentacle having appeared. In fig. I, p. I2, is represented diagrammatically the tentacular plan of the polyp of which the mesenterial system is given in plate 6 , fig. 34. Along with each of the five pairs of third-cycle mesenteries (III) have appeared two corresponding tentacles, and, comparing with fig. 3 , p. 26 , one of the tentacles is seen to be entoccelic (III) and the other exocœlic $(\mathrm{x})$. The new entotentacles, III, are situated beyond the second cycle of entotentacles, II, but within the outermost exocolic cycle; that is, they represent the commencement of a third cycle of entotentacles, and the exotentacles are now being relegated to a fourth cycle. At this stage, therefore, some of the exotentacles may be considered as belonging to the third cycle and some to the fourth cycle. Under the circum- 
stances it was not possible to say whether the new exotentacles appeared in advance of the entotentacles, but from the order actually observed in the first three cycles it may be assumed that such was the sequence. It will be observed that the new tentacular pairs are situated on the dorsal aspect of the four sextants, along with one pair on the ventral side of the right middle sextant.

New exotentacles and entotentacles have been found to arise shortly after the appearance of new mesenterial pairs. Therefore, if the third-cycle mesenteries develop normally with the regularity outlined on $\mathrm{p} .83$, a single entotentacle and exotentacle would be expected to appear on the dorsal aspect of each sextant, and then the corresponding ventral series would commence, both starting with the dorso-lateral systems and proceeding to the ventro1ateral. In a colony where the polyps are so closely arranged as in Siderastrea, however, the later growth rarely proceeds according to such a regular law, so that very little importance can be attached to the order of appearance of the tentacles making up the outer cycles. All the studies on corals seem to indicate that the mesenteries, tentacles, and septa develop conformably to a regular plan for the first and second cycles, but that the regularity is frequently departed from in the later stages.

If the cyclic hexameral plan of the tentacles in $S$. radians were completed the formula would be 6,6, I 2,24 . The first three cycles would be entotentacles and the last exotentacles; the members of any one cycle would be equal in size, but those of the inner cycles somewhat larger than those of the outer cycle. The entotentacles would have appeared in a fairly regular sequence, the inner cycle first, the middle cycle next, and the third cycle last; but it is altogether otherwise with the fourth cycle, constituted only of exotentacles. Six of its members appeared a little in advance of the first cycle of entotentacles; other six a little in advance of the second cycle of entotentacles; and twelve more in advance of the third cycle of entotentacles. The exotentacles at each stage form a complete cycle; first a cycle of six, then a second cycle of twelve, which afterwards becomes a third cycle, and, lastly, a third cycle of twenty-four, which afterwards becomes a fourth cycle. In this way they always constitute the last or outermost cycle for the time being. At the termination of each stage the number of outer simple exotentacles equals the sum of the bifurcated entotentacles making up the inner cycles; but, until the adult stage is reached, as a cycle they occupy the position which later will be occupied by the entotentacles.

When, however, the hexameral cyclic plan is not complete in the adult, that is, where the last cycle of entotentacles commenced is not completed 
according to the hexameral sequence, then the formula must be different from that given above if it has to express the true morphological value of the tentacles as entotentacles and as exotentacles. Cyclic incompletion has been shown to be practically always the condition in adult polyps of $S$. radians; two cycles of entotentacles are hexamerously complete, but the third cycle of entotentacles consists of a variable number, rarely reaching the required number twelve. Regarded cyclically, some of the exotentacles belong to the third and some to the fourth cycles; but until they form a complete hexameral cycle, it is preferable to consider the exotentacles simply as the outermost tentacles, not as forming a cycle. The morphological formula will thus be $6,6, x, 6+6+x$, where $x$ may be any number from one to twelve; the series 6,6 , $x$, will represent the number of entotentacles, and $6+6+x$ the number of exotentacles. The number of exotentacles will vary in the same degree as the number of third-cycle entotentacles. Later, a similar formula is established for the septa.

The different tentacular cycles in the adult polyps of Siderastrea are much more widely apart than in the larval polyps ( $f$. plate 6 , fig. $3 \mathrm{I}$; plate 3, fig. I7). In the latter the closeness of the cycles recalls the condition characteristic of the majority of anemones and corals.

The principal facts concerning the development of the tentacles of $S$. radians may be now summarized.

I. The first tentacles to appear consist of a cycle of six members, one from each of the six primary exocœles. They arise simultaneously, are equal in size, and remain simple throughout.

2. Shortly afterwards six smaller tentacles arise, forming a second cycle, situated internally to the first, and communicating with the six primary entocœles. They may develop either simultaneously or in successive pairs from the dorsal to the ventral aspect. They are not symmetrically situated as concerns the mesenterial chambers. Later, another entocœlic tentacle appears alongside each of the first members, and then a common peduncle is formed which elevates the two moieties so as to form the single bifurcated tentacle of the adult.

3. The second cycle of mesenteries having appeared, a new exotentacle arises from each additional exocœlic chamber within the six primary systems of the polyp. In general the succession is from the dorsal to the ventral systems, and the new tentacle is on the ventral aspect of the older exotentacle belonging to the same system, but many variations occur. The six new exotentacles arrange themselves in the outermost or second cycle, which thus consists of twelve members, equal in size, and all simple. 
4. Additional tentacles are now intercalated between the inner and outer cycles already established. They arise, apparently without any regular sequence, from the six entocœles of the second pairs of mesenteries, and, like the members of the first cycle of entotentacles, are at first simple, but afterwards bifurcated. When the cycle is completed it constitutes the second tentacular cycle of the mature polyp; the original second cycle of six exotentacles, now consisting of twelve members, becomes at this stage the outermost or third cycle (law of substitution).

5. As the pairs of third-cycle mesenteries develop, two tentacles, one entocœlic and one exocœlic, arise in connection with each. The entocœlic representatives appear between the second and outermost cycles of the previous stage, and thus constitute a new third cycle; the exocolic representatives arrange themselves among the members of the outermost cycle, which now becomes the fourth of the tentacular cycles. Here, as in the two previous cycles, the entotentacles are at first simple, then another moiety appears, and finally a common stalk.

6. The hexameral cyclic plan of the third-cycle entotentacles in $S$. radians being usually incomplete, the morphological tentacular formula for the whole polyp with four cycles is $6,6, \mathrm{x}, 6+6+\mathrm{x}$, where $\mathrm{x}$ may be any number from one to twelve.

\section{MESENTERIES.}

FIRST CYCLE OF MESENTERIES (PROTOCNEMES).

The earliest larvæ reveal, both externally and in sections, only eight mesenteries, arranged in four bilateral pairs, two axial and two lateral. Of these the two lateral pairs are already united with the stomodæum, but the dorsal and ventral axial pairs are free, the ventral pair being a little larger than the dorsal (plate I, fig. 3). In other larvæ, only a day or two older, the two ventral mesenteries have become united with the stomodæum, but the dorsal are still free, and two new pairs, the fifth and sixth, are beginning to make their appearance (plate I, fig. 4 , and plate 8, fig. 5 I). At the stage at which the larva settles four pairs of mesenteries, two lateral pairs and the dorsal and ventral axial pairs, are complete, and the fifth and sixth pairs have become a little larger, but remain free from the stomodæum (plate I, fig. 6). This is the stage represented by all the larvæ at or shortly after fixation, and is evidently one of importance in the ontogeny of the polyp, for no further mesenterial development took place for a period of three or four weeks.

In transverse sections of the larvæ the vertical muscle fibers of the mesenteries are already sufficiently well developed to permit of the directive 
and unilateral pairs being established. On the dorsal and ventral axial pairs the musculature is on the faces of the mesenteries turned away from one another, which, by this means, are recognizable as directives. The musculature on each complete lateral mesentery is on the ventral face turned towards the incomplete mesentery, while this bears its muscle fibers on the dorsally directed face, so that each unilateral pair of mesenteries at this stage is made up of a complete and an incomplete moiety (anisocnemic).

On the reasonable assumption that the comparative sizes of the mesenteries indicate their order of appearance in the larvæ, the two bilateral pairs which first unite with the stomodæum (plate I, fig. 3) are the first and second pairs to arise. At the stage available little difference in size is represented by these two pairs, so that it could not be readily determined which is the first pair and which the second. The results of Von Koch (1897), Wilson (I888), and others who have studied earlier stages of coral larvæ, leave no doubt, however, that the ventral of the two pairs is the first, and that the dorsal pair is the second. Frequently in other corals the first pair is for a time much better developed than the others, and bears well-defined filaments (I902, p. 528). From the relationships shown on plate I, fig. 4, and plate 8 , fig. $5 \mathrm{I}$, there can be no uncertainty as to which are the third and fourth mesenterial pairs. The ventral pair of directives is larger, and unites with the stomodæum in advance of the dorsal pair; it is therefore the third pair in the mesenterial sequence, and the dorsal directives will be the fourth.

The incomplete mesenteries on plate $I$, fig. 6 , representing the fifth and sixth bilateral pairs, arise practically at the same time, and for the most part remain equally developed. The more dorsal of the two in some instances outstrips the other, and in other corals and actinians is frequently found to unite with the stomodæum in advance of the more ventral. Whatever differences exist in size or time of union with the stomodæum support the view now generally held that the incomplete pair of mesenteries between the first and second pairs is to be regarded as the fifth, and hence the pair between the first and third pairs is the sixth.

The sequence of the protocnemes thus established for Siderastrea radians is in strict agreement with that ascertained by $\mathrm{H}$. V. Wilson (1888) for Manicina areolata, and by Von Koch (I897) for Caryophyllia cyathus, both of whom had a complete series of larval stages for investigation. It is also supported by the various early stages in other corals which I have had under observation (I902, p. 450). The same order is followed by nearly all 
actinians, * though the evidence for the Ceriantheæ and Zoantheæ is not yet conclusive:

The length of time the young polyps of Siderastrea remained with only twelve mesenteries-eight macrocnemes and four microcnemes-would indicate that the stage is one of phylogenetic, as well as ontogenetic, significance. No marked resting stage in the mesenterial development occurred until this was reached, while none of the polyps showed further progress until the expiration of three or four weeks, and some of the smaller polyps remained thus for three months. Further, the fact that four pairs united with the stomodæum, while two pairs remained separate for the whole seventeen weeks, the six pairs of second-cycle mesenteries arising in the meantime, would suggest a different significance for the complete and incomplete groups $(8+4)$.

The relationship, $8+4$, is characteristic of the larvæ and young polyps of Madreporaria and Actiniaria generally, and persists in some species throughout the life of the polyp. Only the first four pairs of mesenteries are ever united with the stomodæum in the Edwardsidæ, Gonactinia, and some other Actiniaria, and in the mature polyps of all West Indian species of Madrepora and Porites the same eight protocnemes alone are complete, and the other four remain incomplete.

The long retention of freedom of the fifth and sixth pairs of protocnemes suggests to my mind an ancestry in which the mesenteries as a whole, including the metacnemes, were alternately long and short, excluding, of course, the axial directives. Among modern examples this is retained in the mesenterial system of the zoanthids, Porites, and Madrepora, and was perhaps characteristic of the Rugosa. The arrangement of the musculature on the mesenteries in the Ceriantheæ, always on the face towards one aspect of the polyp, can be also understood if one considers that the incomplete mesenteries present in such forms as the zoanthids are never developed; the cerianthids retain the simplest protocnemic stage of any of the forms here considered, having only four bilateral pairs.

In the Ceriantheæ and Zoantheæ the mesenteries beyond the protocnemes arise at only one or two restricted regions of the polyp (bands of proliferation), not all round the circumference, as in most modern anemones and coral polyps; and four such zones or bands of proliferation would appear to have been characteristic of the mesenterial growth in Palæozoic coral polyps. The

* Appellöf (1900) has discussed fully the value to be assigned the accounts of Lacaze-Duthiers, Haddon, and others as to various other sequences of the primary mesenteries in actinians. Throughout their work Delage and Hérouard (1902) transpose the order of the fifth and sixth pairs as given above. 
mesenteries and septa in all these are never more than dicyclic. With the later introduction of a radial polycyclic arrangement of the mesenteries and septa, by the addition of exocœlic pairs in all the sextants, the fifth and sixth protocnemic pairs begin to unite with the stomodrum, and so produce a more approximate radial symmetry in the adult. But that the alternately macrocnemic and microcnemic arrangement is more primitive seems to be still suggested in the long separation from the stomodæum of the fifth and sixth protocnemes, found to be characteristic of recent actiniarian and madreporarian polyps.

The first twelve mesenteries in Siderastrea have been shown to arise in bilateral pairs, a member on each side of the median axis, and the order is such that each new pair appears alternately in the successively oldest chamber. As the mesenteries become fully established another paired arrangement is introduced. The directives throughout the life of the polyp constitute bilateral pairs; but now the second and fifth mesenteries on each side form what I have termed unilateral pairs, and likewise the first and sixth mesenteries on each side. Though varying so much in their order of appearance and in their primary relations to one another, the six pairs in the end constitute a regular cycle and appear all of the same value; at first they are anisocnemic pairs, but they become isocnemic when the fifth and sixth bilateral pairs come into union with the stomodrum. Thus a truly radial disposition of the parts results from a primary bilateral origin, a result found to be continually recurring in the development of the different systems of organs.

SECOND CYCLE OF MESENTERIES (METACNEMES).

For a period of several weeks after fixation no addition to the twelve protocnemes took place; the four incomplete members continued to increase in size, though remaining free from the stomodæum. Mesenterial filaments began to show as dense, more opaque tissues within the interior of the polyp, but their relative development could not be followed in the living polyp.

Towards the end of the fourth week some of the polyps presented rudiments of the second-cycle mesenteries. Their first appearance externally was as two narrow lines along the column wall, towards its aboral termination, and within the dorsal exocœle of the right and left sides. A few days afterwards these were followed by a similar pair of lines within each of the two middle exocœles, and still later by a pair within each ventral exocœle (plate 3, fig. 4 ). The actual time of appearance of the dorsal pairs, and also the intervals between the three sets, varied somewhat in different polyps; 
the periods here given are for the most forward specimens. The six pairs together constituted the second cycle of mesenteries or first cycle of metacnemes, the different pairs diminishing in size from the dorsal to the ventral aspect of the polyp. Their order of appearance and comparative sizes are diagrammatically shown in fig. $8(d-f)$.

The interval between the appearance of the dorsal and middle, and between the middle and ventral pairs, was usually well marked, so that at

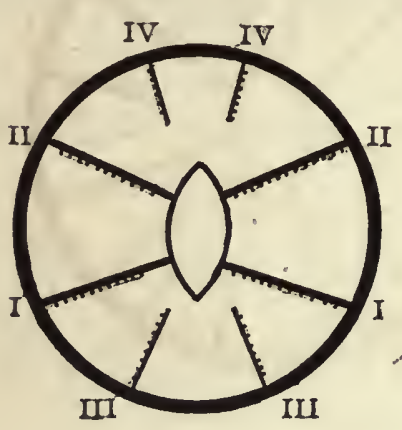

$a$

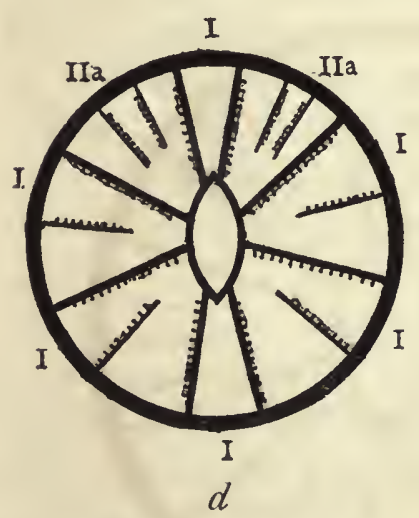

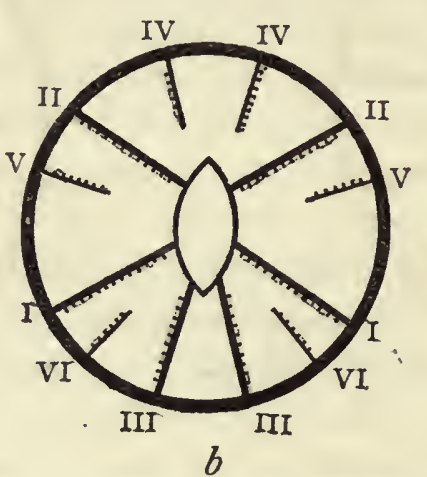

Frg. $8\langle a, b, c, d)$.-Series of diagrams illustrating the order of development of the first three cycles of mesenteries. $a-c$ represent the order for the first cycle (protocnemes), $d$, the first stage of the second cycle (metacnemes).

any time the different phases could be easily observed. About four weeks elapsed between the appearance of the first or dorsal pairs and that of the third or ventral pairs. Usually, the pairs on opposite sides of the polyp would arise simultaneously, but in one instance the left pair in the ventral exocœle was apparent for over a week in advance of the right pair in the corresponding exocœle. In every instance the two members of a unilateral pair appeared simultaneously and developed equally.

The metacnemes increased slowly in length, and reached the aboral termination of the column long before they extended to the distal extremity. For many weeks the pairs differed in their vertical extent corresponding with their dorso-ventral appearance; even at the close of the observations the distinctions were strongly indicated, giving to the polyp a bilateral symmetry (plate 3, fig. I7). After the third month they began to extend across the oral disc, the dorsal pairs being first recognizable, then the middle, and later the ventral. They never, however, reached the stomodæum, this condition being also characteristic of the adult polyp. 
A dorso-ventral sequence in the development of the six pairs of secondcycle mesenteries, as compared with their simultaneous appearance, has long been known in actinians; in fact, from the time of the Dixons' account of
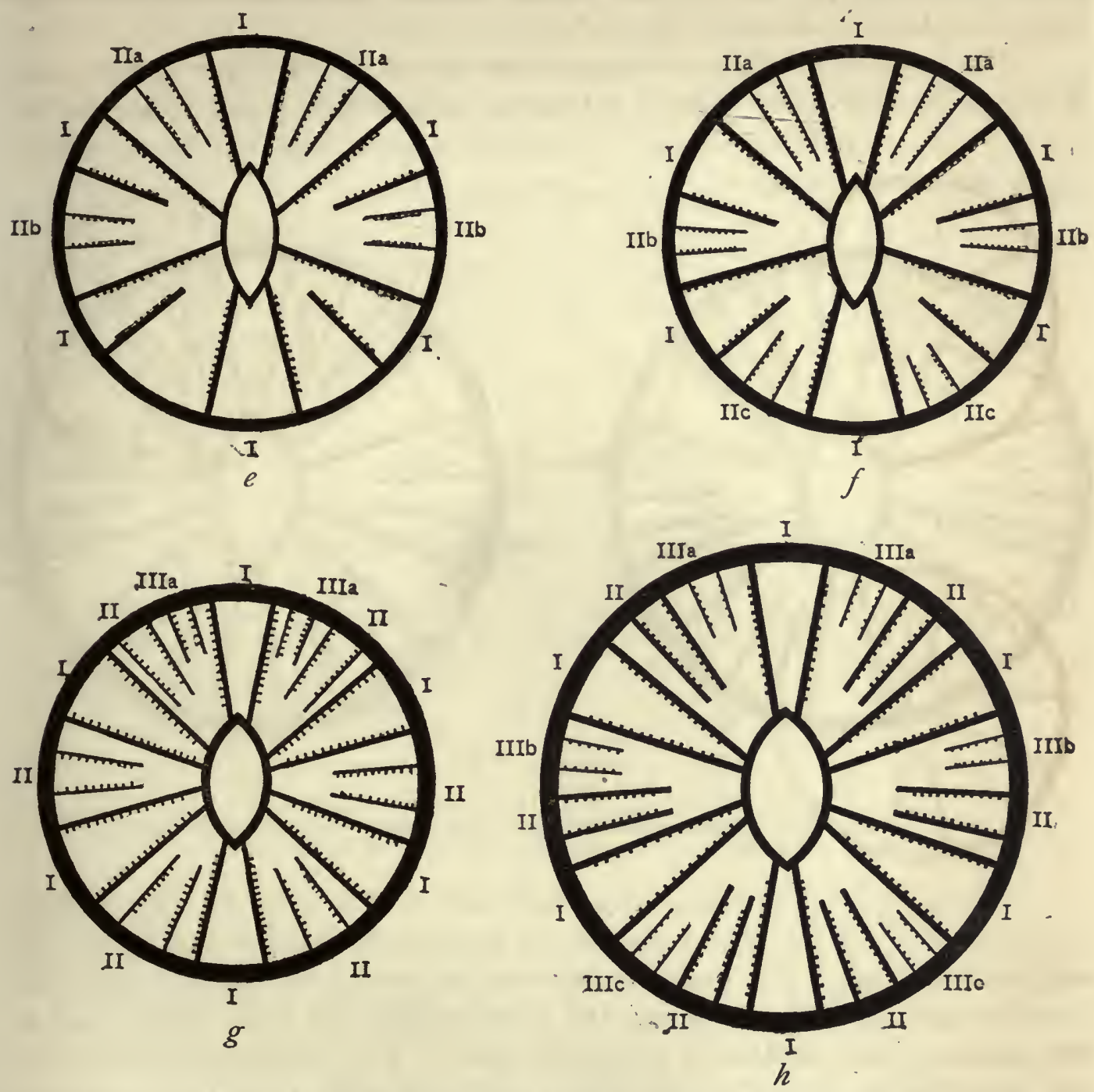

Fra. $8(e, f, \xi, h)$, continued.-Series of diagrams illustrating the order of derelopment of the first three cycles of mesenteries.

$e$ and $f$ represent the second and third stages for second cycle, and $f$ and $h$ are two early stages of third cycle.

the relative sizes of the pairs in certain late larvæ of Bunodes. Apparently, however, the present is the first occasion on which the actual appearance has been followed stage by stage in the living polyp.

The developmental stage now reached is one which frequently recurs in zoantharian studies. Of the protocnemes, the eight Edwardsian members 
are complete and the fifth and sixth pairs are incomplete; the six pairs of second-cycle mesenteries are incomplete, and either equal or show by differences in sizes their dorso-ventral succession. The stage may be found among adult Edwardsias, though two or more pairs of second-cycle mesenteries may here be wanting; adult members of the Ilyanthidæ often present it, and probably all higher actinians in the course of their development. It is repeated by the many pelagic anthozoan larvæ described by Van Beneden (I897, p. I89), numbered vIII to XV, and which the author regards as belonging to the Hexactiniaria.
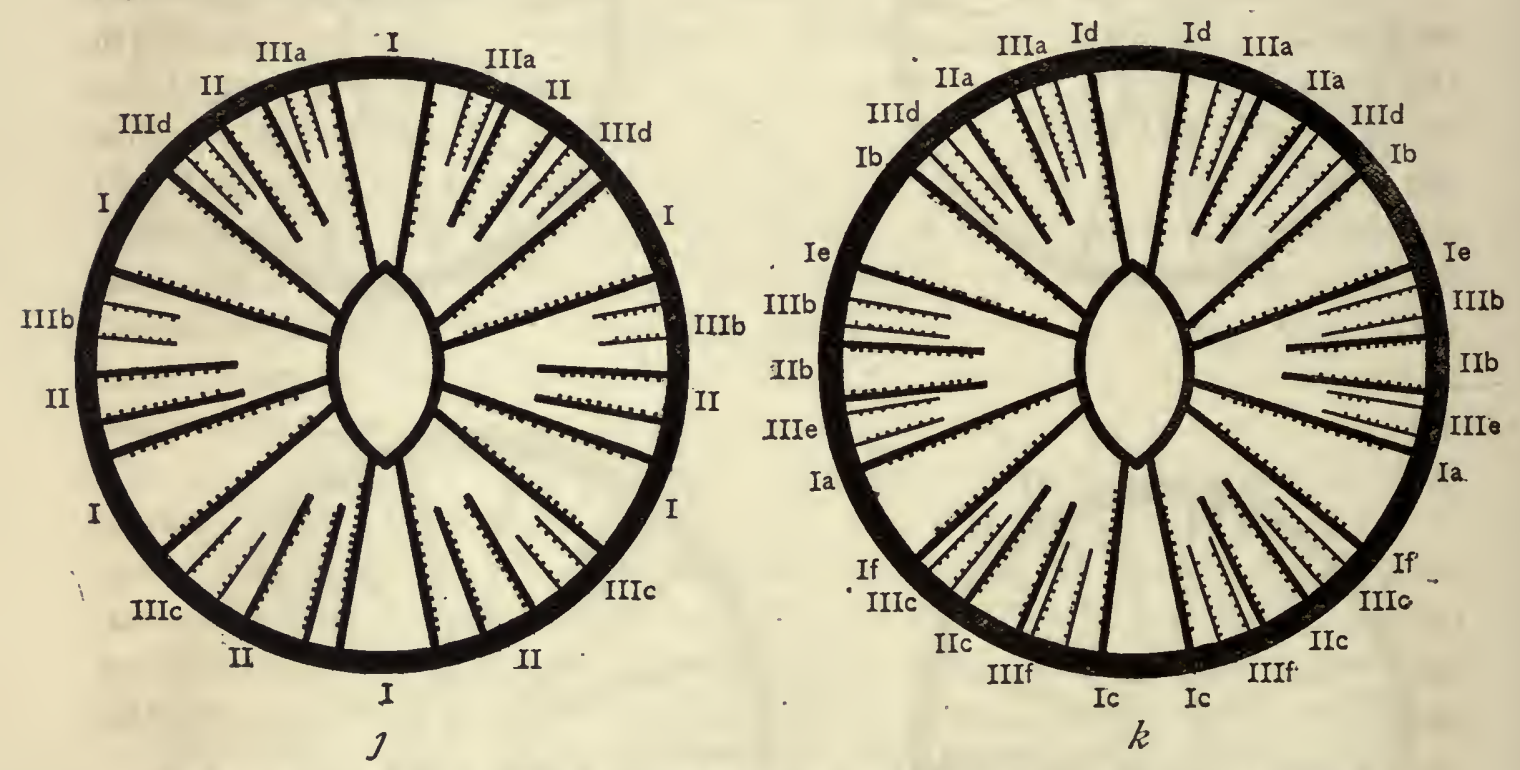

FIG. $8(j, k)$, continued.-Series of diagrams illustrating the order of development of the first three cycles of mesenteries. $j$ is 2 late stage, and $k$ the complete stage in the development of the third cycle. ,

A long interval of time, and a fundamental difference in their manner of appearance, are found to separate the second-cycle mesenteries from those of the first cycle. The primary mesenteries appear in bilateral pairs first towards one aspect of the polyp and then towards the other aspect, and so on, and only later constitute unilateral pairs. The secondary mesenteries, on the other hand, are in unilateral, isocnemic pairs from the beginning, and arise within the six primary exocœlic chambers in a regular dorsoventral succession, alternating with the primary pairs. Though presenting such a difference in development, the two series agree in each forming a cycle or order of six isocnemic pairs when mature.

It was to emphasize these fundamental differences in origin between the primary mesenteries and the later members that, in a former paper, I termed 
the first cycle of six pairs of mesenteries "protocnemes," and all subsequent mesenteries "metacnemes," whether becoming arranged in cycles or not. The protocnemic stage is practically the same for all the different groups of Actiniaria and Madreporaria. It is in the metacnemic stage that distinguishing characteristics are introduced, development in all cases proceeding in a manner altogether different from that of the protocnemic stage. The interval is thus one of the greatest significance in the phylogeny of the Anthozoa, as well as in the ontogeny of the individual polyp.

The metacnemic development here established for Siderastrea is that most usual for ordinary anemones and corals; new isocnemic pairs appear in the six primary exocœles all round the polypal wall. In the group of the Zoantheæ the metacnemes appear at only two restricted regions, one within the exocœle on each side of the ventral directives, and each unilateral pair consists of a large and a small member (anisocnemic). In the Ceriantheæ the metacnemes appear as bilateral pairs at only one region, within what seems to be the entocœle of the ventral directives. Furthermore, the metacnemes in the Zoantheæ and Ceriantheæ do not form one or more cycles distinct from the protocnemes (monocyclic), as in Siderastrea, most other modern corals, and ordinary anemones (polycyclic).

These differences in the origin of the metacnemes separate in the clearest manner the zoanthids and cerianthids from ordinary actinians and corals. On the other hand, the metacnemic similarity in actinians and madreporarians proves that the two groups are much more closely allied to one another than to any other group; the only important difference between the two consists in the presence or absence of a calcareous skeleton.

In general, it will be found that in the Actiniaria and Madreporaria the organs as a whole beyond the protocnemic. stage develop successively from one border of the polyp to the other. The adult cyclic arrangement is clearly a later modification of a primary dorso-ventral plan ; in some instances, however, the cyclic tendency strikes back, as it were, to the first appearance of certain of the organs, for the prototentacles and protosepta usually arise a cycle at a time. The second-cycle septa in $S$. radians are also interesting in this respect, for in some polyps the six members of the cycle appeared simultaneously, but in others in successive pairs (p. 87).

THIRD CYCLE OF MESENTERIES.

The polyps reared from the larva were not kept alive beyond the completion of the first and second cycles of mesenteries; hence for what follows as to the order of appearance of the third cycle recourse will be had to 
colonial polyps arising asexually as buds. Fortunately, in any colony, individuals of various sizes occur, and thus all the stages in the growth of the third cycle can be secured. As already traced, the mesenteries consist of six equal pairs of protocnemes all united with the stomodæum, the fifth and sixth pairs having become complete, and six smaller, incomplete pairs of metacnemes, alternating with the former. Following the laws of hexactinian cyclic symmetry the third cycle of mesenteries should consist of twelve equal pairs situated within the exocœles formed by the first and second cycles; the problem is to determine their order of appearance.

The earliest stage obtained in the formation of the third cycle of mesenteries is diagrammatically represented in fig. $8, g$, p. $8 \mathrm{I}$, taken from one of the small bud polyps of a colony. Iu addition to the primary and secondary cycles an isocnemic pair of mesenteries has appeared on each side of the median axis, in the exocœle between the dorsal directives and the dorsal pair of second-cycle mesenteries. Such an early stage would be expected on the dorso-ventral succession already established for the second cycle. The chamber within which the next pair of mesenteries will arise.is, however, one of much significance. The succeeding exocœlic chamber on each side is between the dorsal pair of second-cycle mesenteries and the dorso-lateral pair of first-cycle mesenteries, and it might be supposed that the new mesenteries would occupy the exocœles in regular succession, from one border of the polyp to the other. Instead of this it is found that the pairs arise successively within only the dorsal of the two exocœles of each system. This condition is shown in fig. $8, h, \mathrm{p} .8 \mathrm{r}$, the next stage available, where a thirdcycle pair (III) is found within the dorsal exocœle of each of the six systems.

A later stage secured in the establishment of the twelve third-cycle mesenteries is given in fig. $8, j, \mathrm{p} .82$, where an additional pair (IrI, $d$ ) has appeared, this time within the ventral exocœle of the two dorsal systems. Clearly, if the succession here indicated were followed with perfect regularity, other pairs would appear within the ventral exocœles of the middle and ventral systems, and the cycle would then be completed according to fig. $8, k$, p. 82. No stage exactly corresponding with this figure, however, has been obtained, as the polyps of $S$. radians very rarely, if ever, complete the third cycle of mesenteries.

The stages above presented prove that in the establishment of the third cycle of mesenteries the dorso-ventral succession is twofold: First, a series of six pairs within the dorsal exocœles, and then a similar series within the ventral exocœles of each system.

The regularity in the sequence, represented by fig. $8, g-k$, was secured 
only after examination of a number of polyps. In a colony in which the polyps are so closely arranged as in $S$. radians it is found that the individuals rarely undergo their later development with perfect regularity all roundsome regions will be in advance of the normal sequence and others behind. The polygonal form assumed by the adults is evidence that pressure is exerted upon a form which otherwise would be circular, as in simple polyps reared from larvæ. Spatial difficulties may therefore be held sufficient to account in a large degree for the many irregularities obtained in the establishment of the third mesenterial cycle.

The mesenterial plan of two other polyps is given in figs. 3 (p. 26) and I I (p. Ioo), and illustrates the variability encountered. In fig. 3 the sequence is normal except that a pair of mesenteries (III $e$ ) has appeared within the ventral exocœlic chamber of the right middle system in advance of the pairs in the dorsal exocœles of the ventral systems. The polyp represented in fig. II presents many departures from the normal regularity; two third-cycle pairs occur within three systems, one pair within another, and two systems are without any third-cycle pairs.

In Astrangia solitaria and Phyllangia americana, where the polyps are practically separated from one another and retain their cylindrical form throughout, the regularity of development all round is more pronounced, and the general order of appearance of the mesenteries established in $S$. radians is found to be maintained from beginning to end (I9O2, p. 459).

Hitherto, the development of the third-cycle mesenteries has not been actually followed either in actinians or corals. Faurot's studies in 1895 were confined mostly to the tentacles. Carlgren* has described a condition of the mesenteries in the actinian Condylactis cruentata, in which the twelve pairs of third-cycle mesenteries as a whole, as well as the exocœlic chambers in which they are situated, show a gradual decrease in size in passing from the dorsal to the ventral border of the polyp. Pairs IIr $a$ and Ind in the enumeration of fig. $8, k, \mathrm{p} .82$, were larger than pairs III $b$ and III $e$, and these than pairs IIIC and IIIf; hence, if the condition obtained by Carlgren really repre sents the sequence followed in the growth of the third-cycle mesenteries in Condylactis, it is altogether different from that of corals, being simple instead of twofold.

I believe it will be found in corals generally that the sequence of the later mesenteries is by no means so regular as that of the earlier cycles. The order followed by the organs in the first and second cycles is fairly constant, but this can not be asserted of the third cycle, and probably the regularity

* "Zur Mesenterienentwicklung der Aktinien," Öfvers af R. ret.-Akad. Förh., Stockholm, 1897. 
will be even less in still higher cycles. As the polyps increase in size the forces of growth are less likely to act with the regularity and uniformity which they do in the earlier stages when the polyps are small; even though in the end the cycles obtain hexameral completion it will be brought about with much individual variation.

No polyps of $S$. radians having mesenteries belonging to a fourth cycle have been found, and nothing is yet known as to the normal sequence according to which the cycle is established in other species.

The chief facts concerning the mesenterial sequence in S. radians may be now summarized:

I. The six pairs of first-cycle mesenteries (protocnemes) arise as bilateral pairs in a regular alternation from one aspect of the polyp to the other. The first four pairs early unite with the stomodæum, but the two last pairs $(\mathrm{v}, \mathrm{VI})$ remain free for a long period. Later, the second and fifth, and the first and sixth mesenteries, on each side, form isocnemic pairs, and the third and fourth pairs constitute the directives.

2. The six pairs of second-cycle mesenteries arise bilaterally as unilateral isocnemic pairs on each side of the polyp, and appear successively in the primary exocœles from the dorsal to the ventral border; ultimately they become equal and exhibit perfect radial symmetry.

3: The twelve pairs of third-cycle mesenteries also arise bilaterally as unilateral isocnemic pairs on each side. Normally six pairs appear in a successive manner from the dorsal to the ventral aspect of the polyp, a pair within the dorsal exocœle of each sextant; then other six pairs appear in the same succession, a pair within the ventral exocœle of each sextant. Generally some of the pairs of third-cycle mesenteries are wanting in mature polyps.

\section{CORALLUM.}

FIRST CYCLE OF RNTOSEPTA AND SECOND CYCLE OF RXOSEPTA.

Three or four days after fixation of the larva the skeleton was first observed through the transparent tissues of the living polyp in the form of six small radiating septal upgrowths, practically equal in size. At the same time a narrow peripheral calcareous ring was seen, its outer surface uncovered by the polypal tissues (plate I, fig. 7). The six septa were perfectly free from one another and from the outer anuulus, and arranged at equal distances apart within the six entocœlic chambers, thus alternating with the cycle of six exocœlic tentacles first to arise. Each septum appeared as a somewhat spindle-shaped bar with the upper edge strongly spinous and the lower edge flat and adherent to the glass to which the polyp was affixed. 
A day or two after the formation of the first cycle of entosepta, the six exocœlic septa began to make their appearance, in some cases simultaneously, but in others in successive bilateral pairs from the dorsal to the ventral border of the polyp (plate 2, figs. 8,9 ). Fig. 8 shows that a pair of septa has appeared within the dorso-lateral exocœles, mere rudiments of septa are found in the middle exocœles, and as yet there is no indication of the ventro-lateral exocœlic pair. For a long time, as shown by the coralla on plates 4 and 5 , the dorso-lateral pair is better developed than the middle pair, and the middle than the ventro-lateral pair. The ventral pair in nearly all cases remained conspicuously smaller than the other pairs. Where, however, the second cycle is fully developed (fig. 9), its six members are disposed midway in the six interspaces between the members of the primary cycle, and remain shorter than the latter. As in the entosepta the surface is spinous along the edge and over both lateral faces.

Thus, within the first week two complete cycles of septa (protosepta) were developed-a primary cycle, consisting of six equal entosepta, and a secondary cycle of six smaller exosepta, the latter having appeared later and diminishing in size from the dorsal to the ventral border. A narrow peripheral calcareous ring, unconnected with the septa, was also formed at the same time. This is shown by later observations to be a marginal continuation or upgrowth of the basal plate (p. II5), and therefore to be regarded as an epitheca. Only the Edwardsian mesenteries were united with the stomodæum, and of the tentacles the six exocœlic members alone were developed.

The order of appearance of the twelve protosepta is thus in marked contrast with that of the twelve protocnemes with which they are associated. The latter have been found to arise in bilateral pairs, first towards one aspect of the polyp and then towards the other, and the six pairs (four macrocnemic and two microcnemic) are fully established before any of the septa arise. The six entosepta, on the other hand, appear simultaneously; and such is usually the case with the six exosepta in other corals, though not in Siderastrea.

The symmetrical growth of the skeletal structures, represented on plate 2, figs. 9 and Io, generally took place only in completely isolated polyps, free to develop equally all round, and even in these irregularities were sometimes introduced. Among the young polyps forming the aggregated miniature colony in fig. 5, p. 6o, the septal development was scarcely alike in any two. Where, as at the two extremities of the colony, one polyp partly overfolds another, only half the number of septa occurs, while in the others the alternation of large and small septa is inconstant; further, the epithecal 
wall of two contiguous polyps is common along the lines of adherence, and the outline, instead of being circular, becomes more or less polygonal as a result of the mutual pressure.

The protoseptal stage was completed in nearly all cases within the first

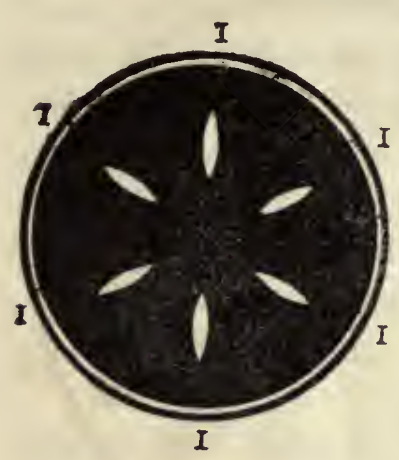

$a$

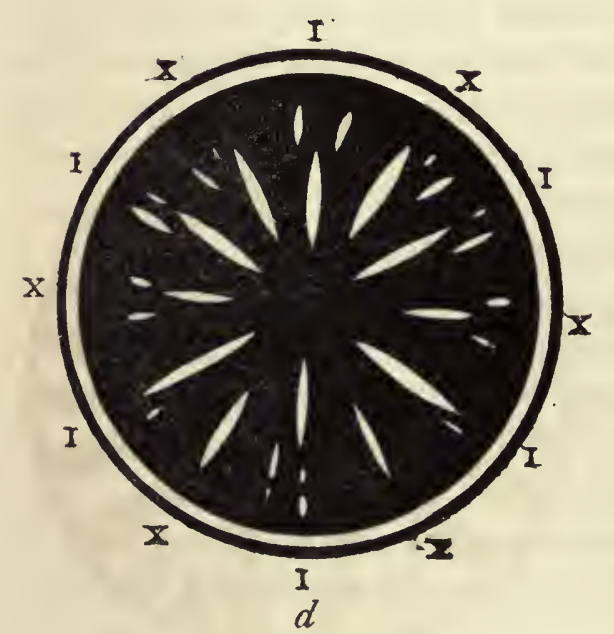

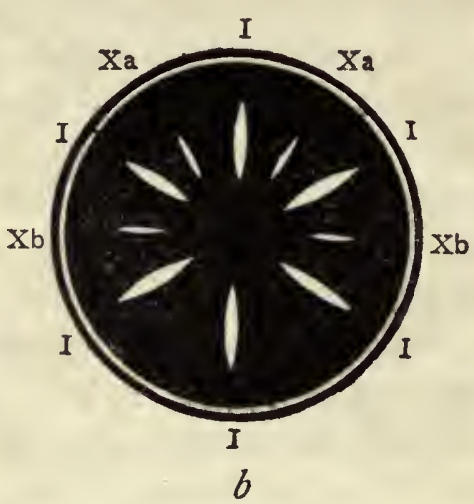

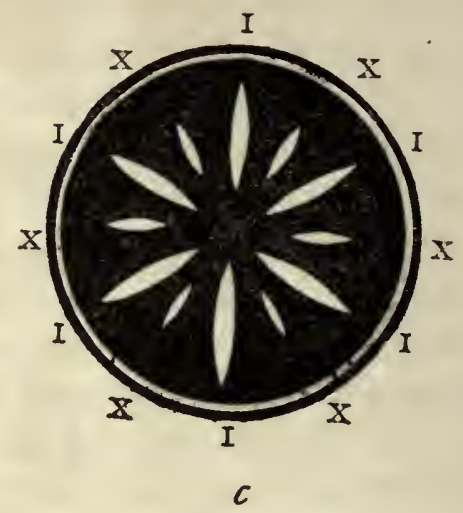

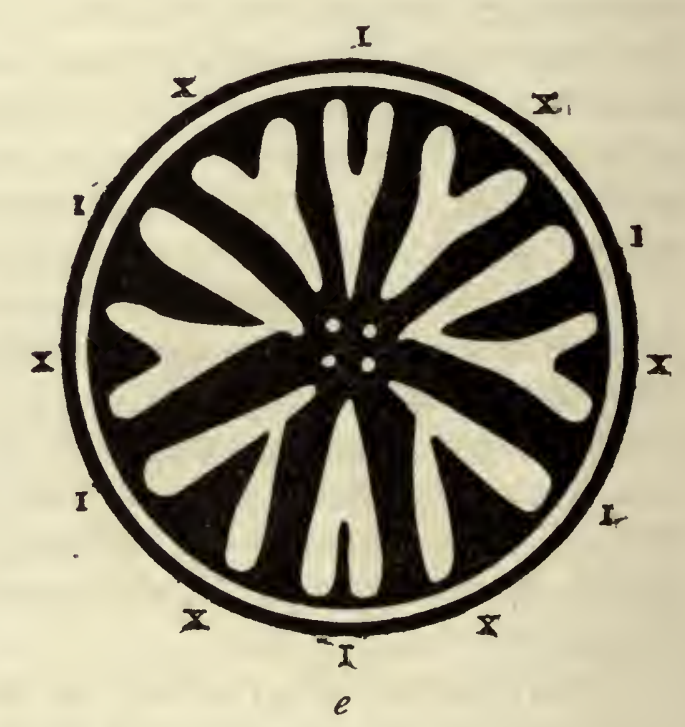

Fic. $g(a-e)$.-Series of diagrammatic figures illustrating the manner of development of the septa from one to three cycles (cf. plates $\mathrm{I}-5$ ). The epitheca is represented 252 white circle distinct from the septa.

fortnight, and some of the smaller polyps never reached beyond; indeed, in a few examples, the exocœlic cycle was never completed. Much variation was observable as to the rate at which the corallum was laid down, growth in larger polyps being always in advance of that in smaller individuals. 
Within the larger, more vigorous polyps, further calcareous upgrowths began to be formed peripherally during the course of the third week, some appearing as angulated extensions of the primary septa and others wholly independent of them (plate 2, fig. 12). Some of the isolated skeletal elements
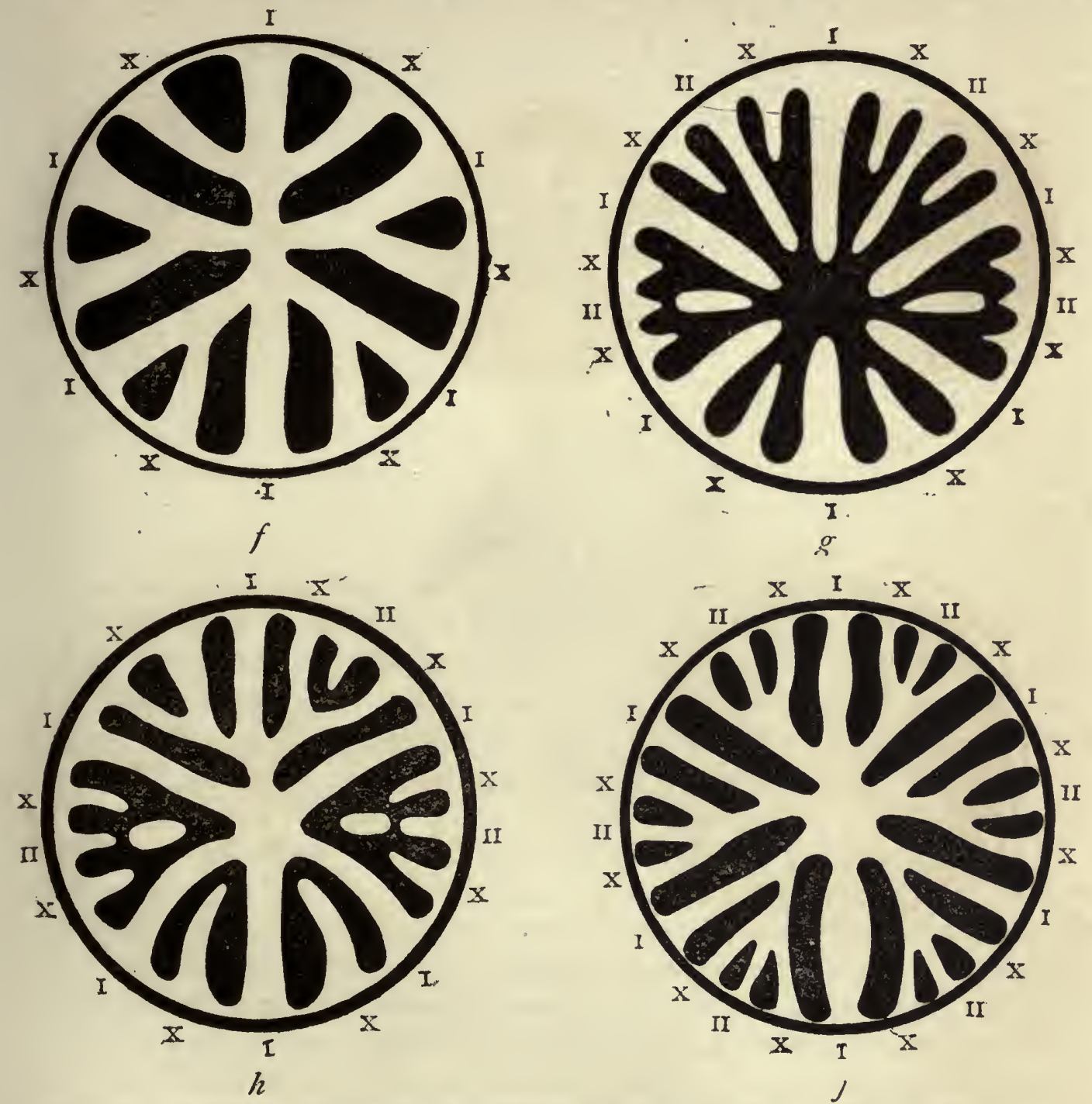

FIG. $g(f-j)$, continued.-Series of diagrammatic figures illustrating the manner of development of the septa from one to three eycles $(f f$. plates $\mathrm{r}-5)$. The epitheca is shown uniting the peripheral ends of the septa.

seemed like short additional septa, situated on different radii from the septa first formed. The new members either retained their independence for a long period or early became fused with the original septum in whose interspace they had appeared. In this latter instance the original septum was 
distinctly angulated at its peripheral end, and where two additional elements were introduced in each chamber the periphery of the septum was strongly bifurcated. In some few cases no separate fragments whatever would arise within au interspace. The septum would then retain its original bar-like form, but become longer and usually more rugged in outline, showing that skeletal matter was being added. The deposition of new matter was usually more forward in the axial chambers than in the lateral, but scarcely any two polyps were alike in the detailed appearance assumed by the skeleton at this period.

Figs. I2, I9, and 20, on plates 2 and 4 , represent the actual polyp or corallum during this stage, while fig. $9, d$, p. 88 , is an attempt to represent diagrammatically the septal conditions at its close. It is a well-defined phase, and important as showing the different methods by which the septa may increase in length and complexity. Although, as above remarked, no two polyps were exactly the same, a general plan was determinable throughout the many examples studied. The septa in all but the pair of ventral exosepta consist of a simple, more central portion and the peripheral additions. The former represents the enlarged primary septa seen in fig. 9, $c$, p. 88, while the latter are newer formations. In general the peripheral deposits consist of two or more separate fragments, placed at an angle with the central bar, the angle being greater in the exosepta than in the entosepta; the entocolic additions are, in fact, nearly parallel with the primary entoseptum, and thus more strictly radial. The two axial or directive septa are usually the most strongly developed of the entire series, and remained thus to the end; in addition, the dorsal and the ventral frequently differ much in form from one another.

In all the figures it will be seen that the two ventro-lateral exosepta remain simple, enlarging but little beyond their primary condition, and the middle exosepta are likewise somewhat less developed than the dorsolateral. Thus a decided dorso-ventrality is indicated in the growth of the peripheral elements of the skeleton, as was the case with the simple exosepta.

For many weeks afterwards the only alteration in the septa consisted in increased growth along the plan thus laid down. As the peripheral fragments enlarged, the members of any group became fused with one another. After the second month the development of the skeleton within the living polyp could with difficulty be followed, owing to the complexity of the internal tissues. Therefore, from this stage onward the septa will be studied mainly from macerated corallites.

Fig. 23, plate 4 , is from a photograpl of the skeleton of a polyp ten 
weeks old, in which only six pairs of primary mesenteries and two cycles of tentacles were present, while fig. $9, e$, p. 88 , is its diagrammatic representation. Each septum now bears a closer resemblance to the septa in the mature corallite, being narrow centrally and broad peripherally, with spinous projections over the entire surface. The general relationships of the septa to the mesenterial pairs could be made out before maceration; hence there is no uncertainty as to the orientation of the corallum. The dorsal and ventral directive entosepta present a somewhat bifurcated peripheral extremity, the two limbs being nearly parallel, but the four lateral entosepta are simple bars, with thickened peripheral ends formed from the enlargement and complete Ifusion of the originally separate elements. On the other hand, the dorso-lateral and middle pairs of exosepta are strongly bifurcated peripherally, while the members of the ventral pair retain their simple character, and are by far the smallest of the six pairs. The peripheral limbs in the bifurcated exosepta may be quite separate from the single radial piece, though usually they are joined. It is readily seen how by the enlargement and fusion of the many detached fragments within each mesenterial space of plate 2, fig. I2, such a septal condition as that of plate 4 , fig. 23 , has been obtained.

With the increase in thickness of the septa the interseptal loculi are correspondingly diminished, but no actual synapticular unions are yet formed across the interspaces. The dorso-lateral exosepta bend laterally and nearly fuse centrally with the dorsal directive septum; the middle exoseptum on each side approaches the corresponding dorso-lateral entoseptum and fuses with it, while the small ventro-lateral exoseptum on each side is fused with the ventro-lateral entoseptum (fig. 9, e, p. 88).

Much older corallites, but still at nearly the same stage of development, are shown on plate 4 (fig. 24) and on plate 5 (figs. 25-27), and diagrammatically by fig. $9, f$, p. 89 . The dorso-lateral exosepta are now fused with the dorsal directive septum, the middle exosepta with two dorso-lateral entosepta, and the ventro-lateral exosepta with the ventro-lateral entosepta. The exosepta, generally, are not so strongly bifurcated as in the corallite on plate 4 , fig. 23 (fig. 9, $e$, p. 88). Fig. 10, $a-d$, on p. 96, shows the diagrammatic relationships of the septa to the mesenteries throughout these early stages.

The general impression produced by the corallum at this stage, as seen under a simple lens or low power of the microscope, is that of two alternating cycles of septa-a larger and a smaller. The tendency to fusion of adjacent septa, exosepta with entosepta, which was found to be so marked a feature of the adult corallite, is already exhibited by the two cycles, and gives a bilateral symmetry to the calice. 
Four distinct stages in the development of the protosepta of Siderastrea radians are thus recognizable:

I. The simultaneous appearance of six equal entosepta, a few days after the larva settles. A very narrow epitheca, distinct from the septa, appears about the same time.

2. The appearance several days later, either simultaneously or in a dorso-ventral sequence, of six exosepta which are smaller than the entosepta and alteruate with them. The septa of both cycles are simple, spinous, wedge-shaped upgrowths from the basal plate.

3. The appearance towards the periphery of most of the septa of one or more short septum-like bars or skeletal nodules.

4. The fusion of these detached fragments with the main septa, so as to give rise to a broad peripheral termination which may be either simple or bifurcated; also the fusion of the exosepta with the entosepta by their inner extremity.

A distinct dorso-ventrality in the rate of growth is maintained from the second stage onwards, particularly with regard to the exosepta, thereby giving a bilateral symmetry to the calice.

The protoseptal development of Siderastrea presents a general agreement with that of other corals whose early history has been followed. Lacaze-Duthiers ( $1873, \mathrm{r} 897$ ), however, found that in Astroides calycularis, Balanophyllia regia, Leptopsammia, and Cladopsammia the six exosepta appeared simultaneously with the six entosepta; but in Caryophyllia cyathus and others there is an interval between the two cycles as in Siderastrea, whereas in Manicina areolata, as I have shown (I9O2, p. 49I), it appears to be doubtful whether exosepta ever appear. Lacaze-Duthiers represents a a decided bilateral condition in the early development of the skeleton in Astroides (1873, plate XIV, fig. 29), but in other known cases the septa of each cycle appear simultaneously, and are equal from the beginning.

The simultaneous appearance of the members of one or both cycles of protosepta and also of the prototentacles may be compared with the successive appearance of the pairs of protocnemes. The protosepta and prototentacles resemble one another in that both appear a cycle at a time, and from the beginning exhibit radial symmetry, whereas the protocnemes arise in bilateral pairs according to a well-defined succession, and, for a time, display a strong dorso-ventrality. The simultaneous appearance of all the members of a cycle is maintained for the septa only so far as the first cycle or, at most, the second cycle of the protosepta; in the later growth of the organs a dorsoventral sequence is followed, quite as conspicuous as that of the mesenteries. 
When it is recalled that the twelve primary mesenteries and their chambers are fully established before the tentacles and septa begin to make their appearance it can be understood how these latter organs may arise a cycle at a time. In their development beyond the protocnemic stage the mesenteries, tentacles, and septa follow one another very closely, and such would probably be the case were the different pairs of protocnemes closely succeeded by their tentacles and septa.* The organs as a whole in the Zoantharia are unquestionably to be regarded as developing in a bilateral dorso-ventral order, not in a cyclic manner. Hitherto the polyps in Siderastrea are alone in the throwing back of the dorso-ventrality of the skeleton as far as the exocœlic protosepta.

The forked or bifurcated continuation of the protosepta, produced either by continued peripheral growth or by the production of independent 11odules, has been observed both in Astroides calycularis and in Caryophvllia cyathus, in addition to the present species. Both Lacaze-Duthiers (1873, 1897) and Von Koch (I882) give figures of the developing corallum which show that the septa are prolonged peripherally much in the same way as in Siderastrea. Von Koch at first considered that the forkings were concerned in the formation of the theca by the union of those from adjacent septa, but in Caryophyllia he found (I897) the true theca (Mauer) to arise independently. In Siderastrea the bifurcations are found to be merely peripheral extensions of the septa, becoming fused with the simple septum in the case of the entosepta, but constituting two new septa in the case of the exosepta. They in no way assist in the formation of a theca.

\section{SECOND CYCLE OF ENTOSEPTA AND THIRD CYCLE OF EXOSEPTA.}

Before describing the further development of the septa it will be helpful to consider what are the septo-mesenterial relationships involved in passing from a polyp with only two cycles of septa to one with three cycles. In the first polyp only six pairs of mesenteries are present, and within the entocœles of these are the six primary entosepta; the alternating six members of the second cycle of septa are within the exocœles, on radii midway between the entosepta (plate 2, fig. 9). In the second polyp with three cycles of septa two alternating cycles of mesenteries are present; the first-cycle septa are contained within the entocœles of the first mesenterial cycle, the second-cycle septa are within the entocœles of the second mesenterial cycle,

*Where in larval actinians only four pairs of mesenteries are present when the tentacles begin to develop, only eight of the latter appear, one from each of the eight inesenterial chambers, and the other four necessary to complete the hexameral plan arise after the establishment of the fifth and sixth pairs of protocnemes. 
while the third-cycle septa are within the twelve alternating exocœles, and are therefore exosepta. Thus at both stages the exosepta form the outermost cycle ( $c f$. fig. Io, $b, f$, p. 96 ). The question naturally arises as to whether, on the appearance of a second cycle of mesenteries, the exosepta of the first stage, which there constitute the second cycle, remain as the second cycle of entosepta of the later stage; were they to do so the twelve exosepta of the latter would be the only new formations. As regards their actual position the six exosepta of the early polyp correspond with the six entosepta of the later polyp, and it would be natural to assume that on the appearance of the second-cycle mesenteries the latter have simply included within their entocœles the exosepta of a former stage, and then new exosepta have arisen within the newly formed exocœles.

The latter is the view commonly held by writers on coral development. Thus Delage \& Hérouard, in their "Traité de Zoologie Concrète" (I gor, p. 558), remark: "Quand, dans les interloges occupées par les septes du dernier cycle, naît un nouveau cycle de couples de cloisons, celles-ci se forment de part et d'autre du septa interloculaire qui, de ce fait, devient loculaire, et bientôt uu nouveau cycle de septes se forme dans les nouvelles interloges qui viennent d'être formées. Les cycles naissent successivement et jamais un cycle ne commence à se former avant que le précédent soit complet." Similarly, J. Stanley Gardiner (I902), in his account of the anatomy of Flabellum rubrum, says (p. r33, italicizing added): "As the growth of any corallite proceeds, more and more septa up to six cycles appear. The former exocelic order of septa become entocelic by the development of new pairs of mesenteries. The increase of mesenteries takes place pari passu with the formation of new septa."

Unfortunately, the relationships involved in the above assertions have not been actually followed, though from the known conditions no other arrangement at first sight seems possible. The problem is one of the most important in the developmental history of corals.

Without doubt the members of the primary cycle of entosepta in adult polyps are the direct representatives or continuations of the six septa first to arise, just as the six pairs of complete mesenteries throughout the life of the polyp are the representatives of the protocnemes. Throughout their - later growth the primary septa retain their individuality, and remain within the entocœles of the primary cycle of mesenteries. Other considerations, however, are involved in the relationships between the septa developing later and those of the adult corallite.

Most of the polyps of Siderastrea remained for some time at the stage 
already described on p. 92 , the second-cycle mesenteries appearing in the meantime and growing towards both the basal and the oral disc. As indicated diagrammatically in fig. ro, $d, p .96$, the new mesenterial pairs correspond with the space inclosed by the bifurcations of the dorso-lateral and median pairs of exosepta, but seem as if about to embrace the incompletely developed ventro-lateral pair.

A bout this time other calcareous upgrowths began to appear peripherally, midway within the exocclic.bifurcations, and necessarily inclosed within the entocœles of the second-cycle mesenteries. Plate 3 , fig. 15 , gives the discal view of such a living polyp in which the six pairs of second-cycle mesenteries had been developed for some time. The new mesenteries, still varying in size in agreement with their order of appearance, have now begun to extend along the periphery of the disc, and the latter is resting upon the upper edges of the septa with the tentacles fully expanded. The septa are clearly seen through the transparent disc. Within the bifurcation of each dorso-lateral and middle exoseptum has appeared an additional free septum, included within the entocœle of the second-cycle mesenteries, and in the same radius as the original exoseptum. Moreover, the exocœlic bifurcations are now seen to be wholly exocœlic in position, situated in the chambers between the pairs of the first and the second-cycle mesenteries; in the dorso-lateral sextants the forkings are free from the original median exoseptum, but in the middle sextants they are united. The primary entosepta remain simple straight bars, and such is yet the condition of the ventro-lateral exosepta. Fig. Io, $e$, p. 96, is a diagrammatic representation of the polyp and corallum at this stage.

The new formations within the second-cycle entocœles suggest an independent series of septa, and subsequent stages show that they represent the second-cycle entosepta. The polyp of plate 3 , fig. I $_{5}$, in fact, displays the early stages in the development of the second cycle of entosepta and the establishment of a third cycle of exosepta, and in such a manner that the actual relationships between the new septa and the second-cycle mesenteries admit of no misinterpretation. The entosepta of the second cycle appear peripherally as separate formations, but in their later growth centrally, as shown on plate 5 , figs. 28,29 , and fig. Io, $f$, p. 96 , they come into union with the primary exosepta, and the two then appear as a single continuous structure. Further, each bifurcation of a primary exoseptum forms a new exoseptum, belonging to a third cycle, and may be either distinct or united by its inturned edge with a second-cycle entoseptum. 
Three important results in the development of the Madreporarian skeleton are thus gained: (I) The primary exosepta do not continue their
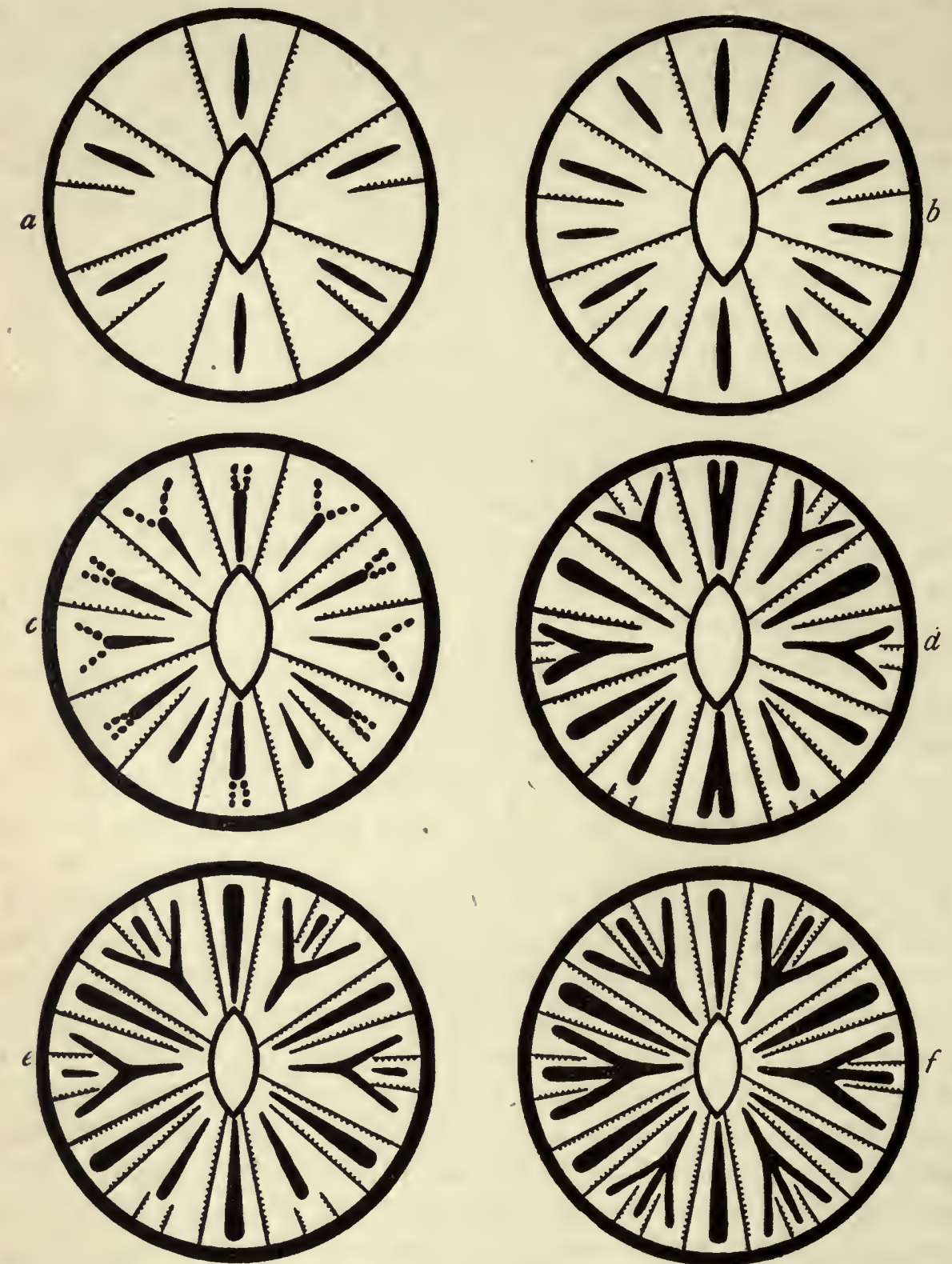

FiG. so $(a-f)$.-Series of diagrammatic figures illustrating the relationships of the mesenteries and septa in the establishment of the first two cycles of mesenteries and three cycles of septa.

growth peripherally in a radial manner, and constitute entosepta by becoming included within the entocœle of the new second-cycle mesenteries. (2) The 
secondary entosepta are new formations, arising within the second-cycle entoccles independently of other septa; the second-cycle mesenteries never embrace the exocolic protosepta as such, but only after their fusion with the new entosepta. (3) The appearance of the second-cycle entosepta is in a dorso-ventral manner, not simultaneous, a cycle at a time.

Other coralla exhibit different stages, all pointing to the same conclusion. That shown diagrammatically in fig. $9, h$, p. 89 , is in somewhat the same stage as fig. Io, $e$. In the upper right sextant the second-cycle entoseptum (II) is yet very distinct from the exocœlic bifurcations, but an irregularity in the rate of growth is exhibited by the corresponding left sextant, in that no entoseptum has yet formed. The growth in the two middle sextants is in advance of it; each of the sextants contains a primary exoseptum, a secondary entoseptum, and two third-cycle exosepta as distinct formations. As before, the development within the two ventro-lateral sextants lags behind that of the middle and dorso-lateral sextants. Fig. 9, $g$, from another corallum, also shows important intermediate stages.

The next stages available are the coralla of the oldest polyps reared, two of which are represented on plate 5 , figs. 28,29 , and diagrammatically in fig. $9, j$, p. 89, and fig. Io, $f$, p. 96 . Each corallite now consists of three complete orders or cycles of septa, the development within the two ventral sextants having reached the same stage as that within the dorsal and middle sextants. The first order contains six large septa radially disposed, the directive septa a little larger than the others. The second order also includes six septa, turned inwardly in such a manner that the two dorsal fuse with the dorsal directive septum, the two middle fuse with the dorsolaterals of the first order, and the two ventral with the ventro-laterals of the first order. The third cycle contains twelve septa, the two adjacent members fusing with each of the six septa of the second order. The coalescence of the septa in this way imparts a bilateral symmetry to the calice which otherwise would be radial. Further, adjacent septa are now for the first time joined by synapticula. The polyps (plate 3 , fig. I7) forming the coralla bore two cycles of mesenteries, so that the first and second orders of septa are entosepta, while the members of the outermost cycle are exosepta.

Previous stages have demonstrated that the members of the second order of septa, although now continuous bars, have really a twofold origin. The peripheral part of each appeared as a separate septum within an entocœle of the second-cycle mesenteries and, later continuing its growth centrally, fused with an exoseptum which was originally a constituent of the second cycle of septa, so that now the two appear as a single septum. In each 
corallum there are indications still remaining of the distinctness of the peripheral and central parts of the entosepta, as in the ventral sextants of fig. 28, plate 5 , where the entocœlic moiety is still free from the exocœlic portion. The fusion of the two parts is a mechanical necessity in the process of growth, seeing that both are on the same radii. It is manifest that it is only by securing such intermediate stages that the true character of the septa at the mature stage can be understood. When the secondary entosepta have come into fusion with the primary exosepta there remains no means of distinguishing their componnd origin, and the ontogenetic and phylogenetic significance of the secondary entosepta is obscured.

The twelve exosepta now forming the tertiary cycle undoubtedly arise as continuations of the bifurcations of the six primary exosepta, but in many places, as on plate 5 , figs. 27 and 28 , they still show a considerable amount of distinctness. Regarding them as continuations of the two forks of each primary exoseptum, it is manifest that they are to be considered as appearing in advance of the entosepta of the second cycle, a relationship which need not be wondered at, considering that in this species the exotentacles are also found to arise in advance of the entotentacles. Originally forming the second cycle, the exosepta now constitute the third septal cycle, their place in the sequence being taken by the new second cycle of entosepta.

It is thus manifest that in the course of development of a coral the exosepta of a former stage do not become the entosepta of a later stage; the latter are new formations appearing after the establishment of the mesenteries with which they correspond, and consequently the mesenteries and their included entosepta have the same ordinal value. The exosepta, on the other hand, have no ordinal value; they appear at each cyclic stage, always constituting the outermost cycle. They are, in a measure, temporary structures, predecessors of the entosepta, until the limit of growth of the polyp is reached; they serve as integral parts of the septal system of the coral during all its intermediate stages, and are then overgrown by later permanent septa."

* In some corals the exoseptal predecessors appear to continue their independent growth in silu without losing their individuality as skeletal structures in the central extension of the entosepta. In these cases the entosepta do not grow far enough centrally to fuse completely with the exosepta already there. I believe it will be found that this is the true nature of pali which are found in some corals as 8 mall septum-like plates in front of the larger septa. The fact that pali seem not to occur before the primary cycle of six septa, but only before those of later origin, is what we should expect if this surmise be correct. The primary entosepta have never had exocœlic predecessors, as is the case with the later entosepta. The pali would thus represent the persistent exoccelic predecessors of the entosepta beyond the primary cycle. 
The closest morphological parallel is proved to exist between the development of the septa and the tentacles. As previously shown, exotentacles are present at each cyclic stage, but a new cycle of entotentacles intercalates itself between the last cycle of entotentacles and the exotentacles, hence the latter always remain as the outermost cycle; only the entotentacles, like the entosepta, have ordinal value. Thus the law of substitution first discovered by Lacaze-Duthiers for the teiltacles of hexactinians is found to hold for the septa also.

Belonging to the soft, fleshy parts of the polyps, it can be easily understood how actual displacement of the tentacles may be carried out, but such is not possible with the hard, rigid skeleton. Hence the process of substitution must be conducted in a different manner in the two sets of structures. A new peripheral entoseptum arising independently can not displace an inner exoseptum already occupying the same radius. In its growth centrally the entoseptum simply fuses with the exoseptum, and thenceforward the whole of the septum must be morphologically regarded as an entoseptum.

The septa, like the tentacles, are thus shown to arise in such a manner that it is impossible to determine their order of development from their relationships in the mature polyp.

Though the septo-mesenterial relationships will remain the same, I conceive that a like adult condition of the septa may be reached in different ways in different forms of corals, as is the case with the tentacles. The actual method followed in Siderastrea can by no means be assumed to be that characteristic of corals generally. Probably some of the stages in Siderastrea might be better interpreted were results available from other forms; such, for instance, as the significance of the forking of the exosepta. The fact that in Siderastrea the septa of one cycle fuse centrally with the septa of the next inner cycle probably obscures the problem somewhat, as compared with forms where the septa remain altogether free from one another.

\section{THIRD CYCLE OF ENTOSEPTA AND FOURTH CYCLE OF EXOSEPTA.}

None of the polyps reared from larvæ were kept alive beyond the formation of the first three cycles of septa, which consist of two cycles of entosepta and one cycle of exosepta. Therefore the development of the fourth cycle of septa must be studied from the bud polyps of a colony. Fortunately, there are many polyps available for such an investigation, as in any stock most of the individuals are at one stage or another towards the establishment of a complete fourth cycle of 24 septa. 
When describing the septo-mesenterial relationships in the mature polyp, it was found that the fourth-cycle septa occur within the exocœles between all the adjacent pairs of mesenteries. On leaving the last section, however, the third cycle was constituted of exosepta; only the first and second cycles were entosepta; therefore, as in the case of the secondary and

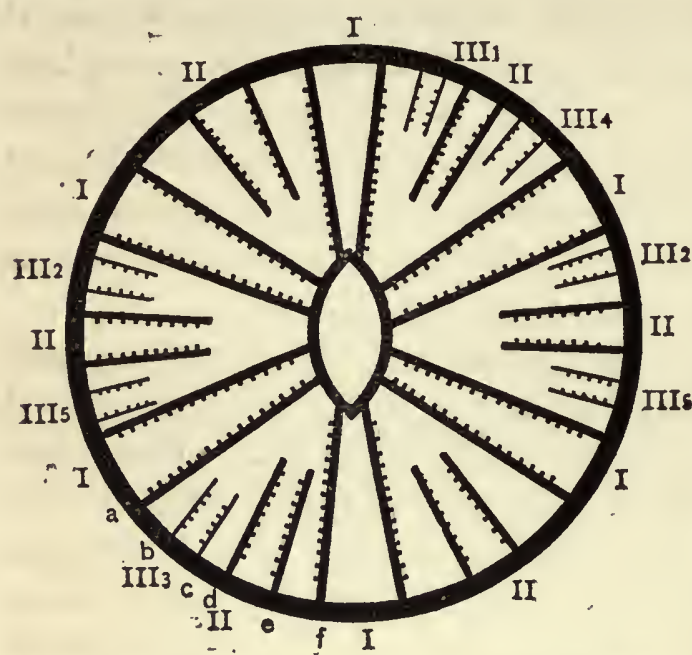

Fic. 11.-Diagram of mesenteries in the polyp from which figs. $54-60$, on plate 9 , were taken. tertiary cycles, the problem is first to determine the morphological relationship of the tertiary exosepta of the developing polyp to the tertiary entosepta, and also to the quaternary exosepta of the mature polyp. Do the tertiary exosepta at the stage where only secondcycle mesenteries are present become the tertiary entosepta when the third-cycle mesenteries appear, or are they continued as the fourth-cycle exosepta, in which case the tertiary entosepta arise de novo?

The relationships to be determined have been studied by means of serial sections of nearly mature decalcified polyps. A complete series of stages, representing the development of a pair of third-cycle mesenteries along with the associated septa in their relation with the older mesenteries and septa, is given on plate 9 , figs. 54-6o. The figures are taken from a series of transverse sections of a retracted polyp, and will be described as seen in passing from the lower stomodæal region to the uppermost margin of the calice and polyp. On account of the presence of synapticula and the peripheral resorption of the mesenteries, certain complications are introduced which render a clear conception of the stages somewhat more difficult than would otherwise be the case. The diagrammatic figures on p. IO3 will assist in following the description of the sections.

The polyp from which the drawings were made is that of which the mesenterial plan is diagrammatically represented in fig. II, p. Ioo. Within the ventral system on the left side occurs a pair of small third-cycle mesenteries $\left(\mathrm{III}_{3}\right)$, situated on the dorsal aspect of a pair of second-cycle mesenteries (II). Plate 9, figs. 54-60, represents the members of this ventral system at different levels, and the mesenteries and septa are indicated by the same 
lettering $(a-\gamma)$ throughout. In the figures mesentery $a$ is the lower moiety of the ventro-lateral pair of first-cycle mesenteries, mesentery $f$ is the left moiety of the ventral directives, mesenteries $d$ and $e$ are the pair of secondcycle mesenteries, while $b$ and $c$ are the two members of the rudimentary pair of third-cycle mesenteries. The incompletely represented entoseptum to the left of $a$ is a member of the primary cycle of septa, as is also the partial septum to the right of $f$; the entoseptum $d$-e belongs to the secondary cycle, while the septa $a-d$ and $e-f$, in figs. 54-56 are exosepta. The upper margin of the section in fig. 54 , is formed by the stomodæal wall, while that in all the subsequent figures is either the depressed disc or column wall. This, upon retraction, has come to rest upon the septal edges, and adapts itself to them in outline, being thrown into ridges and furrows.

Fig. 54 represents a section of the sextant taken from the lower stomodæal region. The members of the mesenterial pair, $b, c$, of fig. II, have not yet reached this level, so that the sextant contains only the pair of incomplete second-cycle mesenteries, $d, e$. The mesenteries $a$ and $f$ are united with the stomodæal wall centrally, but their peripheral extremity has undergone resorption and, therefore, is free. At this level the second-cycle mesenteries, $d, e$, are feebly represented, being much reduced peripherally as a result of resorption. The entoseptum $d-e$ is broad, but the exosepta $a-d$ and $e-f$ on each side of it are narrow and partly turned towards it. Exoseptum $a-d$ is bifurcated at its peripheral end, but before dividing is connected by synapticula with the entosepta on each side. Within the angle of bifurcation occurs a small, empty loculus.

Plate 9, fig. 55, is from a section immediately above the level of the depressed stomodæum, so that it is bounded above by the disc resting upon the septal edges. At this level mesenteries $d$ and $e$ are larger than in the former section and are without any peripheral degeneration; exoseptum $e-f$ is united by its inner edge with entoseptum $d-e$, but the bifurcated exoseptum $a-d$ is free. Within the loculus, at the angle of bifurcation of the exoseptum, the rudiments of the pair of mesenteries, $b, c$, have appeared, but at this stage there is no septal formation whatever within their entocœle. Already, therefore, it is manifest that the new pair of mesenteries does not inclose a previously formed exoseptum; the two members lie close together within the peripheral bifurcation of an exoseptum, $a-d$.

Plate 9, fig. 56, is taken from a section at a somewhat higher level. The second-cycle mesentery $d$ is now united with the depressed disc, but the other moiety $(e)$ of the pair is still free; in none is there any peripheral resorption. Exoseptum $e-f$ is once more distinct centrally from entoseptum 
$d-e$, as in fig. 54 ; a synapticular growth from the left limb of septum $a-d$ perforates the mesentery $b$, and a slight depression of the wall between the mesenteries $b$ and $c$ is the first indication of an entocœlic skeletal ingrowth about to separate the two.

The section from which fig. 57 was taken reveals important alterations taking place. The second-cycle mesenteries $d$ and $e$ are both united with the discal walls, and along with $f$ are at this level not perforated by any synapticular bars. The two peripheral limbs of septum $a-d$ are now becoming free from one another at their inner angle, and also from the central radial portion; both may be regarded as distinct exosepta $a-b$ and $c-d$, though formerly they appeared only as the bifurcations of the single exoseptum $a-d$. For the first time an actual entoseptum now occurs in the entocœle of the new pair of mesenteries $b$ and $c$, and at its free extremity is on the point of uniting with the synapticular process from the exoseptum $a-b$. The septum $b-c$ is clearly a new formation, appearing within the now widely bifurcated peripheral extremity of the original septum $a-d$, or, better, between the two exosepta $a-b, c-d$.

The septal modifications suggested by fig. 57 are completed in the next stage, fig. 58. The exoseptum $c-d$ is now distinct, like septuin $a-b$, from the central radial part, while exoseptum $a-b$ and entoseptum $b-c$ are united with one another towards their free edge by a synapticulum perforating the mesentery $b$.

The section represented by fig. 59 passes through the exsert edges of the septa, so that the column wall forms the lower boundary while the upper boundary passes through the tentacular region of the disc, four tentacular thickenings being represented. The mesenteries extend uninterruptedly from one wall to the other, and include the free septal edges within their chambers. The mesentery $c$ is still free at its inner end, while the mesentery $b$ is perforated by the synapticulum still joining septa $a-b$ and $b-c$. The central portion of the original exoseptum $a-d$ has now nearly disappeared.

The next stage, fig. 6o, is from a section near the uppermost extremity of the retracted polyp and its calice, so that now each septum and the body wall surrounding it are becoming distinct. The mesenteries $b$ and $c$ both extend across the two portions of the column wall, and the septa $a-b, b-c$, and $c-d$ are distinct from one another, the eutoseptum $b-c$ being as yet smaller than the exosepta on each side of it.

Omitting the synapticula as merely incidental structures the development of the three septa $a-b, b-c$, and $c-d$ can be diagrammatically represented as in fig. I2 $(a-f)$ below, which shows also their relations to the mesenteries. 
The first two figures $(a, b)$ correspond with plate 9 , figs. $54-56$, of the sections. The exoseptum is here simple, but bifurcated towards its peripheral extremity. At first no mesenteries are included within the augle of bifurcation, but a pair has appeared in fig. I $2, b$. In relation to the mesenteries the two limbs are clearly exocœlic, and may even at this stage be regarded as two individual exosepta.

In fig. I 2, c, one exoseptum has become distinct, and a short septum has appeared midway between the two older septa (cf. plate 9, fig. 57). Clearly this is a new entoseptum arising a little later than the new pair of mesenteries. In fig. $12, d$, the right exoseptum has also separated from the more central portion which is along the same radius as the entoseptum ( $c f$. plate 9, fig. 58). The next figure, $e$, shows the exsert septa ( $c$. plate 9, fig. 59); the central part is becoming smaller, while it has disappeared in the last
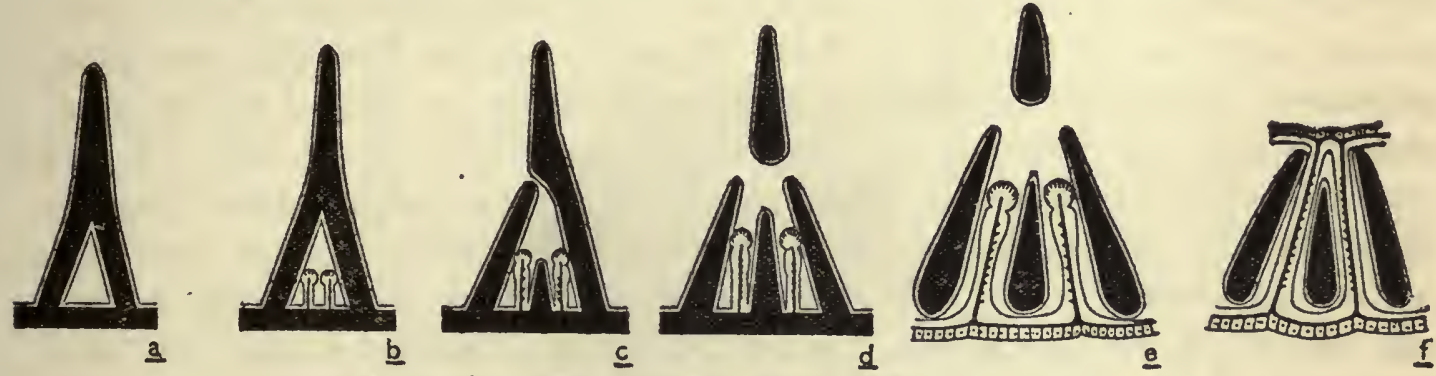

FIG. 12.-Series of diagrammatic figures illustrating figs. St-60 on plate 9 .

figure, $f$ ( $c f$. plate 9, fig. 60). The entoseptum throughout extends the shortest vertical distance of the three, and so far as the development has proceeded remains the smallest radially. Clearly when growth is completed the three septa will be related as shown in the six groups of fused septa in fig. Io, $f, p .96$, which is the usual relationship of the exosepta and entoseptum; the entoseptum in its further growth will have extended more centrally and fused with the central portion of the original exoseptum, and the two exosepta will turn inwardly to unite with it.

The series of sections plainly demonstrates that a new entoseptum arises shortly after a new pair of mesenteries, not in advance of it, and the two peripheral limbs of a bifurcated exoseptum become distinct, so that each constitutes a new exoseptum. The new entoseptum takes the place of the inner simple part of an exoseptum situated in the same radius.

The members of the third-cycle entosepta of the older polyp are new formations which take the place of the earlier third-cycle exosepta. The dorsal and ventral moieties of the bifurcated periphery of the third-cycle exo- 
septa become fourth-cycle exosepta; in other words, the fourth-cycle exosepta in the mature polyp are the peripheral continuations of the third-cycle exosepta, which in their turn have been shown to be the peripheral bifurcations of the primary exosepta. Exosepta thus remain exosepta to the end, each time constituting a later cycle as new entosepta arise to take their place.

The results from a study of a series of sections from a nearly mature bud polyp thus agree stage by stage with those obtained in the progressive development of the three cycles of septa in polyps reared from larva. The figures given bear the closest comparison with the corresponding details in fig. Io $(d-f)$, p. 96 , which represents three stages in the septal development of a larval polyp.

Close examination with a lens of the surface of macerated coralla often reveals one or more stages similar to the above. In practically all the corallites of a colony the altermation of large and small (entocolic and exocœlic) septa is strongly marked; but amongst the youngest corallites, especially those around the margin of colonies, the regularity of the alternating large and small septa is not always so pronounced. Occasionally a group of two or three septa is seen presenting quite different relationships, which can be explained only upon the septal development here described.

An exoseptum is sometimes seen with its peripheral end conspicuously bifurcated, as in fig. I2, $a$, p. IO3; in several instances a stage in which a septum is beginning to appear midway between the bifurcation has been met with, recalling the conditions in fig. I $2, c, d$; while very often in a group of developing septa a marked interval occurs between the central and the peripheral halves of an entoseptum, and the exosepta on each side are wholly free. In these instances it would seem that the new entoseptum has not yet fully united with the central part of the old exoseptum, being in the same stage as fig. I2, $d, e$.

It still remains to be seen what is the order followed in the appearance of the third-cycle entosepta, for these do not appear a cycle at a time any more than the six members of the second cycle of entosepta. The septa alone in the dried corallum are insufficient to enable their sequence to be made out, as they afford no certain means by which the principal or directive axis can be determined, and from this the dorsal and ventral borders of the calice. It has been shown, however, that in the case of each of the three cycles of entosepta the mesenteries appear in pairs only a little in advance of the corresponding entosepta within them; therefore, if the sequence of the third-cycle mesenteries be determined, it can be assumed that the third-cycle entosepta follow the same order. 
The order of appearance of the twelve pairs of third-cycle mesenteries has been fully described on p. 83. It is found that the members arise after the formation of the six second-cycle pairs as unilateral pairs in a twofold succession. Normally a pair appears within the dorsal exocœle of each sextant, successively from the dorsal to the ventral border of the polyp; then another pair appears within the ventral exocœle of each sextant, following the same succession as the first series.

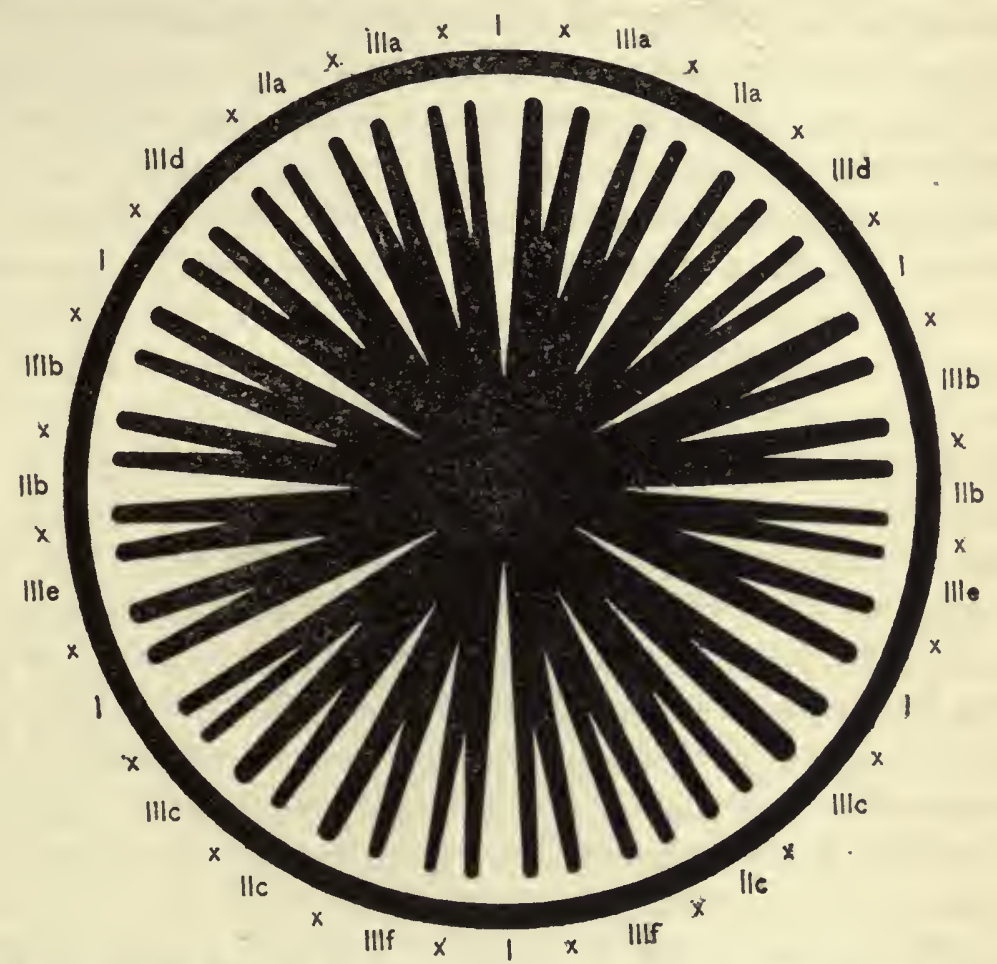

Frg. 13-Diagram illustrating the order of development of the first three cycles of septa (I-III). The small letters accompanying the Roman numerals indicate the sequence of the individual septa in the cycle.

The normal sequence of the third-cycle mesenteries in Siderastrea being established, we are justified in assuming that a like succession will be maintained by the third-cycle entosepta, seeing that they arise shortly after the mesenteries with which they are associated. This is shown in fig. $\mathrm{r}_{3}$, p. I05, by the numerals Ina-IIIf. The figure also represents the normal sequence for all the entosepta of the first three cycles. The six primary septa appear together, a cycle at a time; the six members of the second order arise bilaterally in a simple dorso-ventral succession; the twelve members of the third also arise bilaterally in a dorso-ventral succession, but in two series-first, a series of six within the dorsal of the two interspaces in each 
sextant, and then the remaining six in a like order, but within the ventral of the two interspaces. The exosepta coustituting the last outermost cycle have no corresponding ordinal significance.

Studies on the mesenterial sequence of other corals indicate that a similar septal succession will in all probability be followed by forms in which the adult calice shows a regular hexameral cyclic plan. Individual departures from the order may be expected, but are to be looked upon as irregularities; regularity of growth of the higher cycles is by no means so pronounced as in the first and second cycles, which are less likely to be influenced by spatial considerations. The sequence given is altogether different from anything which has hitherto been surmised for any coral, and further studies are desirable to determine how far it admits of general application in the group.

From what has been revealed it is manifest that the exosepta do not possess any true ordinal sequence comparable with that of the entosepta. Exosepta have been found to be present at each stage, always constituting the outermost cycle, and equaling in number the sum of the inner entosepta. We may consider them as the direct continuations of the six primary exosepta, or, less likely, as arising anew with each cycle of entosepta. Regarded as the persistent representatives of the primary exosepta, they more nearly conform to the law of substitution of the exotentacles in actinians as established by Lacaze-Duthiers and Faurot. In actinians generally it is found that after the protocnemic stage the tentacles appear two at a time, one entocœlic and one exocœlic, corresponding with the two chambers formed upon the appearance of a new pair of mesenteries; sometimes the entotentacles appear in advance of the exotentacles, the reverse of what happens in Siderastrea radians. The entotentacles are always larger than the exotentacles, the length of the former being in accordance with the order of appearance of the cycle to which they belong, the largest being the first to appear. The exotentacles all attain an equal length and are all relegated to the outermost cycle, whatever be the cycle of entotentacles with which they appeared. They constitute a single cycle of which the members are always smaller than those of the cycle of entotentacles last to appear, and the number of exotentacles in the last cycle is always half the total number of tentacles, and, of course, equal to the number of entotentacles.

As new entotentacles are added the exotentacles become pushed aside so as to occupy different radii at different times. The calcareous septa being hard, fixed structures, do not admit of such rearrangement; the new septal growth has to be adapted to the old, resulting in the fusion of the new entosepta with the old exosepta. 
Partial studies on other corals, as well as considerations on the tentacular development in actinians, suggest that the exosepta may arise in different ways in different species, and that a more precise significance as to their relationships at different stages may be forthcoming than is possible in Siderastrea. There are indications that in some forms an entoseptum and an exoseptum arise together, thus more closely recalling the method followed by the tentacles. Regarded as arising anew in each cycle, the two exosepta in Siderastrea appear somewhat in advance of the entoseptum which is included between them.

The relationships proved to exist between entosepta and exosepta involve important considerations when the cyclic hexameral sequence is not completed in the mature corallite, as almost invariably happens in $S$. radians, as well as in many other species of corals. As regards both the septa and mesenteries it is found that the last cycle is rarely a multiple of 6 , but some irregular number from I to 32 , resulting from the fact that at maturity the polyp does not complete the last cycle begun. Exosepta have been shown to appear always in close association with entosepta, whatever be the number making up a corallite; and, as often remarked, the two series are equal in number and the exosepta always outermost in position.

If we regard a septal cycle as made up only of entosepta, or of exosepta, then in mature corallites of $S$. radians the third entocœlic cycle and fourth exocœlic cycle of septa will vary in the same degree. Whatever number of entosepta be lacking from the third cycle to form the complete cycle of 12 , a like number of exosepta will be wanting from the fourth cycle.

When describing the number of septal cycles within a calice, the cyclic hexameral plan of which is incomplete, it is usual in systematic works on corals to regard the hexameral multiples as completed as far as the number of septa will permit, and then to relegate to the last cycle all the remaining septa not included in the hexameral formula. The cycles are all supposed to be hexamerously complete with the exception of the last. Thus, with regard to S. radians, Milne-Edwards states: "Three cycles of septa con1plete, and, in general, a variable number of a fourth cycle." Likewise Verrill (rgor, p. I53), describing the same species, says: "They [the septa] form three complete cycles, with part of the fourth cycle developed, so that the number is usually 36 to $40 . "$

The relationships proved to exist between the entosepta and exosepta indicate that the above formulæ do not express the true morphological character of the septa. Any hexameral incompletion in the number of septa making up a corallite affects both the entosepta and the exosepta, that is, both the penultimate and the last cycles. If any septa are wanting to complete 
the hexameral multiple of the last cycle of entosepta, the same number will be lacking from the exosepta. The third complete cycle, as understood by Milne-Edwards and Verrill, is really made up of both tertiary entosepta and of tertiary exosepta. The two kinds of septa are of very different value in their development and relations to the polyp, and, as a matter of fact, will be scarcely of the same thickness and radial length to justify their being regarded as a cycle.

The cyclic formula, as above understood, may be written $6,6,12, \mathrm{x}$, where $\mathrm{x}$ will represent any number from $\mathrm{I}$ to 24 . Formulated in this way the number 12 conveys the impression that the third cycle is really completed, and that all the additions made will belong to the next or fourth cycle, whereas they will belong to both the third and fourth cycles. Beyond the two first cycles the septa do not arise a cycle at a time, but the penultimate and last cycles are formed concurrently, or almost so. Incomplete cyclic hexamerism, as met with in S. radians, is an intermediate condition in the establishment of two adult hexameral cycles, not of one alone, and attention should be drawn to this in the septal formula.

According to the relationships now established the morphological septal formula for $S$. radians should be written $6,6, \mathrm{x}, 6+6+\mathrm{x}$. In this formula, $6,6, \mathrm{x}$ will represent the number of septa in the two completed entocycles, $\mathrm{x}$ being the number in the last entoseptal or penultimate cycle which does not yet complete the hexameral sequence; while $6+6+\mathrm{x}$ will represent the total number of exosepta, $\mathrm{x}$ being the same number as before; some of the exosepta will be tertiaries and some will be quateruaries, the number of the latter being always double the number of tertiary entosepta. The formula for a corallite having 36 septa would, according to the ordinary cyclic formula, be written $6,6,12,12$, whereas, considered as entosepta and exosepta, the formula will be $6,6,6,18$, the three first numerals indicating the entosepta and the last the exosepta; the usual cyclic formula of a corallite with 40 septa would be $6,6,12,16$, and the morphological formula $6,6,8,20$. In the first case 12 of the exosepta will be quaternaries and 6 will be tertiaries; in the second 16 will be quaternaries and 4 tertiaries.

Where the relationships of the septa to the mesenteries are clearly known the morphological formula will more nearly express the real value of the septa than the ordinary cyclic formula; the latter has little significance unless the hexameral sequence is fully completed. One can not say that a cycle is really complete unless its constituents all have the same morphological value, which is not the case where some are entosepta and some are exosepta.

The bilaterality of the polyp during development may be looked upon as associated in turn with each cycle individually. Any cycle tends to attain 
its radial plan before the next cycle commences to form, when the additions take place in such a manner as to again confer bilaterality upon the polyp as a whole. Thus the first two cycles of septa become perfectly radial before an additional cycle commences, and the growth of this is then continued in a bilateral manner; likewise, the new second and third cycles assume their radial stage before the members of the fourth cycle make their appearance, proceeding from one border to the other. In like manner the first-cycle mesenteries are nearly radial before those of the second cycle arise and introduce a conspicuous bilateral symmetry; and on these assuming the radial plan the third-cycle mesenteries begin to appear, again in a bilateral manner.

The successive dorso-ventral growth followed by the constituent mesenteries and septa of each cycle may also be regarded as conferring a certain individuality upon the cycle. The different cycles, arising independently, seem to represent so many distinct recurring phases of growth in the life of the polyp, not a continuous addition from one aspect to the other, as is usual in permanently bilateral animals, particularly segmented forms. The members of a cycle appear in a dorso-ventral sequence, and may retain their differences in size for a long time, but in the end they become equal and thereby confer radial symmetry upon the polyp. Then another cycle commences to form in somewhat the same bilateral dorso-ventral succession, displays for a time its consecutive origin, and afterwards attains radiality.

The conception of recurring phases of growth in cyclic coral polyps is best realized when comparison is made with the mesenterial increase characteristic of the Ceriantheæ. Here the mesenteries beyond the protocnemes always develop in a regular bilateral successive manner, from the dorsal (anterior, sulcar) to the ventral (posterior, asulcar) aspect, the oldest being dorsal or anterior and the youngest ventral or posterior, recalling more the method of growth of segmented animals; in cerianthids there is never a reversal of growth to the anterior end, followed by a successive series to the other, such as occurs in ordinary hexactinians. Employing the term "band of proliferation," introduced by Van Beneden in I897, we may say there is only one median band of proliferation in cerianthids, while in hexactinians there are many such bands, the number increasing with age-at first 6 , then I2, 24, etc.

In the Zoantheæ also mesenterial growth is always in the same succession after the protocnemic stage. The increase takes place within the two exocœlic chambers on each side of the ventral directives; there are only two bands of proliferation or zones of growth. In this case, however, the order 
followed by the new mesenteries differs from that in hexactinians and cerianthids; it proceeds from the ventral (posterior, sulcar) to the dorsal (anterior, asulcar) aspect of the polyp, not from the dorsal to the ventral.

The bilateral development of the organs, from one border of the polyp to the other, in ordinary actinians and corals, would seem to have no phylogenetic significance beyond the group of the cœlenterates, and as yet we appear to have no definite understanding as to what even this may be. The approximate radial symmetry of adult cœlenterates is assumed from very diverse developmental conditions ( $f f$. hexactinians, zoanthids, cerianthids, and the tentacles and other cyclic organs in the Hydromedusæ and Scyphomedusæ). Whatever may be said in favor of Sedgwick's well-known view that the mesenterial arrangement found in cerianthids suggests the metamerism of higher animals, there is clearly no support for such a conception in the development of the organs in hexactinians.

\section{SUMMARY.}

I. In Siderastrea radians the six members of the first cycle of septa appear simultaneously, shortly after fixation of the larva, situated within the entocœles of the first cycle of mesenteries.

2. Six members of a second cycle are developed within the primary exocœles, shortly after the primary cycle of entosepta. They are the temporary predecessors of a later permanent cycle, and arise either simultaneously or in bilateral pairs in a dorso-ventral order. Later, each becomes bifurcated peripherally, either by the direct extension of the original septum or by the production of separate fragments which subsequently fuse. The bifurcations also appear in a bilateral dorso-ventral order.

3. The six members of the permanent second cycle of entosepta arise within the entocœles of the second-cycle mesenteries soon after these make their appearance. The two right and left dorsal septa appear first, then the two middle members, and, at a much later period, the two ventral, the series thus exhibiting a decided dorso-ventrality. In the end they become equal, and each fuses with the central part of the corresponding second-cycle exoseptum previously developed, which now lose their individuality.

4. Twelve members of a temporary third cycle are situated within the exocœles between the primary and secondary pairs of mesenteries, and represent the bifurcated extensions of the six primary exosepta. The original second-cycle exosepta thus become the third exocœlic cycle, their. place having been taken by the permanent second cycle of entosepta.

5. The later development of the septa in buds proves that a new third 
cycle of 12 or less septa arises on the appearance of the pairs of third-cycle mesenteries, in a similar manner to that followed by the permanent second cycle. New entosepta appear within the entocœles of the third-cycle mesenteries, and the bifurcations of the third-cycle exosepta become the exosepta of the fourth cycle.

6. The third-cycle entosepta, following the mesenteries, are developed in a bilateral dorso-ventral order, but in two series-first a series within the dorsal moiety of each sextant, and then a second series within the ventral part of each sextant.

7. Exosepta are present at each cyclic stage in the growth of the corallim, alternating in position and corresponding in number with the sum of the entosepta. They never become entosepta, but always constitute the outermost cycle of shorter septa; only the entosepta have any ordinal significance. Until the adult condition is reached the exosepta are the temporary predecessors of the entosepta. The developmental relationships between the entosepta and exosepta are closely comparable with those between the entotentacles and exotentacles. The law of substitution, first discovered by Lacaze-Duthiers for the tentacles of Hexactiniæ, is thus found to hold also for the septa.

8. Where the cyclic hexamerism of a corallite is incomplete the ordinary cyclic formula does not express the true relationship of the septa. The entosepta and exosepta vary in the same degree, so that the morphological septal formula for a corallite with three entoseptal cycles and one exoseptal cycle is $6,6, \mathrm{x}, 6+6+\mathrm{x}$, where $\mathrm{x}$ may be any number from $\mathrm{I}$ to $\mathrm{I} 2$.

9. The cycles of septa and mesenteries represent so many distinct recurring phases of growth all around the polyp, not a continuous increase from one extremity to the other as in metameric animals. With the exception of the first the members of each cycle follow a dorso-ventral succession, display a bilateral symmetry for some time, and ultimately assume an approximate radial plan. The succession for the third cycle of entosepta is twofold.

BASAL PLATE.

G. vo11 Koch, in the course of his embryological studies of corals, found a deposit of calcareous matter to take place between the ectoderm of the base and the surface of attachment of the polyps. It is the first part of the skeleton to be formed by the activity of the calicoblasts, and from its position is known in coral literature as the basal plate. It is present in the photographic reproductions on plates 4 and 5 , and its relationship to the polyp, at a rather late stage, is shown on plate 9 , fig. 53 . 
In Astroides calycularis Von Koch (1882) found the basal plate to take the form of a thin circular disc, composed of spheroidal or elliptical crystalline bodies, from 0.005 to $0.008 \mathrm{~mm}$. in transverse section. At first the calcareous elements were arranged in an interrupted manner, but later the openings were filled by further deposit of skeletal matter, and the plate as a whole became thickened. In Caryophyllia cyathus (I 897) the first rudiments of the basal plate consisted of a small central deposit surrounded by six thin, nearly triangular plates, interseptal in position. For a time these were distinct from one another, but later united with the central circular patch, and, by further additions, became joined along their edges, thus constituting a complete flattened disc or plate. The presence of a basal plate has since been recognized in many forms of corals, and it is extremely doubtful whether it is really wanting in any species.

For a long time the developing polyps of $S$. radians gave no external indication of any skeletal formation which could be regarded as the basal plate. The first evidences of the corallum were the six entocœlic septa, which appeared to rise directly from the surface of attachment. Under transmitted light they stood out as nearly opaque objects, while the interseptal spaces at this and later stages were quite clear and apparently devoid of any calcareous crystals. For nearly two months the laboratory notes contained the assertion that no basal plate was developed in Siderastrea, for, excepting the presence of the septa and epitheca, there was no interruption in the ordinary light passing through the polyp. When, however, the living or preserved polyps were examined by means of polarized light, the bright colors of the basal region revealed the presence of crystalline matter. This is well seen in the photograph reproduced on plate 4, fig. 22, taken with an exposure of twenty minutes to polarized light. Between crossed nicols the field was black except in the region of the polyp; the septa also appeared black owing to their thickness and the irregular disposition of their crystalline constituents, while all the interseptal areas were brightly and variously colored.

It is obvious, therefore, that a basal plate was already developed between the polyp and its surface of attachment, but was too thin to offer any appreciable obstruction to the transmission of ordinary light. The plate must have begun to form a day or two after fixation of the larva, for the septal upgrowths were observed on the third and fourth days, and the deposit of basal skeletal matter probably preceded them. As stated below, the plate does not undergo much thickness, even in later stages; hence, at no time would it offer much interference to the passage of light. 
When any of the young polyps, two or three weeks old, were macerated later, it was found that a thin continuous plate remained adherent to the incrusted surface; but none of the earliest stages in its formation were obtained, showing whether it originated as a continuous layer or in separate parts. All the polypal tissues have been macerated from the young coralla represented on plate 4 , figs. 19 and 20 ; they now show a well-developed basal plate, slightly upturned at the periphery, and bearing the septa on the upper surface.

A portion of the basal plate of a macerated corallum of two weeks, magnified about 300 times, is represented in surface view on plate II, fig. 69. At the upper boundary of the figure the epitheca also is shown in section, and upon the plate are the first thickenings which will form the septa. The entire surface of the plate exhibits a number of very thin, flat scales, roughly polygonal in form. Sometimes they appear as if joined edge to edge like the cells of an endothelium, or at other places as if overlapping. The average diameter of the individual scales is about $0.03 \mathrm{~mm}$. In most of them a distinct fibrous structure can be recognized, the fibro-crystals either lying parallel or, less often, presenting a radiating appearance. There is, however, no suggestion of the fibers being arranged around a center of calcification, as in the trabeculæ of the septa.

According to Miss Ogilvie ( 1897, pp. I I4-I I 7 ) similar scale-like elements are present on the surface of the corallum of corals generally, and she has succeeded in isolating them from the almost transparent dissepiments of Galaxea. Their breadth in this genus varies on an average from r.or to 0.OI $5 \mathrm{~mm}$., while their height is about $0.003 \mathrm{~mm}$. A number of fibers are present in each, sometimes in the form of divergent groups, but often lying loosely side by side. It was from a study of these that Miss Ogilvie came to the conclusion that each isolated skeletal element represented a calcified calicoblast cell, thus returning to the old view of von Heider as to the origin of the calcareous skeleton of corals in contrast with the more accurate results of von Koch, Bourne, and Fowler, which show that the calcareous matter is secreted wholly external to the ectodermal cells. The structure of the calicoblast layer in the polyps of Siderastrea is also very conclusive as to the ectoplastic origin of the calcareous fibers. Everywhere it has been found to be a simple layer, never many cells deep, as would be the case were the calicoblasts themselves calcified and shed from time to time to build up the skeleton.

From the relationships of the basal plate to the polyp, increase in its thickness can obviously take place only on the upper surface. In addition to the 
septal rudiments, small projections are present here and there on this surface, especially towards the middle of the plate, and some continue growing until they become raised much above the general level of the plate and constitute columellar spines. In the basal plate we have the skeleton in its earliest and simplest condition as a flat deposit, and the septal and columellar formations are vertical upgrowths from it. The latter represent areas at which the calcareous matter is laid down with greater rapidity by the activity of the calicoblasts. The basal plate, however, is covered by polypal tissues on only its upper surface, while the upgrowths from it-septa and columella-are covered on both sides; hence the difference in their microscopic structure shown on plate II, fig. 70. There are no axial centers of calcification in the elements of the basal plate, while such are very distinct in the septa.

When the young corallum is detached from a smooth surface, the lower surface of the basal plate is also smooth and even, but when growing over a rough surface it adapts itself to the irregularities.

The basal plate increased considerably in diameter from the time of its first formation, keeping pace with the general growth of the corallum. In the early stage on plate 4 , fig. I9, it is only I.3 mm. across, while in the corallum of plate 5 , fig. 28 , it is $2 \mathrm{~mm}$. in diameter.

As shown in the next section an epitheca begins to form at the edge of the basal plate whenever growth ceases, while when lateral growth is continued there is little or no possibility of any upturned marginal deposit.

Apparently the original basal plate of $S$. radians never becomes much thickened. Some of the oldest coralla reared rather suggest that the central interseptal portions may be resorbed, or, at any rate, remain extremely delicate. When coralla of four months were macerated and separated from their surface of attachment it was found that interseptally the basal deposit had disappeared from the central regions, though retained towards the periphery and along the septa. It may be that on account of its thinness interseptally it had broken away in the process of maceration, while it was supported septally and peripherally.

In colonial corals the basal plate is generally represented only in the corallum of the primary larval polyp, the later bud polyps not admitting of its formation. But wherever in growing colonies of $S$. radians the marginal corallites extend beyond the incrusted object a thin parchment-like deposit is found basally. It constitutes the basal skeletal support of the young bud polyps, in the same manner as the basal plate of larval polyps, or as the dissepiments at a later stage. 
Along with the first formation of the radiating septal upgrowths appeared a narrow, peripheral calcareous ring, somewhat less opaque than the septa, and for a long time wholly unconnected with them (plate 2). The most careful examination of the living polyps proved that the annulus was altogether external to the soft tissues; while in preserved and cleared specimens the polypal wall was found to pass within the inner border of the skeletal deposit, not to be folded over it. The formation is undoubtedly to be regarded as an epitheca, according to the definitions of this structure given below.

The epitheca increased in height along with the growth of the polyp, at the same time often narrowing a little transversely. It remained throughout uncovered by any polypal tissues on its outer surface, though lined by the polypal wall on its inner surface (plate 9, fig. 53). Where most fully developed its outer surface exhibited distinct incomplete annulations, wrinklings, or accretion lines, as if representing separate intervals in the deposition of calcareous matter (plate 4). By the time the polyps were six or seven weeks old the lower region became discolored by the adherence of foreign matter, such as filamentous algæ and diatoms, and only the actual margin was fresh and white. Opposite the septa the epithecal margin was sometimes a little indented, but otherwise was of the same height all round, somewhat exceeding that of the septa. Whenever, owing to uncongenial conditions, the polyps shrunk from their former size, the peripheral deposit remained behind, distinct and complete; the growth of a second annulus then took place at the new margin of the narrowed polyp, in such a way that the new ring was wholly within the old (plate 5, figs. 25-27).

Later, as the septa increased in radial length, some of them came in contact with or were actually fused with the epithecal deposit, but the microscopic structure of the two remained distinct. When the coralla were freed from their surface of attachment the epitheca was seen to be a direct upward continuation of the edge of the basal plate, and, like it, shows no centers of calcification. It is made up of circular lamellæ, the fibro-crystals of which are arranged at right angles to the polypal wall (plate II, figs. 69, 70); the epithecal deposit, in fact, corresponds to but one-half of a septum.

The epitheca was found to vary greatly in the extent of its development in the various polyps. In some of the most forwardly developed specimens it was practically absent or represented only by a thickened marginal ring (plate 4, figs. I9, 20); in others it appeared as a very distinct parapet, 
elevated beyond the level of the septa (plate 5). Where two or more polyps developed contiguous to each other a common epitheca was formed along the line of contact (plate 5, fig. 30), but each became distinct later. In one instance two polyps, along with their septa, were embraced in a common epitheca.

This surprising variation in the amount of epithecal deposit appears to be determined by the rate of growth of the polyp. As already noticed, the polyps varied greatly in this respect, and the epitheca was best developed in individuals which increased but little in size. The transverse narrowing in the later stages may be taken to indicate that the polyps had become somewhat less in their basal diameter. Where a polyp was growing rapidly, enlarging the diameter of its basal disc and extending the septa peripherally, it is manifest that an epitheca could not be formed, or, if formed, would need to be resorbed. In the two coralla represented on plate 5 , figs. 28 , 29, there is practically no epitheca, but the basal plate is much thicker in its peripheral half than in the middle. Presumably, the polyp did not rest long enough at any one stage to permit of the secretion of an epitheca. Until maturity, therefore, it is possible that individual corallites of the same species of coral may be provided with or be destitute of an epitheca, according to the slow or rapid rate of growth of the polyp; the morphological value of the structure becomes somewhat lessened when its formation is shown to be dependent to such an extent upon physiological conditions.

The peripheral skeletal formation in Siderastrea is of interest in connection with the much discussed question as to the nature of the thecal and epithecal wall of corals. In some respects the structure recalls that described as theca (Mauer) by von Koch (I897) in his paper on the development of the skeleton of Caryophyllia cyathus, but a comparison at-once establishes their different values. In both species the structure in question arises as an independent peripheral part of the corallum, and narrows from below upwards. But in the species investigated by von Koch the annulus is inclosed on both its inner and outer sides by an upgrowth of the basal wall, while in Siderastrea it is external from the beginning, only covered by the polypal tissues on its inner wall and growing margin (plate 9, fig. 53). Again, in the first the deposit early unites the edges of the septa, but in the other it remains entirely free from septal connection for a long time, and then only joins their edges as an independent external covering. The different character of the theca (pseudotheca and true theca) in various Madreporaria has already been alluded to (p. 45), and the original peripheral structure arising in Caryophyllia would certainly belong to the "true theca" type. Miss Ogilvie (I897, p. 
I 59) separates the theca from the epitheca, as follows: "The essential difference which may be said to distinguish "theca " from "epitheca" is that the theca, or wall, must be structurally associated with the peripheral ends of septa, whereas the epitheca is in no structural connection with the septa, but is a continuous concentric deposit exterior to all the other skeletal structures of a calyx." And again (p. 248): "The epitheca is an external basal structure, laid down at the angle of the aboral wall, where it bends towards the oral or peristomal region of the polyp (figs. 22,36 ). It is the continuation upwards or outwards of the embryonic 'basal plate,' and may be well-developed or remain rudimentary." G. von Koch (I896, p. 254) describes the structure in much the same terms.

These two definitions serve to distinguish clearly between the peripheral annulus found in Caryophyllia cyathus and that in S. radians. In the one case it is structurally associated with the outer ends of the septa, while in the other it is quite independent of these; in one it is developed within a special invagination, "thecal refoulement," of the skeletotrophic wall which lines both its inner and outer surfaces, in the other it is wholly external to the polyp, covered on one side only by the skeletogenic tissues, not by an upfolding. In Caryophyllia von Koch found no trace of an epitheca in addition to the theca, while in Astroides and now in the early corallum of Siderastrea there is found to be an epitheca but no true theca. Whatever calicinal wall is found in the mature corallum of these two genera is a later structure formed by the coalescence of the outer edges of the septa (pseudotheca).

By Ogilvie (p. 248) and Vaughan (p. 48) the epitheca is regarded as a primitive structure in Madreporaria, while the thecal structures are of secondary origin. The latter writes: "The oldest type is where the ends of the septa did not fuse distally, but simply had their outer ends bound together by an epithecal covering." This clearly describes the early epithecate corallum of Siderastrea. In this respect, therefore, the genus must be considered as representing an older type than the truly thecate corallum of such a form as Caryophyllia. Its very rudimentary condition in some of the young polyps and its almost complete absence from the adult colony would seem to prove that in this genus it is an embryonic structure of diminishing importance.

\section{COLUMELLA.}

For a time the central part of the basal plate was free from any calcareous deposit which could be regarded as a columella (plate 4), but, as the septa increased in size, spinous upgrowths began to form near their inner extremity, 
extending as far as the center of the calice (plate 5). Some of these upgrowths appeared as separate projections from the basal plate, as if produced by special invaginations of the basal wall of the polyp-the refoulement columellaire of Delage \& Hérouard (Igor, p. 558); others seemed to be direct continuations of the septa, not requiring a separate upfolding of the basal disc. The former undoubtedly represent a true independent columella, while the latter by their union might give rise to a so-called pseudocolumella. At no time, however, could any sharp distinction be drawn between the septal and the independent upgrowths, except as regards their position. In the coralla represented on plate 4 , figs. 23 and 24 , two or three of the middle granules are obviously distinct basal formations, while exactly similar spinous projections occur at the end of some of the septa. The middle of the corallum on plate 5 , fig. 28, is also occupied by distinct spinous upgrowths, both basal and septal in character.

A further stage in the columellar growth is represented in the coralla of figs. 28 and 29. Here the intervals between the spines are becoming partly occupied by the deposition of secondary calcareous matter, so that their actual origin is obscured. In the mature corallum it was frequently found (p. 53) that the columella is minutely spinous or papillose as seen from the surface, and that in sections for some distance below it remains spongy, becoming compact in the deeper regions by the later deposition of calcareous matter. Further, where the coralla are very strongly calcified the spinous character of the columella disappears even superficially, the interspaces being altogether occupied by the secondary deposit, which keeps pace with the septal and columellar spinous formations. These differences in the mature calice thus coincide closely with those represented in the larval coralla of figs. 23 and 29.

Both from its origin and mature characters the columella of $S$. radians is therefore formed from three independent sources: (I) Separate basal upgrowths; (2) septal spines, continuous with the central ends of the septa ; (3) a secondary deposit filling up the interstices between $x$ and 2. Histologically the trabeculæ of all three are alike (plate Io, fig. 65).

The columella of Siderastrea is thus a "true" columella, to be distinguished from a "false" or "pseudocolumella" where there is no direct basal upgrowth, but the entire structure is formed from the inner septal edges. In its development it agrees most closely with the account which von Koch ( 1897, p. 769$)$ gives of the formation of the columella in Caryophyllia. 


\section{ANATOMY AND HISTOLOGY OF LARVA AND YOUNG POLYP.}

A number of free-swimming larvæ were preserved in corrosive acetic, and later studied by means of transverse and longitudinal sections, when all were found to be at about the same stage of development. Only the important features in which they differ from mature polyps will be here noticed.

The larval ectoderm is somewhat broader than the same layer in the adult polyp. In sections it measures about $0.04 \mathrm{~mm}$. across while that of the adult is $0.03 \mathrm{~mm}$. The outer surface is strongly and uniformly ciliated, the enlarged base of each cilium being well defined. Numerous clear and gran-. ular gland cells occur, and towards the margin a zone of small nematocysts o.or $5 \mathrm{~mm}$. in length. The layer further differs from that of the adult in containing a few Zooxanthellæ, mainly restricted to the oral extremity. These have been already noticed among the external characters as giving a brownish color to the oral pole of the larva, and are apparently liberated from time to time.

The larval ectoderm is broader at the base, where it measures $0.06 \mathrm{~mm}$. across, and, in addition, has undergone certain histological modifications. The cells as a whole seem more compactly arranged, gland cells are less numerous, and a nerve layer is present; but nematocysts do not seem more numerous than elsewhere. The whole structure recalls the aboral sense organ which has already been found by McMurrich, Appellöf (I900), and myself (I902, p. 524), to occur in certain actinian and coral larvæ, and is evidently widely, though not universally, present in these two groups. The characteristics of the organ, however, are usually more conspicuous than in the present species, especially as regards the degree of development of the nervous elements.

The stomodæal communication between the exterior and the larval cavity was already established in all the larvæ studied. In most the lumen is circular, while in others it is slightly oval. The surface is more strongly ciliated than that of the outer ectoderm, and fewer gland cells occur; the two agree in the presence of Zooxanthellæ, though these are never found in the ectoderm of the adult stomodæum.

The mesenterial filaments on pairs I and II on plate 8 , fig. 52 , stand out conspicuously from the endoderm on account of the number and deeplystaining character of their nuclei, and their histological structure recalls that of the stomodæal ectoderm. In the larvæ, however, the organs are not yet rounded off from the mesenterial endoderm. 
In the serial transverse sections from which figs. $5^{\mathrm{I}}$ and 52 , on plate 8 , were taken, the stomodæal ectoderm appears to be continued uninterruptedly as the mesenterial filaments down the edge of the two lateral pairs of complete mesenteries on their becoming free; but the ventral and dorsal directives (III, IV), which are only attached to the stomodæal wall for part of their length, are without such modified tissue along their free edge.

The continuity of the stomodæal ectoderm with the mesenterial filaments in the various larvæ of Siderastrea, and the close histological similarity of the two, seem at first sight undoubted evidence of the ectodermal origin of the latter, especially when it is found that filaments are not present on mesenteries which do not reach the stomodæum, or do not extend as far as its inner termination. In the larvæ of many other Actiniaria and Madreporaria, however, it has been found that filaments may appear on mesenteries before they reach the stomodæum, and even in complete mesenteries an interval of undifferentiated endoderm often occurs between the termination of the stomodæal ectoderm and the filaments. From observations on other corals I consider that the mesenterial filaments arise from the larval endoderm independently of the stomodæal ectoderm, but that continuity is early established in the case of those mesenteries which unite with the stomodæum (I902, p. 476).

The internal cavity of the larvæ is very limited in extent, the endoderm nearly filling the whole chamber. In the youngest examples mere slits represent the lines along which the polypal cavity will be formed later. The cells of the endoderm are much vacuolated, and contain numerous Zooxanthellæ scattered throughout. The lining of the mesenteries and also of the intervening portion of the column wall is not arranged as a simple epithelial layer such as characterizes the adult. Within most of the intermesenterial spaces the endoderm is greatly thickened, and in transverse sections stands out as a very distinct triangular projection into the cœlomic cavity, leaving only a narrow slit between itself and the mesenterial lining. The vertical projections are the "Vorsepten" or prosepta of von Koch (r897); they are the persistent parts of the mass of endoderm which at an earlier stage occupies the whole interior of the early larva. On plate 8 , fig. $5^{2}$, taken from a rather late larva, the prosepta are still conspicuous, and some are associated with rudiments of the mesenteries ; the mesenterial endoderm is still greatly thickened, and the central cavity is beginning to enlarge.

In an earlier paper on the larva of the actinian Lebrunia coralligens (I899), I have shown that most anthozoan larvæ are for some time nearly solid, owing to the enormous development of the endoderm. There are, how- 
ever, very narrow, canal-like slits, and from these the adult gastro-cœlomic cavity is derived by the disintegration of the more central endoderm and the shrinkage of that lining the body-wall and mesenteries.

Some of the larvæ of Siderastrea sectionized reveal a gastro-cœlomic cavity further developed than that represented in figs. $5 \mathrm{I}$ and 52 . Below the stomodæal region the parenchymatous endoderm has broken down, and the middle of the cavity is occupied by organic débris, in which Zooxanthellæ, cell walls, and granules of various kinds are recognizable. There is no doubt that this is the organic débris which is extruded from time to time by the larvæ soon after their liberation from the parent polyp (p. 58). At the stage in the young polyp at which the septa are well advanced (plate 9, fig. 53), the endoderm has become a simple epithelial layer throughout, resembling in all respects that of the mature polyps.

In the earliest larvæ sectionized eight mesenteries were already developed, arranged in four bilateral pairs, as shown diagrammatically in fig. 8, $a$, p. 80 . The twolateral pairs are united with the stomodæum, while the dorsal and ventral axial pairs, representing the directives, are free, and of the two directive pairs the ventral are slightly larger than the dorsal. In larvæ a day or so older the ventral directives have united with the stomodæum, while the dorsal are still free (plate 8 , fig. 5I) ; also at the stage with three complete mesenteries two other bilateral pairs of mesenteries, the fifth and sixth in the sequence, have made their appearance, arranged as on plate 8, fig. 52. Afterwards the dorsal directive mesenteries unite with the stomodæum, and the larva has reached the Edwardsian stage of mesenterial development presented at the time of fixation (fig. $8, a-c$, p. 8o).

There appears to be no resting stage in the appearance of the mesenteries between the tetrameral and hexameral condition, such as seems to characterize certain actinians (Lebrunia), nor in the successive union of the first four pairs with the stomodæum. As already shown, however, the fifth and sixth pairs remain as microcnemes for a prolonged period.

As represented on plate 8 , figs. 5 I and 52 , the mesenterial mesogloa is extremely thin. The cut ends of very delicate muscular fibrils can be recognized in transverse sections, and, according to their disposition on one side or other of the mesoglœa, assist in the determination of the paired arrangement.

The further development of the mesenteries, after fixation has taken place, can be easily followed through the transparent tissues of the living polyp, and has been already described. 


\section{YOUNG POLYPS.}

Very few of the young polyps reared were available for anatomical and histological study, owing to the greater importance of the corallum at this stage; in most cases the soft tissues were removed by maceration in order to secure the skeleton. A vertical section through a decalcified retracted larval polyp, of about two months, is represented on plate 9 , fig. 53. The section of the skeleton has also been added, the details being taken from various coralla of this age. The section of the polyps includes the oral aperture, and on the right is truly radial, passing through a mesenterial space and cutting a septal invagination obliquely, while on the left side it passes obliquely through a mesentery and also through a septal invagination. A third invagination is included in the middle region of the section and probably represents an early columellar upgrowth. The upper wall on the left has come to rest upon one of the invaginations.

The septal and columellar invaginations are here of the simplest character. They are merely continuous upgrowths of the basal wall of the polyp, and agree with it histologically. They line both sides of the calcareous upgrowths from the basal plate, while the latter in its turn is laid down by the flattened part of the disc, increase in thickness taking place only on the upper side.

Sections of coral polyps at such an early stage are the most favorable for demonstrating conclusively that the madreporarian skeleton is laid down wholly outside the polypal tissues, and that all the skeletal complications are formed within extensions of the basal disc, the invaginations proceeding pari passu with the deposition of calcareous matter. This truth was first established by von Koch by means of sections of polyps of Astroides, somewhat similar to that of plate 9, fig. 53; further, von Koch was able to demonstrate the calcareous spheroids of the basal plate and septa in situ. His polyps for this purpose were adherent to pieces of cork, so that the polyp and its attachment could be sectionized together. The polyps of Siderastrea being adherent to glass could be sectionized only after being freed through decalcification.

Decalcification of the polyp from which fig. 53 was taken was carried out with great care, but only fragments of a very narrow skeletogenic ectoderm remained. No hints of any mesoglœal processes or desmocytes occurred, but such would scarcely be expected considering their rarity in the adult polyp of Siderastrea. The mesoglœa itself is a very thin lamella. The basal 
endoderm also has undergone a great alteration compared with the same layer in the other regions of the polyp. It is much thinner, all traces of cell limitations are lost, and Zooxanthellæ are wholly absent, while elsewhere in the endoderm the algal cells occur in some abundance.

The passage from the calicoblastic ectoderm to the ectoderm of the column wall is gradual, and can be studied on both sides of the section. It is at this point that the epitheca is laid down.- Were there any doubt as to the epithecal or thecal nature of the peripheral calcareous ring such sections prove absolutely that the deposit is uncovered by the polypal tissues on its outer sides. Were it otherwise an invagination of the base would occur towards the periphery, but none of the sections show any such folding.

At the region of the epitheca there is no sharp distinction between the column wall and the basal disc. The ectoderm of the former is a broad columnar epithelium, having many clear unicellular mucous glands distributed among the supporting cells; the nuclei are restricted mostly to the inner. half of the layer. The left half of the disc includes the section of a tentacle, represented only by the knob which is crowded with long, narrow nematocysts. As in adult retracted polyps, the stem of the tentacle is not distinct from the disc. Histologically the walls of the stomodæal invagination closely resemble those of the adult polyps, and the ectoderm is marked off from the rest of the body wall by its numerous ciliated supporting cells.

On both sides of the section represented in fig. 53 the stomodæal wall terminates freely, but in sections which include a mesentery the ectoderm is seen to be continuous with the mesenterial filaments along the free edge of the mesentery. The two, stomodæal ectoderm and mesenterial filament, are much alike histologically, and by their brightly-staining character are easily recognizable among the other tissues. 



\section{REFERENCES.}

(Only the more frequently recurring references are here given; the others are inserted in the text.)

1900. Appellöf, A. : "Studien über Actinien-Entwicklung." Bcrgens Museums Aarbog. Igoo, no. 1. 1897. VAn Beneden, E. : "Les Anthozoaires de la Plankton-Expedition." Résultats de la "Planktonexpedition der Humboldt-Stiftung." Vol. II, Kiel et Leipsic.

1887. Bourne, G. C. : "The anatomy of the Madreporarian Coral Fungia." Quart. Journ. Micr. Sci., vol. XXvir.

1893. — : "On the postembryonic development of Fungia." Trans. Roy. Dublin Soc., ser. II, vol. v.

1899. - - "Studies on the structure and formation of the calcareous skeleton of the Anthozoa." Quart. Journ. Micr. Sci., vol. XLI.

1901. Delage, Y., and Herouard, E. : "Traité de Zoologie Concrète. Les Cœlentérés." Tom. II, pt. 2.

1899. Duerden, J. E : "The Edwardsia-stage of the actinian Lebrunia, and the formation of the gastrocœlomic cavity." Journ. Linn. Soc., Zool., vol. xxvir.

1902. —_ : "West Indian Madreporarian Polyps." Mem. Nat. Acad. Sciences, vol. virr, 7th Mem.

1895. 'Faurot, L. : "Etudes sur l'anatomie, l'histologie et le développement des Actinies." Arch. de Zool. Exp. et Gén., ser. 3, tom. III.

1888. Fowler, G. H. : "The anatomy of the Madreporaria, IV." Quart. Journ. Micr. Sci., vol. xxvir.

1902. GARDiNer, J. S. : "South African corals of the genus Flabellum, with an account of their anatomy

- and development." Marine Investigations in South Africa, vol. II, Cape Town.

1882. von KocH, G. : "Ueber die Entwicklung des Kalkskeletes von Asteroides calycularis und dessen morphologischer Bedeutung." Mitt. a. d. Zool. Stat. zu Neapel, bd. III.

1896. —_ : " "Das Skelett der Steinkorallen." Festschrift fuir Carl Gegenbaur. Leipzig.

1897. - : "Entwicklung von Caryophyllia cyathus." Mitt. a. d. Zool. Stat. zu Neapel, bd. xı.

1872. Lacaze-Duthers, H."DE: "Développement des Coralliaires. Prem. Mém., Actiniaires sans Polypier." Arch. de Zool. Exp. et Gén., tom. I.

1873. - : "Développement des Coralliaires. Deux. Mém., Actiniaires à Polypier." Arch. de Zool. Exp. et Gén., tom. II.

1897. - - " " Faune du Golfe du Lion. Coralliaires. Zoanthaires Sclérodermés." Arch. de Zool. Exp. et Gén., 3 ser., tom. v.

I897. Ogruvi, M. : "Microscopic and systematic study of Madreporarian types of corals." Phil. Trans., vol. CLXXXVir.

1900. Vaughax, T. W. : "The Eocene and Lower Oligocene Coral Faunas of the United States." U. S. Geol. Survey, Monogr. Xxxix.

Igor. Verkill, A. E. : "Variations and nomenclature of Bermudian, West Indian and Brazilian Reef corals, with notes on various Indo-Pacific corals." Trans. Conn. Acad. Science, vol. XI.

I888. Wilson, H. V.: "On the development of Manicina areolata." Journ. Morph., vol. jI (1889). 


\section{EXPLANATION OF PLATES.}

\section{Plate 1.}

FIG. 1. - Larva immediately on extrusion, viewed by refected light. The uniform covering of cilia is indicated, and also the distinction between the outer ectoderm and the solid internal endoderm. The darker color of the broader oral pole is due to the presence of Zooxanthellæ in the ectoderm. The narrower aboral pole is anterior in swimming; the mouth is not yet functional.

Fig. 2.-Abnormal larva with two oral poles and one aboral.

Fig. 3.-Larva shortly after extrusion. The larva is now more swollen and transparent, so that four pairs of mesenterial lines are seen; the mouth is also functional. Two pairs of mesenteries reach the stomodæum, and two other pairs are free.

Fig. 4.-A second-day larva just before settling. Six pairs of mesenteries are now present, three pairs of which reach the stomodæum.

Fig. 5.-Three larvæ settling close together by the narrow aboral pole.

Fig. 6.-A group of seven third-day larvæ which have settled so close together that their walls partly overlie. Four pairs of mesenteries now reach the stomodæum, and on three of the individuals the rudiments of the six exocœlic tentacles have appeared.

FIG. 7.-A living polyp two or three days after settling, viewed by transmitted light. The dark outermost rim represents the epitheca; the next lighter zone is the flat margin of the polypal wall into which the polypal cavity does not extend. The six entosepta are opaque, but in such a view there is no evidence of the basal plate. The six tentacles are exocclic and alternate with the septa. The internal Zooxanthellæ have accumulated mainly along the sides of the mesenteries; the ectodermal Zooxanthellix have disappeared except immediately around the mouth. Diameter of original, $1.5 \mathrm{~mm}$.

Plate 2.

Fig. 8. - Living polyp with a dorso-lateral pair of exosepta and a rudimentary pair of median exosepta in addition to the six entosepta.

FıG. 9-Polyp with six entosepta and six exosepta, the latter still revealing their dorso-ventral order of development by differences in magnitude.

Fig. 10.-A living polyp of about the same stage as fig. 9, fully expanded and viewed from the side as a transparency. Of the mesenteries only the insertions are represented.

Fig. 11.-Polyp with twelve fully expanded tentacles, six large outer exocclic and six small inner entocœlic. Fifth week.

Fig. 12.- Polyp showing the irregular manner in which peripheral additions are made to the primary septa. The ventral directive tentacle is double. Diameter of original, $1.7 \mathrm{~mm}$.

Plate 3.

Fig. 13.-Expanded disc showing the doubling of certain of the entotentacles and the asymmetrical position of others.

FIG. 14- Expanded polyp viewed from the side so as to display the manner of appearance of the second-cycle mesenteries on the column wall.

FIG. 15.-Expanded disc resting on the septa and exhibiting the relationship of the second-cycle mesenteries to the new entosepta and exotentacles. An additional exotentacle has appeared within the middle sextant on each side, and the dorso-lateral entotentacles have each a single stem bifurcated distally.

Fig. 16.-Expanded disc showing the manner of increase of the tentacles. An exotentacle protrudes from each of the two exocceles in the dorso-lateral and median sextants, but as yet there is only one froin the ventro-lateral sextants. The tentacle from each dorso-lateral entocole is already bifurcated as in the adult.

Fig. 17.-The same polyp as in fig. 16 at a later stage. On each side a second-cycle tentacle (II) has grown out over the entocœle of the median second-cycle mesenteries, and the four lateral first-cycle entotentacles (I) are bifurcated. Diameter of original, $2 \mathrm{~mm}$.

Fig. 18.-A larval polyp of three months in which the disc and tentacles are indrawn and the disc is almost covered by the overfolding column wall. The epitheca is shown around the margin. 
Plate 4.

FIG. 19.-Photograph of early corallum with six entosepta and six exosepta. The basal plate (prototheca) is fully formed, but somewhat irregular in outline; it is a little thicker and upturned towards the margin. The six entosepta are nearly equally developed, while the alternating exosepta vary much in size; the dorso-lateral pair are best developed and peripherally seem double, the middle pair are a little smaller, while the ventro-lateral are yet rudimentary. Diameter, $1.6 \mathrm{~mm}$.

Fig. 20.-A somewhat later corallum. The directive entosepta are irregular in form and differ from one another, the ventral appearing as if bifurcated peripluerally; the two dorso-lateral and right middle exosepta also appear bifurcated; the ventro-lateral exosepta are still much smaller than the other exosepta.

FIG. 2I.-A young preserved polyp photographed by transmitted light. In such a view the basal plate is not apparent owing to its transparency. The septa are non-transparent and stand out as black objects. Indications of the six pairs of radiating mesenteries are seen and also some of the tentacles, but the details around the mouth are obscured by the mesenterial filaments and stomodæum. The dotted surface of the polyp is due to the presence of internal Zooxanthellæ. The septa are a little further developed than in fig. 20, the exosepta still showing a decided dorso-ventrality. There is a marked difference in form between the dorsal and ventral directive septa. Diameter, $1.7 \mathrm{~mm}$. (In the process of engraving the principal axis of the polyp has been turned counter-clockwise through an angle of about 20 degrees from the vertical.)

FIG. 22. - The same polyp as in fig. 21 photographed by an exposure of 20 minutes to polarized light between crossed nicols. Only the calcareous crystals transmitted the variously colored light. The mottled surface represents the basal plate which is not indicated in the previous figure. The crystalline matter of the septa is so thick and irregularly arranged that no light was transmitted; hence the structures appear black.

FIG. 23.-A typical corallum at a later stage, growth having proceeded upon the septal plan of figs. 19 and 20. The polyp remained at this stage for some time, and a well developed wrinkled epitheca has formed, its upper edge higher than the septa; the latter are fused peripherally with the epitheca, but there is no theca. The directive septa are somewhat bifurcated peripherally and also the dorso-lateral and median exoseptal pairs. The dorso-lateral pair are almost fused centrally with the dorsal directive, the middle exosepta are fused with the dorso-lateral entosepta on each side, and the ventro-lateral exosepta with the ventro-lateral entosepta. The ventro-lateral exosepta are the smallest of the whole series. Separate columellar nodules are present in the middle. For diagrammatic plan see p. 88 . Diameter, 1.8 $\mathrm{mm}$. (In the process of engraving the principal axis of the corallite has been turned clockwise through an angle of about 20 degrees from the vertical.)

Frg. 24.- Another corallum at about the same stage as fig. 23, but showing variation in detail.

Plate 5.

FIG. 25. A corallum in which the epitheca has gradually receded from the margin towards the middle of the calice as the polyp shrunk in size. The older part of the epithecal deposit covers the peripheral parts of the septa. The newest portion of the epitheca is the inner annulus. The septa are at about the same stage as in fig. 23.

FIG. 26.-Corallum in which the polyp has twice diminished in size, somewhat suddenly. Three concentric epithecre have been formed, the peripheral ends of the septa being partly exposed between each.

Fig. 27.- The septa are a little further advanced than in figs. 23-26. In the left dorso-lateral sextant there are three distinct septa, a large median and two lateral; the median septum consists of a larger central (exoseptum) and a small peripheral part (entoseptum). In the right middle sextant are also three septa, the median of which consists of a central and a small peripheral part ( $c f$. fig. 15).

FIG. 28. - This and the next corallum are the two oldest reared. Each contains three complete cycles of septa, and some of the sextants show important stages in the passage from the second to the permanent third cycle. In the polyps which formed the coralla the first and second cycles of mesenteries were fully developed. The diagrammatic representation of the stage is given on p. 89 , and emphasizes the manner of fusion of the various septa with one another. The directive septa are stouter than any of the others. The three septa within the ventro-lateral sextants are not so strongly developed as those within the median and dorso-lateral sextants, and show very distinctly the twofold constitution of the median entoseptum 
and the independent character of the exoseptum on each side ( $c f$. fig. 15). Synapticula now connect some of the adjacent septa. The origin of part of the columella from nodular upgrowths, independent of the inner septal edges, is very evident. The basal plate is thicker peripherally than centrally, and the epitheca is only feebly developed at the margin. Diameter of original, $2 \mathrm{~mm}$.

FIG. 29. - The details presented are practically the same as in the previous figure, but the growth of the three septa within the ventro-lateral sextants has reached the same stage as in the other sextants. The epitheca is better developed than in fig. 28 .

Fig. 30.-Double corallum produced by two polyps the larvæ of which settled close together. Each has an independent epithecal formation, the part common to both being very irregular. The septa have not preserved the regular hexameral plan.

\section{Plate 6.}

Fig. 31. - Three fully expanded adult polyps, showing the forms assumed by the polyps and the arrangement of the bilobed and simple tentacles.

Fig. 32. - Nearly mature polyp preserved in formalin in a partly expanded condition; surface view. The tentacles over the third-cycle entosepta (III) are still simple and resemble the exotentacles (X).

FIG. 33.-An isolated interseptal lamella from a decalcified polyp. The lower margin represents the part of the lamella which rested upon a dissepiment, and about the middle nearly surrounded a synapticulum. The apertures (syn) are the spaces formerly occupied by the synapticula. The column wall, disc, a bifurcated tentacle, stomodæum, and a mesenterial filament are shown.

FIG. 34.-Transverse section of a mature polyp, passing through the stomodæal region. The figure shows the arrangement of the mesenteries, the septal invaginations, and synapticula. In this and other figures the spaces occupied by the skeleton are represented by the dotted areas.

FIG. 35.-Transverse section through a portion of the calicinal ridge of two retracted polyps, showing the continuity between the mesenterial chambers of adjacent polyps, and also the vertical free edge of the mesenteries as they extend from the column wall to the skeletotrophic tissues. In the upper part the septa are exsert, but below they are united with the calicinal wall (ex. sept., exoseptum; ent. sept., entoseptum).

Fig. 36. - Tangential section towards the periphery of a polyp. The column wall rests upon the septal edges, and the mesenteries have a short vertical extent.

Plate 7.

Fig. 37. $-a$, fully expanded entotentacle; $b$, fully expanded exotentacle.

Fig. 38. - Transverse section of the same polyp as in fig. 34 , taken a little below the stomodæal region.

Fig. 39. - Transverse section of a polyp towards its aboral region. The mesenterial loculi are altogether isolated at this level, and appear further broken up by the synapticula stretching from one septum to another. The mesenteries have almost disappeared and the middle of the section is occupied by the columella. The skeletal ectoderm and endoderm are both represented.

Fig. 40.- Tangential section through the tentacular region. A single bilobed entocalic tentacle is almost resting upon a septal edge. In the septal invagination (sep. inv.) the calicoblast layer is represented.

Fig. 41.- Transverse section through a mesentery at the level represented in fig. 35 . The mesoglœal plaitings for the support of the retractor muscles are simple in character, the oblique musculture is feebly seen, and also the desmoidal processes where the mesentery is attached to the skeletotrophic layer (sk. l.).

FIG. 42.-Transverse section through a mesenterial filament immediately below the stomodæal region.

FIg. 43. - Transverse section of a mesentery some distance below the stomodæal region, showing the form of the mesenterial filament, and also a single ovum; the peripheral end of the mesentery is undergoing resorption.

FIG. 44. $-a$, small nematocysts from the knob of the tentacle and column wall; $b$, elongated form of nematocysts from the knob of the tentacle and mesenterial filaments; $c$, large oval nematocyst from the lower part of the mesenterial filaments. 
Plate 8.

FIG. 45.- Section through part of a mesentery in union with the skeletotrophic tissues where they surround a synapticulum. The mesenterial mesogløa for some distance from its termination is finely striated, forming a desmoidal process. The skeletotrophic ectoderm on the left side shows faintly a narrow portion of the homogeneous skeletal matrix.

Fig. 46. - Transverse section through an isolated portion of the lining wall of an interseptal loculus. Each lateral extremity was terminated by a synapticulum. The section was stained in iron hæmatoxylin, and shows very distinctly the mucous spaces in the inner endoderm and calicoblast layer. The latter also contains coarsely granular cells and nematocysts.

Fig. 47. - Transverse section through the skeletotrophic layers in their uppermost part. showing the very narrow endoderm and calicoblast layer. The layers are syncytial in character. Irregular canal-like spaces are filled with a deeply-staining substance. Small irregular particles are adherent to the free surface of the ectoderm.

FIG. 48. -Transverse section througl a part of the skeletotrophic layers from the lower region. The section gives practically the same details as fig. 46 , but is more highly magnified.

Fig. 49. - Longitudinal section through an expanded tentacle. The stem is simple in character, while the swollen knob has a nerve and a muscle layer at the base and nematocysts and gland cells ( $g r . g . c$. ) towards the periphery.

Fig. 50.- Transverse section through a portion of a mesentery showing the system of irregular spaces in the endoderı. The Zooxanthellæ and cut ends of the retractor muscle fibers arranged along mesoglœal plaitings are also represented.

Fig. $5^{1}$. - Transverse section through the stomodral region of a larva preserved shortly after extru. sion. The six primary pairs of mesenteries are present, but the dorsal directives (IV, Iv) and pairs $\mathrm{v}$ and vi are yet free from the stomodæum. The gastro-colomic cavity is beginning to be established in the nearly solid endoderm; Zooxantluellæ are present in the thick stomodæal ectoderm. In this and the next figure the histological details of the endoderm are represented, while the ectoderm is conventionally depicted.

FIG. 52.- Transverse section through the same larva a little below the stomodral region. Mesenterial filaments are forming at the free end of the first and second pairs of mesenteries. Endodermal thickenings (Prosepten) are present between the larger pairs of mesenteries.

$$
\text { Plate 9. }
$$

Frg. 53. - Radial vertical section through a young polyp, showing its relationship to the early coral. lum. In the latter are shown the basal plate (b. pl.), epitheca (ep.), two septa, and a columellar upgrowth (col.)

Figs. 54-60.- - Serial transverse sections through a portion of a polyp, showing the relationships of the inesenteries and septa in the development of a third-cycle entoseptum $(b-c)$ and two fourth-cycle exosepta $(a-b, c-d)$. The full description of the series is given on p. 100 .

\section{Plate 10.}

Fig. 61.-A free corallum. Natural size.

Fig. 62.-A portion of the same corallum magnified about four times, showing various characteristics of the corallites and their relationships to one another.

Fig. 63. - Upper part of three septa as seen in a vertical surface view. The left and middle septa extend across a calice, but are separated in the middlc by the columella and the broken central edges of other septa in union with it. The right septum belongs to an adjacent calice, and is separated from the middle septum by a vertical ridge which represents the line of fusion of an adjacent septum not in the same radius. The two or three vertical rows of large elevations on each septum represent the broken surfaces of synapticula; the smaller elevations are granules. The inner central margin of the left septum shows the denticulations as they unite with the columellar tangle, and near them the fractured surfaces indicating where an adjacent septum was interruptedly united by its inner margin.

Fig. 64.-Ground surface of a portion of a corallum showing the relationship of a single calice to the six adjacent calices. Surface view. The long axis of the columella represents the principal axis of the calice, the directive septa being at opposite extremities, and not quite in the same plane.

Fig. 65.-Portion of a thin transverse section of a single corallite showing the microscopic structure. The columella, septa, and synapticula seem as if constituted of spheroids fused together; the spheroids represent transverse sections through so many individual trabeculæ. 


\section{Plate ix.}

Fig. 66. - Transverse section through a single trabecula, penetrated by filamentous boring alg:a, and showing the growth lamellw and their fibrous character.

Fig. 67.-Vertical section through a part of two adjacent septa. The septa are made up of trabeculæe arranged in a radiating manner; they diverge from a continuous median trabecula which represents the boundary between the two adjacent calices. The different appearances presented by the various trabeculæo are dependent upon the part included in the section. Where the section passes along the middle of a trabecula the interrupted dark centers of calcification are seen; elsewhere only the diverging bundles of fibro-crystals appear. The growth lamellæa are not shown (cf. fig. 68). New trabeculio are intercalated at intervals. The dark circular and oval patches are sections of synapticula.

FIG. 68. - Terminal portion of two trabeculro as seen in longitudinal radial section, that is, parallel to the surface of the septum, more highly magnified than in the previous figure. The section passes along the middle of the trabeculis so that all the dark centers of calcification are seen. In the corallite from which the section was taken the growth lamella were very distinct, the boundary of each being indicated by a dark granular deposit similar to that at the centers of calcification. The growth lamellæare arranged parallel with the toothed edge, that is, with the calicoblast layer which secretes them, while the fibrocrystals making up the lamellæare arranged at right angles. The figure should be compared with fig. 66, which shows a trabecula in transverse section.

Fig. 69.-Portion of basal plate and epithecal boundary of a very early corallum. The epitheca is seen in section, and the basal plate is sufliciently thin to allow of the passage of light. The basal plate is made up of more or less distinct granules or scales showing a fibrous structure; the aggregation of darker granules represents the first formation of a septum.

FIG. 70.-Portion of basal plate, septa, and epitheca of a somewhat older corallum than that of fig. 69. The septa and epitheca are ground down to nearly the level of the basal plate. Centers of calcification are not present in the basal plate and epitheca but are very prominent in the septa. 


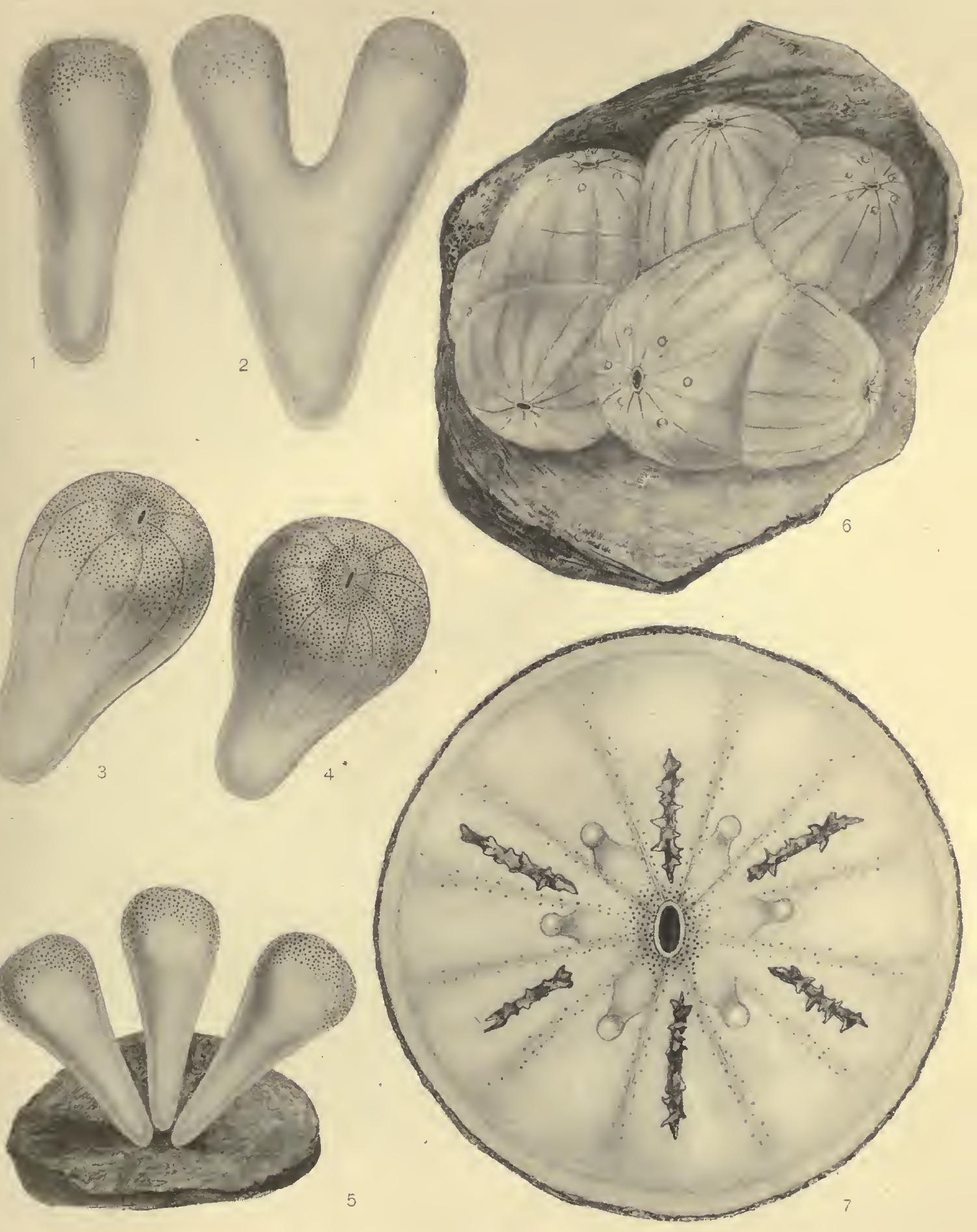





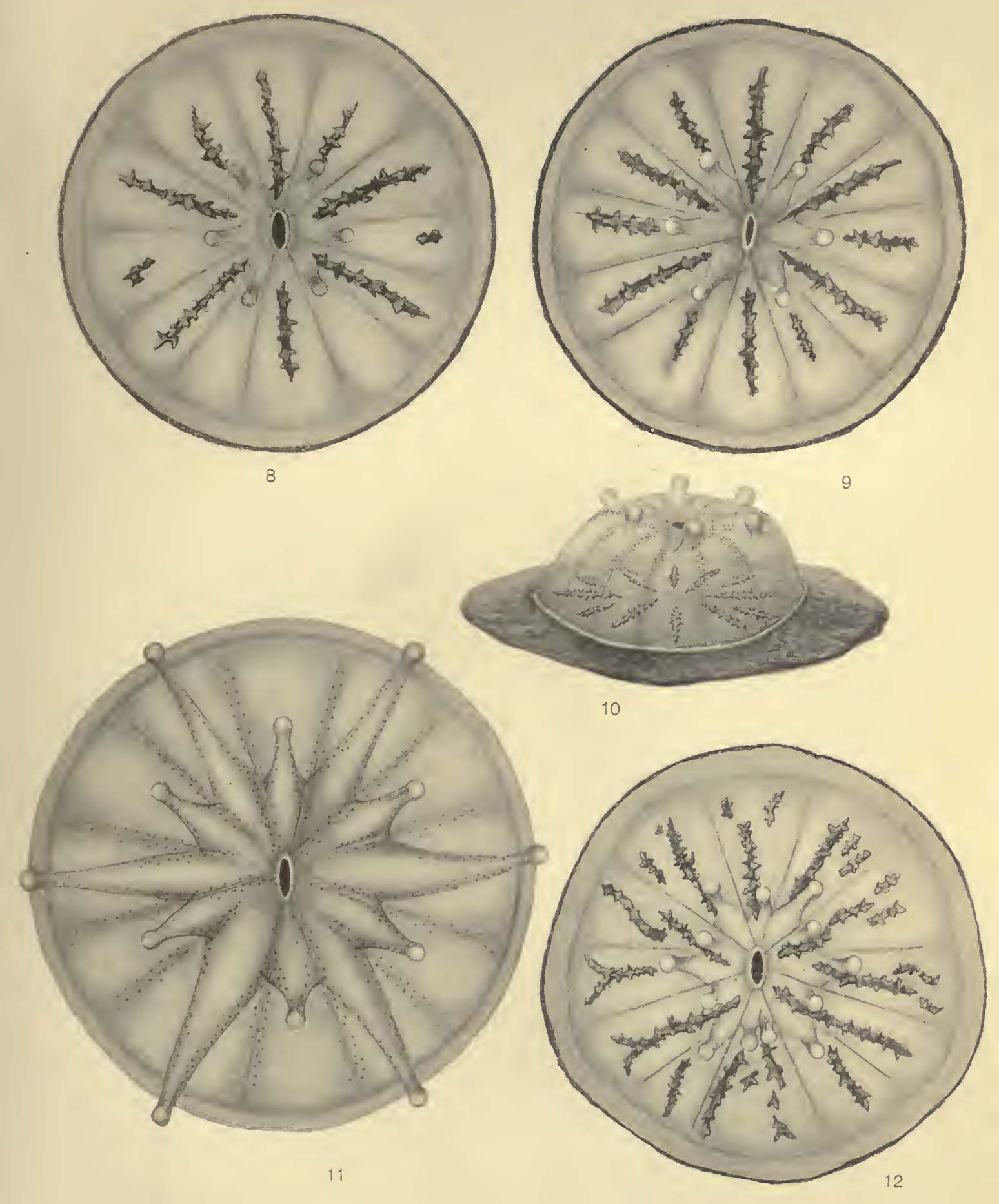





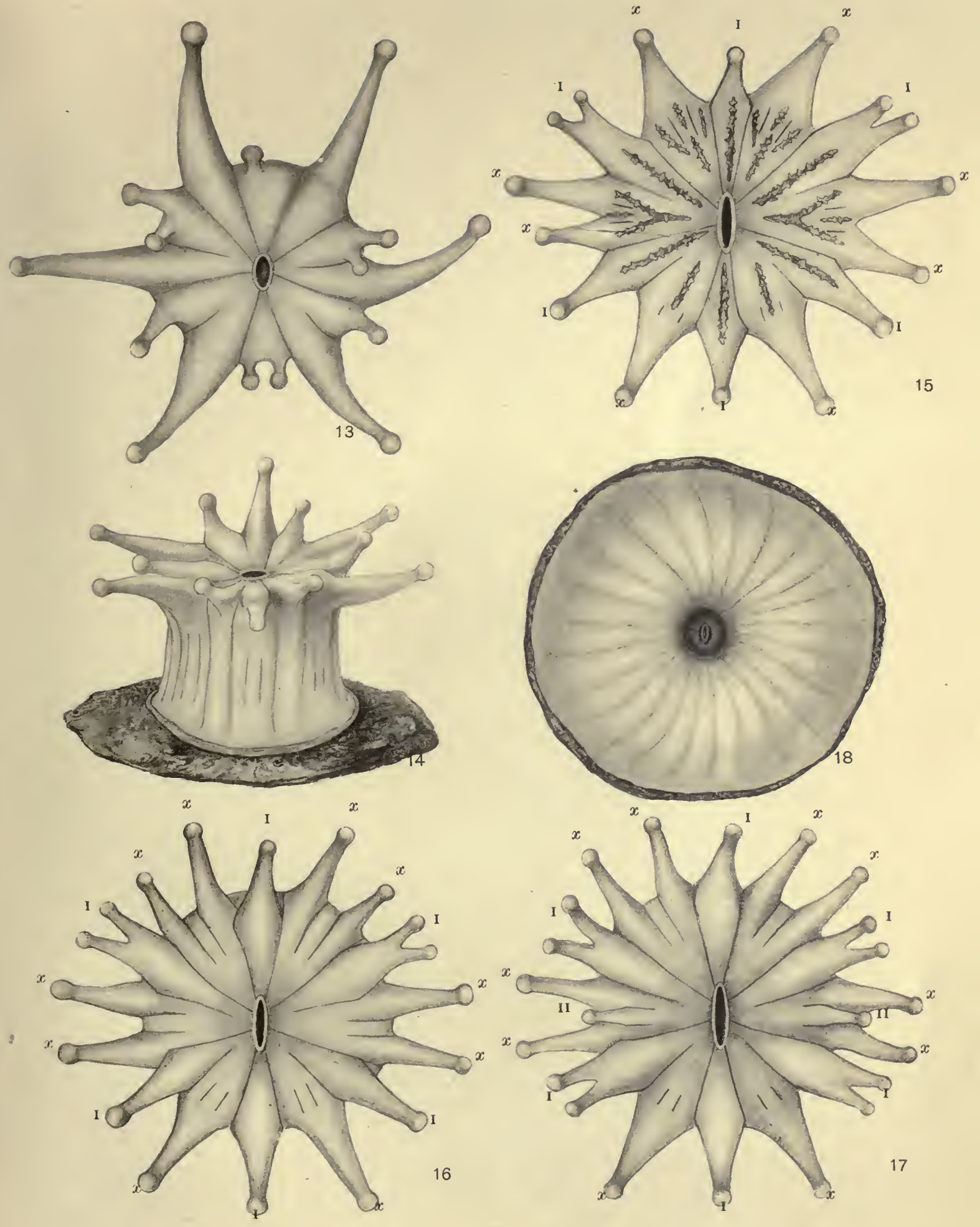





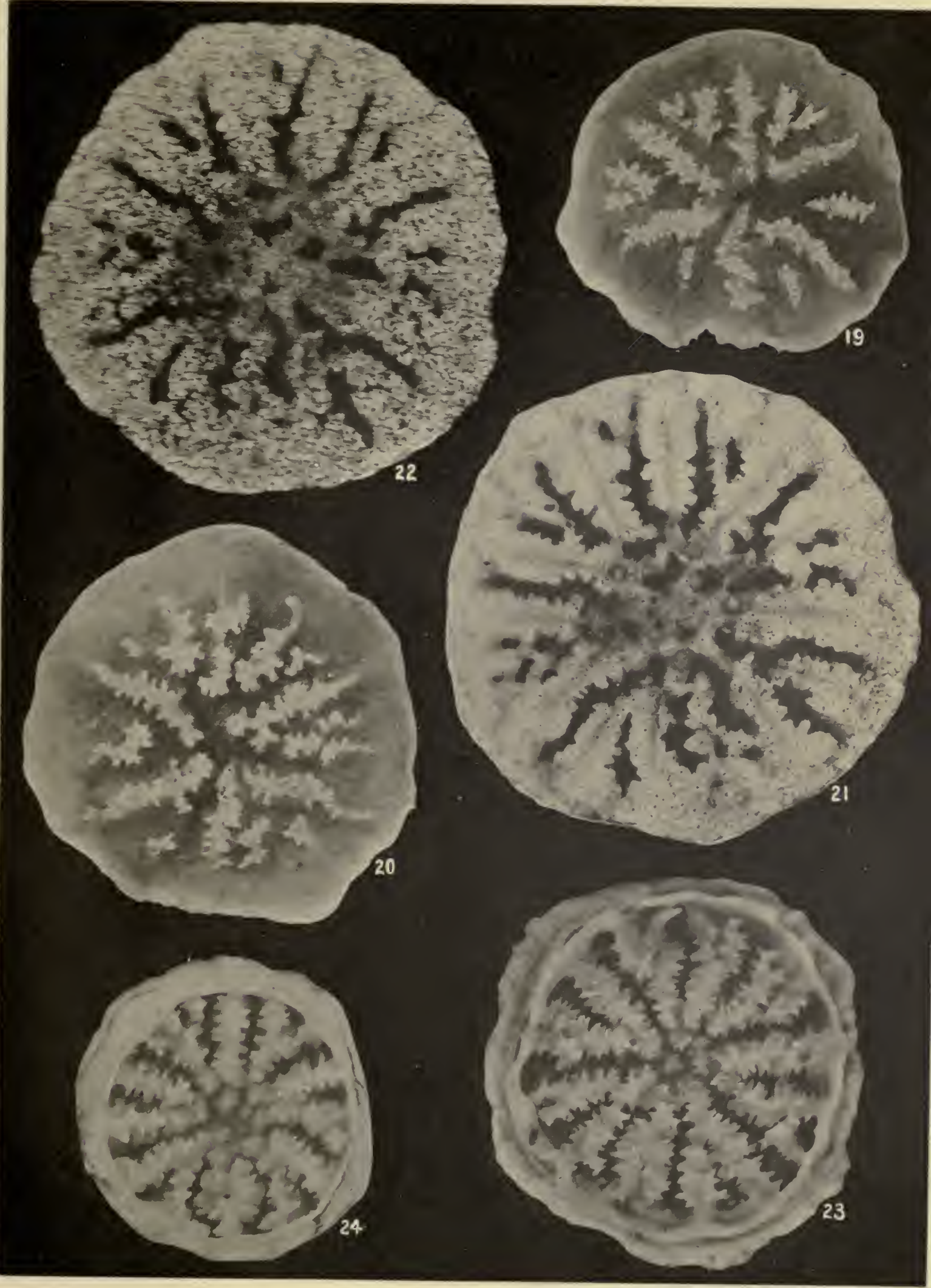





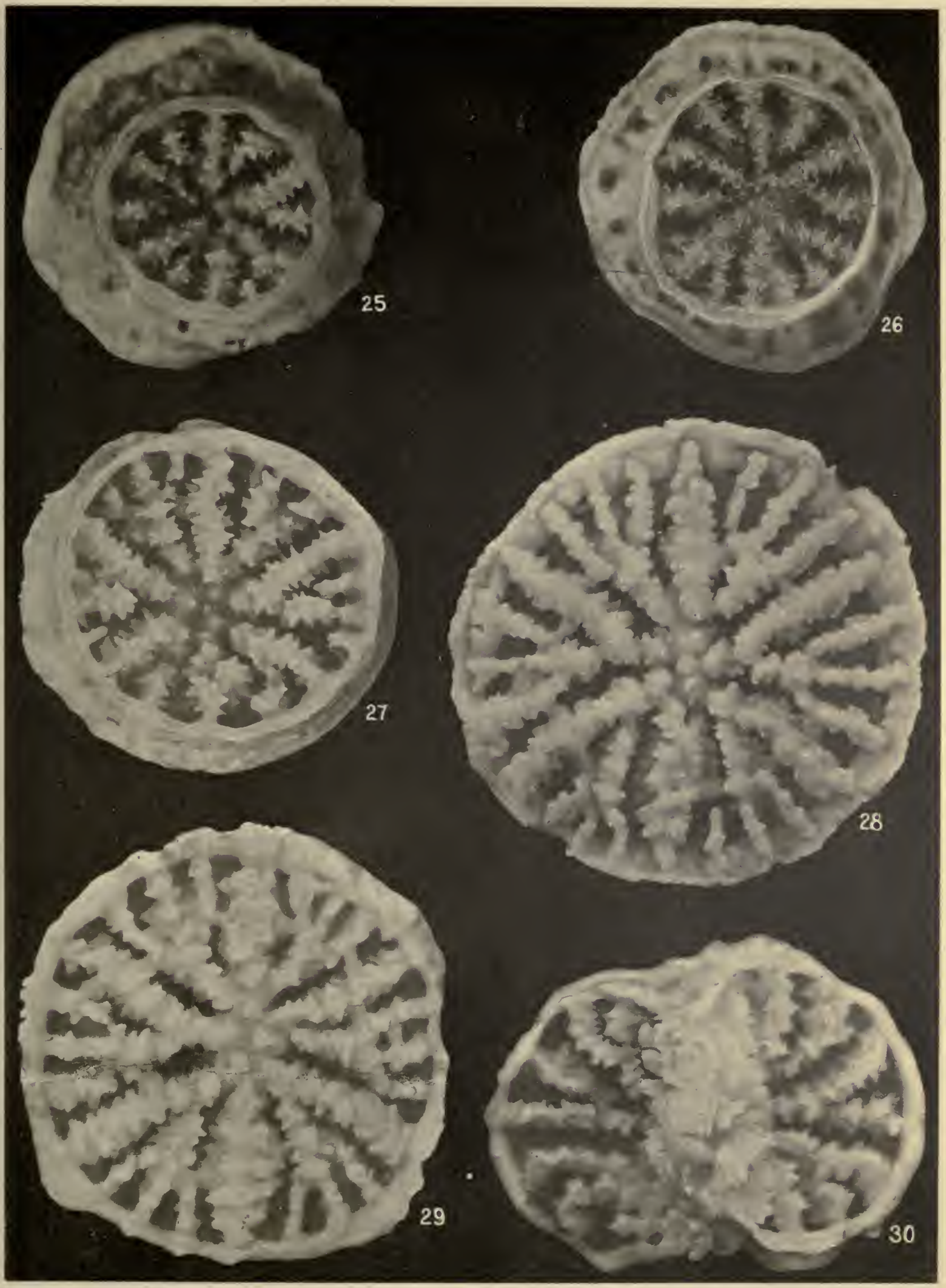





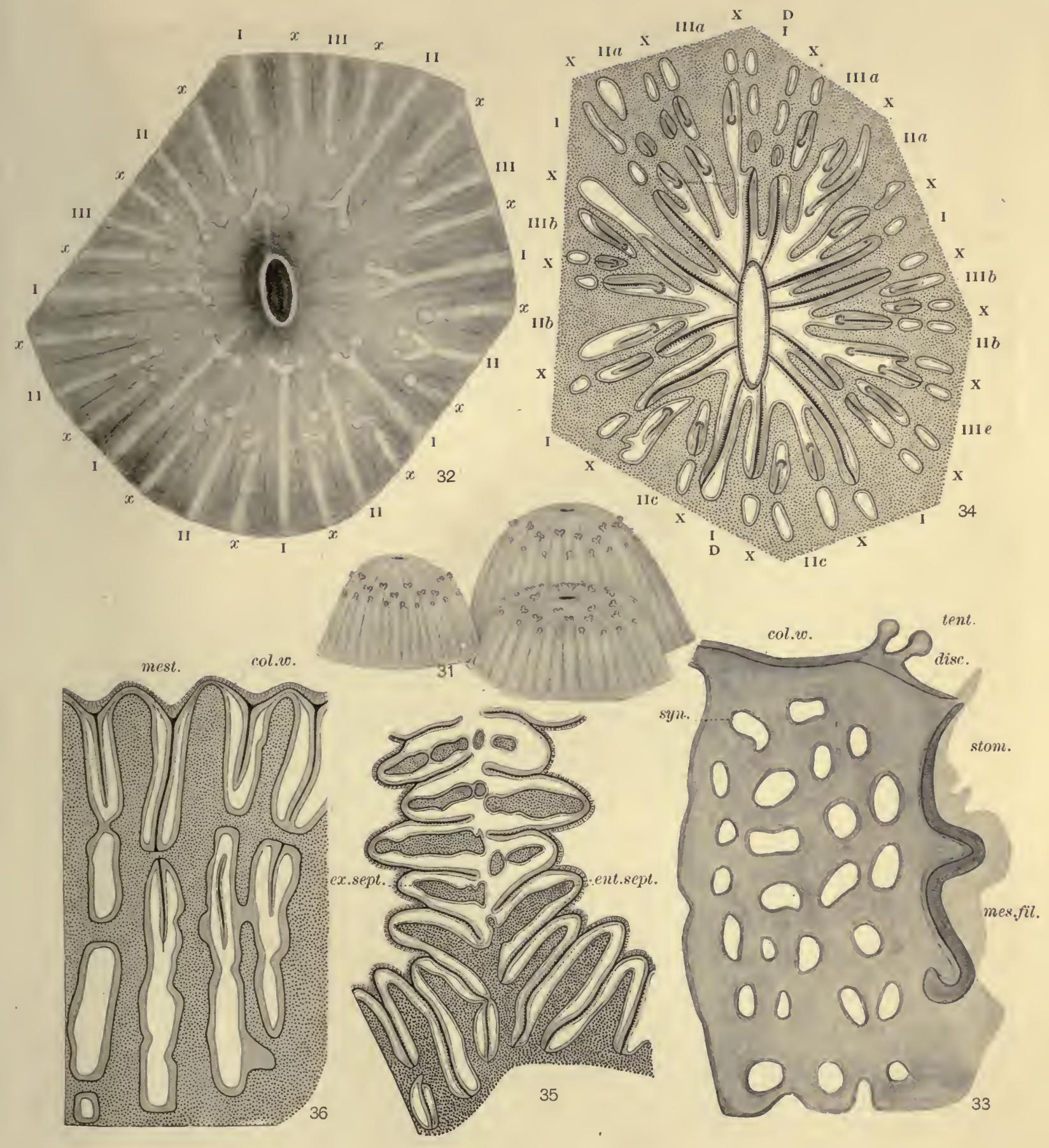




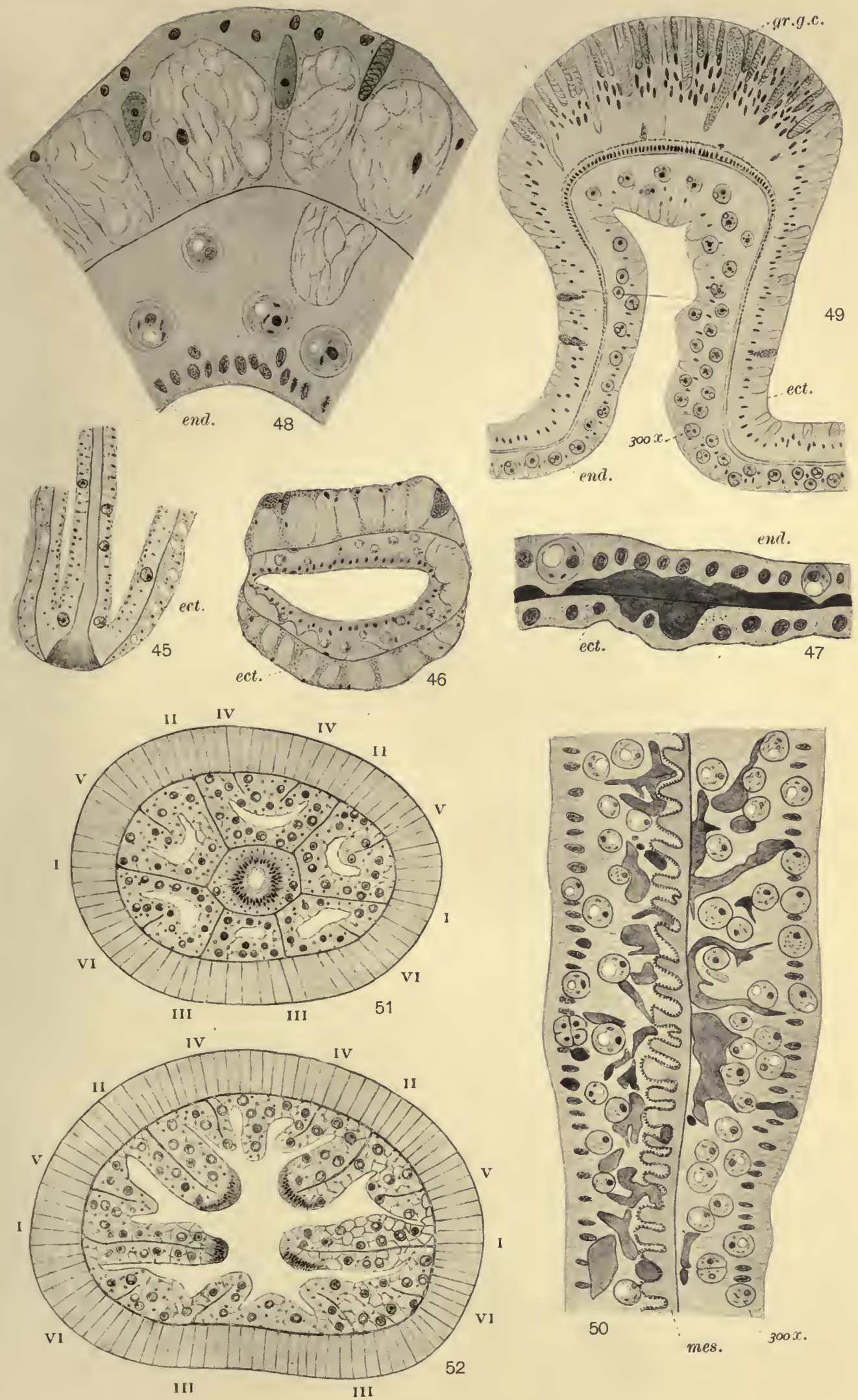




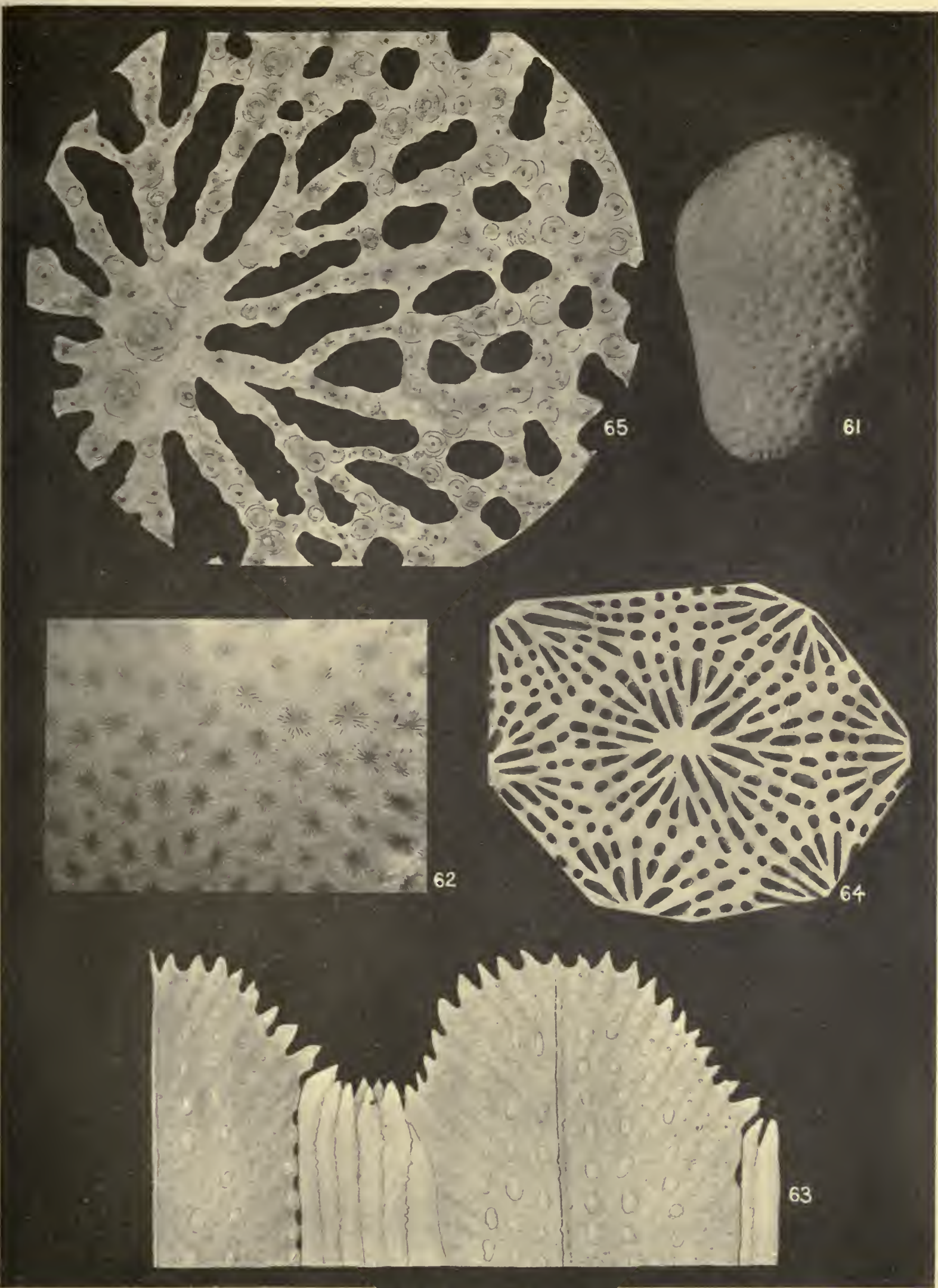






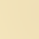









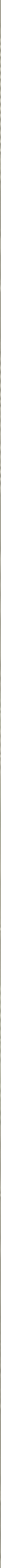


